\title{
Lithologic Controls on Silicate Weathering Regimes of Temperate Planets
}

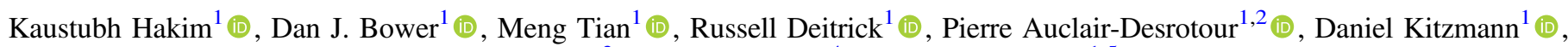 \\ ${\text { Caroline } \text { Dorn }^{3} \text { (D), Klaus Mezger }}^{4}$ (D), and Kevin Heng ${ }^{1,5}$ (D) \\ ${ }^{1}$ University of Bern, Center for Space and Habitability, Gesellschaftsstrasse 6, 3012 Bern, Switzerland; kaustubh.hakim@csh.unibe.ch \\ 2 ASD IMCCE, CNRS-UMR 8028, Observatoire de Paris, PSL, UPMC, 77 avenue Denfert-Rochereau, F-75014 Paris, France \\ ${ }^{3}$ University of Zürich, Institute for Computational Science, Winterthurerstrasse 190, 8057 Zürich, Switzerland \\ ${ }^{4}$ University of Bern, Institute of Geology, Baltzerstrasse 1+3, 3012 Bern, Switzerland \\ ${ }^{5}$ University of Warwick, Department of Physics, Astronomy and Astrophysics Group, Coventry CV4 7AL, UK \\ Received 2020 August 26; revised 2021 January 21; accepted 2021 January 29; published 2021 March 11
}

\begin{abstract}
Weathering of silicate rocks at a planetary surface can draw down $\mathrm{CO}_{2}$ from the atmosphere for eventual burial and long-term storage in the planetary interior. This process is thought to provide essential negative feedback to the carbonate-silicate cycle (carbon cycle) to maintain clement climates on Earth and potentially similar temperate exoplanets. We implement thermodynamics to determine weathering rates as a function of surface lithology (rock type). These rates provide upper limits that allow the maximum rate of weathering in regulating climate to be estimated. This modeling shows that the weathering of mineral assemblages in a given rock, rather than individual minerals, is crucial to determine weathering rates at planetary surfaces. By implementing a fluid-transportcontrolled approach, we further mimic chemical kinetics and thermodynamics to determine weathering rates for three types of rocks inspired by the lithologies of Earth's continental and oceanic crust, and its upper mantle. We find that thermodynamic weathering rates of a continental crust-like lithology are about one to two orders of magnitude lower than those of a lithology characteristic of the oceanic crust. We show that when the $\mathrm{CO}_{2}$ partial pressure decreases or surface temperature increases, thermodynamics rather than kinetics exerts a strong control on weathering. The kinetically and thermodynamically limited regimes of weathering depend on lithology, whereas the supply-limited weathering is independent of lithology. Our results imply that the temperature sensitivity of thermodynamically limited silicate weathering may instigate a positive feedback to the carbon cycle, in which the weathering rate decreases as the surface temperature increases.
\end{abstract}

Unified Astronomy Thesaurus concepts: Exoplanets (498); Habitable zone (696); Greenhouse gases (684); Exoplanet surface composition (2022); Surface processes (2116); Ocean-atmosphere interactions (1150); Carbon dioxide (196)

\section{Introduction}

Greenhouse gases such as $\mathrm{CO}_{2}$ are essential in raising Earth's surface temperature (Kasting et al. 1993; Kopparapu et al. 2013). To regulate the amount of $\mathrm{CO}_{2}$ in the atmosphere, processes such as the weathering of rocks, degassing, and regassing are necessary (Ebelmen 1845; Urey 1952); but see Kite \& Ford (2018). One of the basic assumptions for the definition of the classical habitable zone is therefore the presence of the carbonate-silicate cycle (carbon cycle) that regulates the long-term climate (Kasting et al. 1993). However, it remains unclear how this cycle may operate on rocky exoplanets where surface conditions could depart from those on modern Earth. The essence of inorganic carbon cycle is captured by the Ebelman-Urey reaction involving the conversion of a silicate mineral (e.g., wollastonite $\mathrm{CaSiO}_{3}$ ) to a carbonate mineral (e.g., calcite $\mathrm{CaCO}_{3}$ ) in the presence of atmospheric $\mathrm{CO}_{2}$,

$$
\mathrm{CaSiO}_{3}+\mathrm{CO}_{2} \longleftrightarrow \mathrm{CaCO}_{3}+\mathrm{SiO}_{2}
$$

The reverse of reaction (1), metamorphism, converts carbonates back to silicates and releases $\mathrm{CO}_{2}$ into the atmosphere. In addition to metamorphic decarbonation, the degassing of the

Original content from this work may be used under the terms of the Creative Commons Attribution 4.0 licence. Any further distribution of this work must maintain attribution to the author(s) and the title of the work, journal citation and DOI. mantle at midocean ridges and at volcanic arcs also contributes to the $\mathrm{CO}_{2}$ supply to the atmosphere. Although wollastonite is used to exemplify the carbon cycle, in reality, its contribution is insignificant. In this study, we evaluate the contribution of silicate minerals and rocks to the weathering component of the carbon cycle.

An important feature of the carbon cycle on Earth is the negative feedback of silicate weathering (e.g., Walker et al. 1981; Berner et al. 1983; Kump et al. 2000; Sleep \& Zahnle 2001; Abbot et al. 2012; Foley 2015; Krissansen-Totton \& Catling 2017; Graham \& Pierrehumbert 2020). This feedback buffers the climate against changes in stellar luminosity and impacts the extent of the habitable zone (e.g., Kasting et al. 1993; Kopparapu et al. 2013). This feedback is sensitive to the partial pressure of $\mathrm{CO}_{2}$ in the atmosphere, surface temperature, and runoff, which facilitates weathering reactions and transport of aqueous chemical species from continents to oceans (e.g., Walker et al. 1981; Berner et al. 1983). In oceans, cations and bicarbonate or carbonate ions react to form carbonates that are deposited on the seafloor, thereby removing $\mathrm{CO}_{2}$ from the atmosphere-ocean system (e.g., calcite; Ridgwell \& Zeebe 2005). High concentrations of $\mathrm{CO}_{2}$ in the atmosphere elevate the surface temperature due to the greenhouse effect of $\mathrm{CO}_{2}$. High temperatures give rise to high evaporation and high precipitation (rainfall) rates. As precipitation intensifies, runoff also intensifies. As a result, silicate weathering intensifies, reducing the abundance of atmospheric $\mathrm{CO}_{2}$, which in turn 
decreases the temperature. When temperatures become low, evaporation and precipitation rates become low, thereby decreasing runoff and weathering. In the absence of intense weathering, volcanic degassing increases the abundance of $\mathrm{CO}_{2}$ in the atmosphere sufficiently to increase the temperature again. In the absence of a self-regulating mechanism, the fate of Earth's atmosphere may have been like that of Venus (Gaillard \& Scaillet 2014).

In addition to silicate weathering on continents, silicate weathering on the seafloor also has the potential to provide equivalent negative feedback (e.g., Francois \& Walker 1992; Brady \& Gíslason 1997; Sleep \& Zahnle 2001; Coogan \& Gillis 2013; Krissansen-Totton \& Catling 2017; Charnay et al. 2017). Seafloor weathering is the low-temperature $(<313 \mathrm{~K})$ carbonation of the basaltic oceanic crust facilitated by the circulation of seawater through hydrothermal systems (Coogan \& Gillis 2018). Seafloor-weathering reactions, like continental weathering reactions, dissolve silicate minerals constituting rocks in the presence of water and $\mathrm{CO}_{2}$. Most studies modeling the carbon cycle expect the contribution of seafloor weathering to be smaller than continental weathering by up to a few orders of magnitude and thus ignore it (e.g., Walker et al. 1981; Berner et al. 1983; Caldeira 1995; Berner \& Kothavala 2001). However, recent studies have claimed that seafloor weathering is likely a significant component of global weathering during Earth's history (e.g., Coogan \& Gillis 2013; Charnay et al. 2017; Krissansen-Totton et al. 2018); but see Isson \& Planavsky (2018). Seafloor weathering may be of critical importance on ocean worlds (e.g., Abbot et al. 2012; Foley 2015; Höning et al. 2019); but see Kite \& Ford (2018).

A prevalent assumption among studies modeling silicate weathering is that kinetics of mineral dissolution reactions determines the weathering flux:

$$
w=w_{0}\left(\frac{P_{\mathrm{CO}_{2}}}{P_{\mathrm{CO}_{2}, 0}}\right)^{\beta} \exp \left[-\frac{E}{R}\left(\frac{1}{T}-\frac{1}{T_{0}}\right)\right],
$$

where the subscript " 0 " denotes reference values, $P_{\mathrm{CO}_{2}}$ is the partial pressure of $\mathrm{CO}_{2}$ in the gaseous state, and $\beta$ is the kinetic power-law constant constrained empirically from laboratory or field data (e.g., Walker et al. 1981; Berner et al. 1983; Kasting et al. 1993; Sleep \& Zahnle 2001; Foley 2015; KrissansenTotton \& Catling 2017). The activation energy $E$ is also determined empirically from the dependence of kinetic rate coefficients on the Arrhenius law with $T$ as the surface temperature and $R$ as the universal gas constant (Palandri \& Kharaka 2004; Brantley et al. 2008). Walker et al. (1981) adopt $\beta=0.3$ based on kinetic rate measurements of feldspar weathering in a laboratory (Lagache 1965). Later studies adjusted the value of $\beta$ using more laboratory and field measurements or balancing carbon fluxes (Brantley et al. 2008). A Bayesian inversion study performed by KrissansenTotton \& Catling (2017) for the carbon cycle on Earth based on data from the past $100 \mathrm{Myr}$ shows that the value of $\beta$ for continental weathering is largely unconstrained: between 0.21 -0.48 (prior: $0.2-0.5$ ) for their nominal model and between 0.05-0.95 (prior: 0-1) for their Michaelis-Menten model (Volk 1987; Berner 2004). Moreover, the power-law exponent of seafloor weathering in Equation (2) is either assumed to be equal to 0.23 (Brady \& Gíslason 1997) or varied between 0-1 (e.g., Sleep \& Zahnle 2001; Coogan \& Dosso 2015). More sophisticated formulations of seafloor weathering assume a dependence on the oceanic crustal production rate with yet another power-law exponent between 0 and 2 (KrissansenTotton et al. 2018).

The flow of fluids such as rainwater through the pore space of soils facilitates silicate-weathering reactions on continents. If the fluid residence time is shorter than the time needed for a reaction to attain chemical equilibrium, the reaction becomes rate limiting and reaction kinetics govern the amount of solute released (e.g., Aagaard \& Helgeson 1982; Helgeson et al. 1984). Then, the weathering is kinetically limited. In contrast, at long fluid residence times, silicate-weathering reactions reach chemical equilibrium resulting in a thermodynamic limit (also known as the runoff limit, Kump et al. 2000; Maher 2011). The thermodynamic limit of weathering is referred to as the transport limit in recent literature (e.g., Winnick \& Maher 2018); however, the transport limit is traditionally used to describe weathering limited by the supply of fresh minerals, i.e., supply-limited weathering (Thompson 1959; Stallard \& Edmond 1983; Maher 2011; Kump et al. 2000). In this study, the use of the term transport limited is avoided. Observations that regional weathering fluxes on Earth depend on runoff (e.g., Riebe et al. 2004) in addition to reaction kinetics suggesting that global weathering fluxes are a mixture of kinetically and thermodynamically limited regimes. The fluid-transport approach (Steefel et al. 2005; Maher 2010; Maher \& Chamberlain 2014; Li et al. 2017) allows the modeling of both thermodynamic and kinetic limits of weathering on temperate planets (Winnick \& Maher 2018; Graham \& Pierrehumbert 2020).

The lithology (rock type) is anticipated to play a role in the intensity of the silicate-weathering feedback (e.g., Walker et al. 1981; Stallard \& Edmond 1983; Kump et al. 2000). At the thermodynamic limit of weathering, Winnick \& Maher (2018) demonstrate that minerals in the feldspar mineral group exhibit feedback that is weaker to stronger than the kinetic weathering feedback. For example, their calculations show that the thermodynamic $\beta$ (or $\beta_{\mathrm{th}}$ ) is 0.25 for albite and K-feldspar and 0.67 for anorthite, compared to the classic kinetic $\beta=0.3$ from Walker et al. (1981). The kinetic weathering models are based on reaction rates of feldspars, common silicate minerals comprising granitic rocks on modern continents (e.g., Walker et al. 1981). However, rocks on the Hadean and early Archean Earth were more mafic than present-day Earth and therefore poorer in $\mathrm{SiO}_{2}$ and feldspar content (e.g., Chen et al. 2020); but see Keller \& Harrison (2020). The modern seafloor mostly contains basaltic rocks. Observations of clay minerals on Mars suggest past weathering processes (Bristow et al. 2018). Clues from stellar elemental abundances point to diverse planetary compositions (e.g., Wang et al. 2019; Spaargaren et al. 2020). Consequently, the surface lithologies (and therefore weathering fluxes) on rocky exoplanets are not necessarily similar to modern Earth.

In this study, we develop a silicate-weathering model of the inorganic carbon cycle with key inclusion of lithology by applying the fluid-transport model of Maher \& Chamberlain (2014) to fluid-rock reactions: CHILI (CHemical weatherIng model based on LIthology). This model tracks the aqueous carbon reservoir assimilating three weathering regimes as a function of lithology. In addition to continental weathering, this model is applied to seafloor weathering. The primary goal is to determine lithology-based weathering fluxes on the surface of temperate exoplanets by mitigating the impact of present-day 


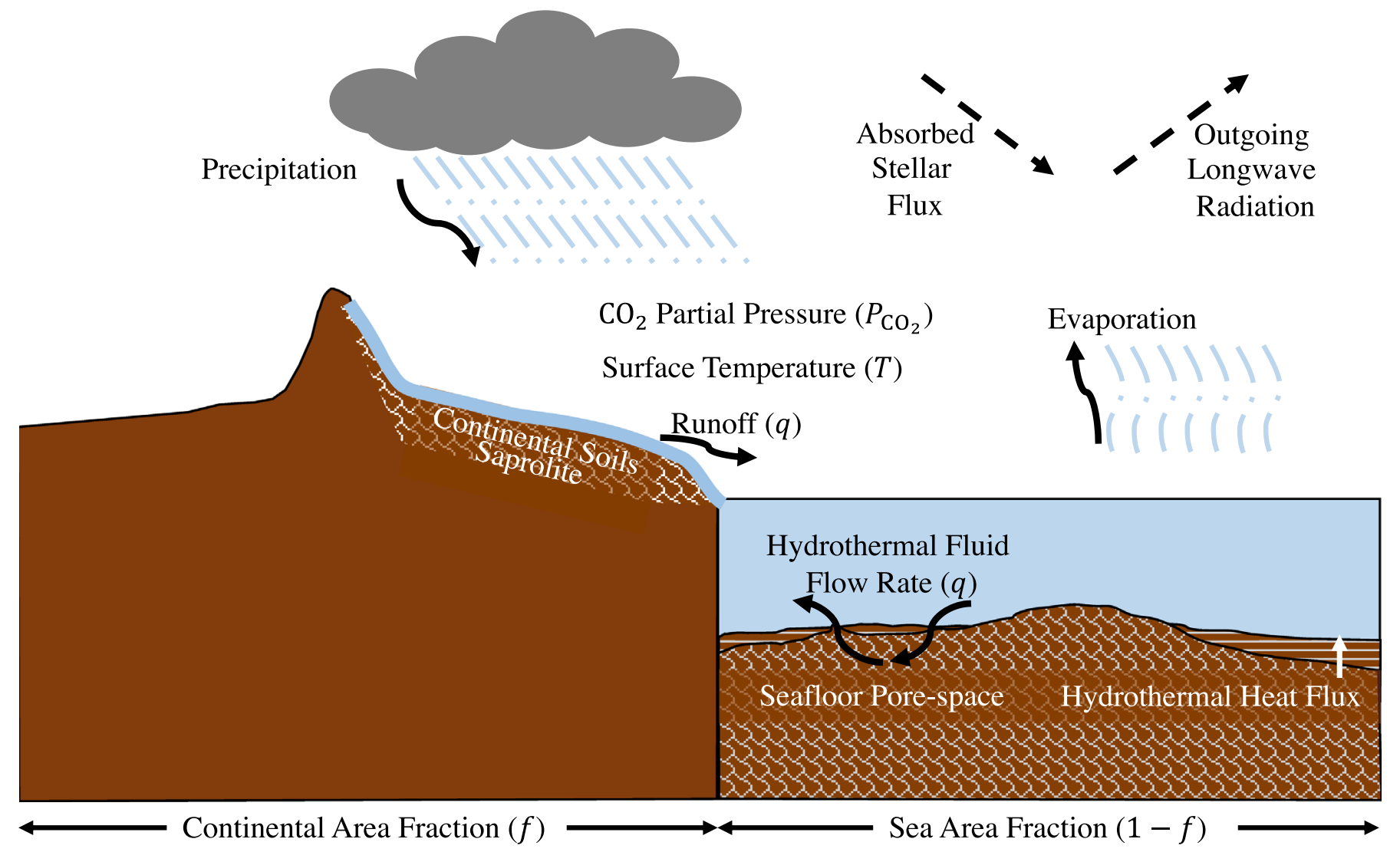

Figure 1. Silicate-weathering model based on weathering reactions and fluid flow rates. The continental runoff and the seafloor fluid flow rate enable weathering reactions in continental soils and saprolite, and seafloor pore space, respectively. Key parameters and processes are labeled (see Tables 1-3 for all parameters and computed quantities).

Earth calibrations. The key philosophy behind this study is to investigate the extent to which the silicate-weathering model may be generalized, beyond its Earth-centric origins, in order to apply it to rocky exoplanets with secondary atmospheres.

\section{Weathering Model}

\subsection{Proxies for Weathering}

Continental weathering occurs in continental soils and saprolite where runoff (water discharge per unit surface area) facilitates fluid-rock weathering reactions (Figure 1). Seafloor weathering occurs in pores and veins of the oceanic crust (hereafter, pore space) where seawater reacts with basalts. Analogous to runoff, the fluid flow in off-axis low-temperature hydrothermal systems facilitates seafloor-weathering reactions (Stein \& Stein 1994; Coogan \& Gillis 2018). The fluid flow rate $q$ (either runoff or hydrothermal fluid flow rate) is a free parameter in CHILI (Table 1). On Earth, the present-day continental runoff varies between $0.01-3 \mathrm{~m} \mathrm{yr}^{-1}$ with a mean of approximately $0.3 \mathrm{~m} \mathrm{yr}^{-1}$ (Gaillardet et al. 1999; Fekete et al. 2002). On the seafloor, the non-porosity-corrected hydrothermal fluid flow rates are between $0.001-0.7 \mathrm{~m} \mathrm{yr}^{-1}$ with a mean of about $0.05 \mathrm{~m} \mathrm{yr}^{-1}$ (Stein \& Stein 1994; Johnson \& Pruis 2003; Hasterok 2013).

In the fluid-transport-controlled model of continental weathering, the weathering flux $w\left(\mathrm{~mol} \mathrm{~m}^{-2} \mathrm{yr}^{-1}\right)$ is the product of the concentration of a solute of interest $C$ and runoff $q$ (e.g., Maher \& Chamberlain 2014),

$$
w=C q .
$$

Table 1

Control Parameters and Their Reference Values for Modern Earth

\begin{tabular}{llc}
\hline \hline Symbol & Description & Reference \\
\hline$P_{\mathrm{CO}_{2}}$ & $\mathrm{CO}_{2}$ partial pressure & $280 \mu \mathrm{bar}$ \\
$T$ & Surface temperature & $288 \mathrm{~K}$ \\
$P$ & Surface pressure & $1 \mathrm{bar}$ \\
$q$ & Runoff or fluid flow rate & $0.3 \mathrm{~m} \mathrm{yr}^{-1}$ \\
$t_{\mathrm{s}}$ & Soil or pore-space age & $10^{5} \mathrm{yr}$ \\
$\psi$ & Dimensionless pore-space parameter & 222750 \\
\hline
\end{tabular}

Note. $T$ is not a control parameter for some calculations $\left(T=f\left(P_{\mathrm{CO}_{2}}\right)\right.$, Section 2.5).

We also apply the same approach to seafloor weathering. The total silicate-weathering rate $^{6} W\left(\mathrm{~mol} \mathrm{yr}^{-1}\right)$ is the sum of the continental ( $\left.W_{\text {cont }}\right)$ and seafloor-weathering rates $\left(W_{\text {seaf }}\right)$. These rates are given by the product of the continental $\left(w_{\text {cont }}\right)$ or seafloor-weathering flux $\left(w_{\text {seaf }}\right)$ and the continental $\left(f A_{\mathrm{s}}\right)$ or seafloor surface area $\left((1-f) A_{\mathrm{s}}\right)$, where $A_{\mathrm{s}}$ is the planet surface area and $f$ is the continental area fraction:

$$
W=w_{\text {cont }} f A_{\mathrm{s}}+w_{\text {seaf }}(1-f) A_{\mathrm{s}} .
$$

To model silicate weathering, the aqueous bicarbonate ion concentration $\left[\mathrm{HCO}_{3}^{-}\right]$is normally used as a proxy for weathering because it is a common byproduct of silicate

\footnotetext{
6 The weathering rate has dimensions of moles per unit time, whereas the weathering flux has dimensions of moles per unit area per unit time (Table 2).
} 
(a)

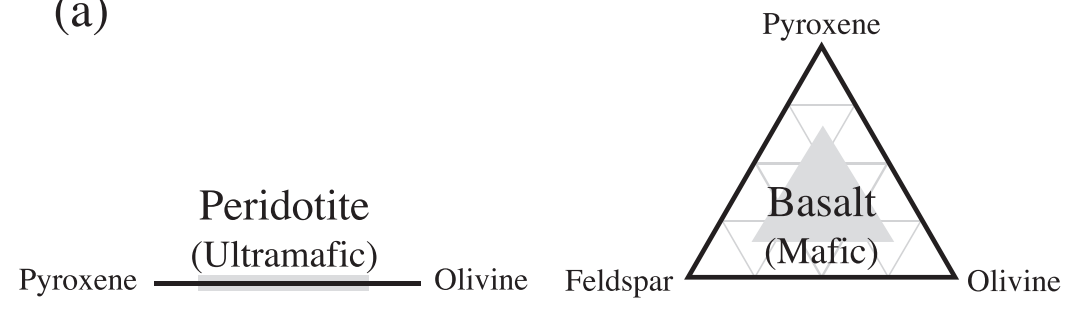

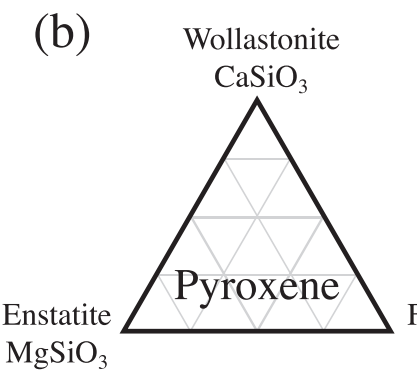

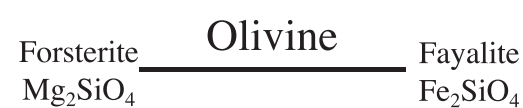
$\mathrm{Fe}_{2} \mathrm{SiO}_{4}$

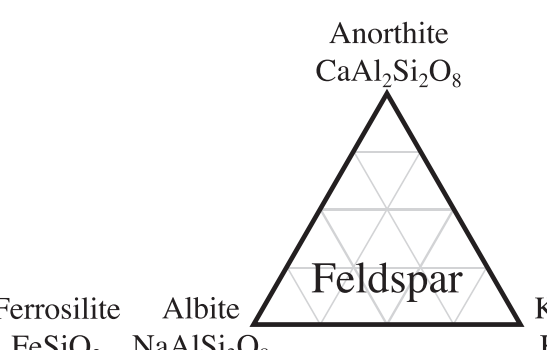

$\mathrm{FeSiO}_{3} \quad \mathrm{NaAlSi}_{3} \mathrm{O}_{8}$

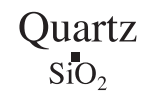

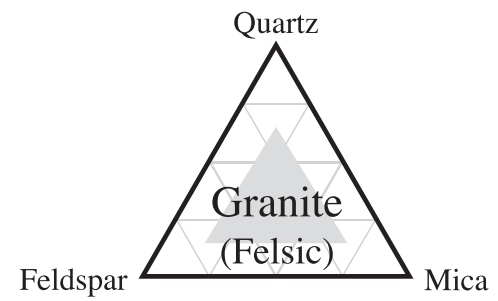

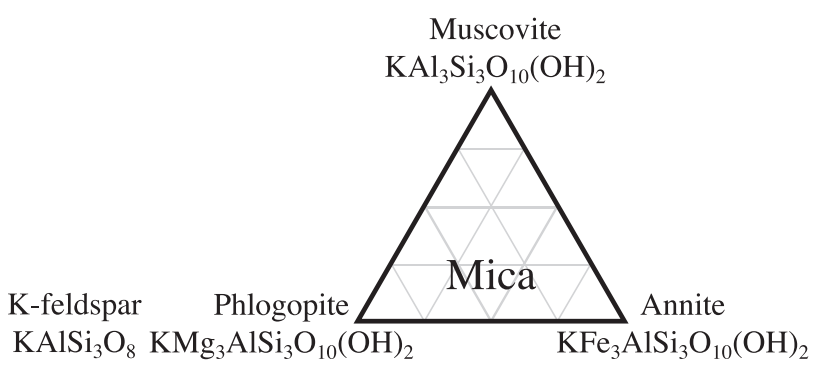

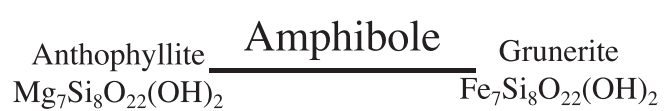

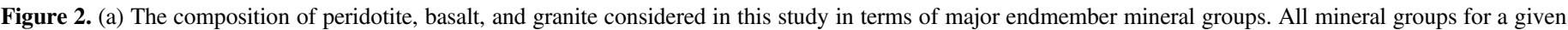

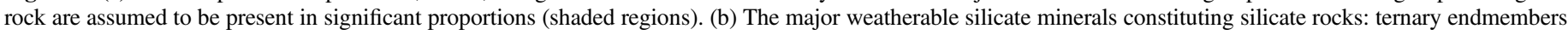

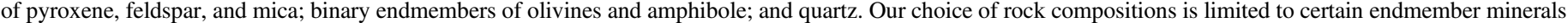

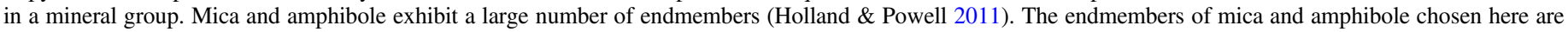
merely illustrative.

Table 2

Computed Quantities

\begin{tabular}{llc}
\hline \hline Symbol & Description & Units \\
\hline$w$ & Weathering flux & $\mathrm{mol} \mathrm{m}^{-2} \mathrm{yr}^{-1}$ \\
$W$ & Weathering rate & $\mathrm{mol} \mathrm{yr}^{-1}$ \\
$T^{\prime}$ & Seafloor pore-space temperature & $\mathrm{K}$ \\
$A$ & Carbonate alkalinity & $\mathrm{mol} \mathrm{dm}^{-3}$ \\
$\mathrm{pH}$ & Negative logarithm of $\mathrm{H}^{+}$activity & $\cdots$ \\
$C$ & Concentration & $\mathrm{mol} \mathrm{dm}^{-3}$ \\
{$[\mathrm{C}]$} & Concentration of a species C & $\mathrm{mol} \mathrm{dm}^{-3}$ \\
$a_{\mathrm{C}}$ & Activity of a species C & $\cdots$ \\
$D_{w}$ & Damköhler coefficient & $\mathrm{m} \mathrm{yr}^{-1}$ \\
$K$ & Equilibrium constant & $\cdots$ \\
$k_{\mathrm{eff}}$ & Kinetic rate coefficient & $\mathrm{mol} \mathrm{m}^{-2} \mathrm{yr}^{-1}$ \\
$E$ & Activation energy & $\mathrm{kJ} \mathrm{mol}^{-1}$ \\
$E_{\mathrm{th}}$ & Thermodynamic activation energy & $\mathrm{kJ} \mathrm{mol}^{-1}$ \\
$\beta$ & Power-law exponent & $\cdots$ \\
$\beta_{\mathrm{th}}$ & Thermodynamic power-law exponent & $\cdots$ \\
\hline
\end{tabular}

weathering (e.g., anorthite weathering, Winnick \& Maher 2018),

$$
\begin{aligned}
& \mathrm{CaAl}_{2} \mathrm{Si}_{2} \mathrm{O}_{8}+2 \mathrm{CO}_{2}+3 \mathrm{H}_{2} \mathrm{O} \\
& \quad \rightarrow 2 \mathrm{HCO}_{3}^{-}+\mathrm{Ca}^{2+}+\mathrm{Al}_{2} \mathrm{Si}_{2} \mathrm{O}_{5}(\mathrm{OH})_{4}
\end{aligned}
$$

This is a good assumption under modern Earth conditions as $\mathrm{HCO}_{3}^{-}$is the primary $\mathrm{CO}_{2}$-rich product of continental silicate weathering that is carried to oceans by rivers and reacts with $\mathrm{Ca}^{2+}$ to precipitate Ca-rich carbonates on the seafloor. We are interested in modeling weathering under conditions more diverse than those on modern Earth. In highly alkaline conditions, the carbonate ion $\mathrm{CO}_{3}^{2-}$ is produced in amounts similar to or exceeding $\left[\mathrm{HCO}_{3}^{-}\right]$. Both $\mathrm{CO}_{3}^{2-}$ and $\mathrm{HCO}_{3}^{-}$ have the potential to contribute to $\mathrm{Ca}-\mathrm{Mg}-\mathrm{Fe}$ carbonate precipitation on the seafloor (e.g., calcite precipitation, Plummer et al. 1978),

$$
\begin{aligned}
2 \mathrm{HCO}_{3}^{-}+\mathrm{Ca}^{2+} & \rightarrow \mathrm{CaCO}_{3}+\mathrm{CO}_{2}+\mathrm{H}_{2} \mathrm{O} \\
\mathrm{CO}_{3}^{2-}+\mathrm{Ca}^{2+} & \rightarrow \mathrm{CaCO}_{3} .
\end{aligned}
$$

Equation (6) exemplifies that, in addition to bicarbonate and carbonate ions, divalent cations are required to drive the flux of $\mathrm{CO}_{2}$ out of the atmosphere-ocean system. Nonetheless, because twice as many $\mathrm{HCO}_{3}^{-}$ions as $\mathrm{CO}_{3}^{2-}$ ions are needed to precipitate 1 mole of carbonate (Krissansen-Totton \& Catling 2017), in addition to $\mathrm{HCO}_{3}^{-}\left(C=\left[\mathrm{HCO}_{3}^{-}\right]\right.$in Equation (3)), we consider carbonate alkalinity $A$ resulting from reactions between silicate rocks and fluids as a proxy for weathering ( $C=A$ in Equation (3)), where

$$
\begin{aligned}
& A=\left[\mathrm{HCO}_{3}^{-}\right]+2\left[\mathrm{CO}_{3}^{2-}\right] . \\
& \text { 2.2. Major Silicate Lithologies }
\end{aligned}
$$

Previous studies applying the fluid-transport-controlled model to continental weathering limit the lithology to monomineralic (e.g., oligoclase feldspar, Graham \& Pierrehumbert 2020) or one rock type (e.g., granite, Maher \& Chamberlain 2014; Winnick \& Maher 2018). However, the chemistry of common silicate rocks ranges from ultramafic to felsic, with increasing $\mathrm{SiO}_{2}$ content. To model the surface mineralogy of terrestrial exoplanets, we approximate an ultramafic, a mafic, and a felsic lithology with major mineralogical compositions of peridotite, basalt, and granite, respectively. Peridotites are upper-mantle rocks rich in $\mathrm{MgO}$ and $\mathrm{FeO}$ and poor in $\mathrm{SiO}_{2}$ relative to basalts and granites. Basalts are igneous rocks that are common examples of rocks present in the oceanic crust of Earth, lunar mare on the Moon, and the crust of Mars. Granites are present on the modern 
continental crust of Earth. These are highly differentiated rocks that are rich in $\mathrm{SiO}_{2}, \mathrm{Na}_{2} \mathrm{O}$, and $\mathrm{K}_{2} \mathrm{O}$ due to partial melting and crystallization processes.

The three rock types (peridotite, basalt, and granite) considered in this study are assumed to be composed of two to three major mineral groups and can thus be projected onto binary or ternary diagrams spanned by the major mineral groups considered (Figure 2(a)). Each mineral group is similarly defined by one to three endmember minerals (Figure 2(b)). For instance, olivine is a solid solution of two endmember minerals, forsterite, and fayalite. In the reduced set of mineral groups with only endmember minerals, we represent peridotite using pyroxenes (wollastonite and enstatite) and olivines (forsterite and fayalite), basalt using plagioclase feldspars (anorthite and albite), and pyroxenes (wollastonite, enstatite, and ferrosilite), and granite using alkali feldspars (Kfeldspar and albite), quartz and biotite micas (phlogopite and annite). Halloysite, a phyllosilicate mineral, is a byproduct (secondary mineral) of the weathering of basalt and granite but not of peridotite (see Appendix B). Kaolinite, another phyllosilicate secondary mineral, is also considered but no secondary minerals containing divalent and monovalent cations are modeled. The choice of endmember primary minerals to define these rocks makes them idealized compared to natural rocks. Moreover, for a rock, not all endmember minerals of a mineral group can be modeled due to the unity activity assumption for endmember minerals (Section 2.3). Only major minerals in typical rock types are considered, and minor minerals such as magnetite, hematite, and pyrite are not discussed. Because the net contribution of carbonate weathering on the carbon cycle is small on timescales of the order of $100 \mathrm{kyr}$ for Earth (e.g., Sleep \& Zahnle 2001), the weathering of carbonate minerals is ignored.

\subsection{Maximum Weathering Model}

Concentrations of products of weathering reactions at chemical equilibrium allow one to calculate a thermodynamic upper limit to weathering (maximum weathering). To calculate concentrations of silicate-weathering products, a number of chemical reactions need to be considered. Reactions between water, $\mathrm{CO}_{2}$, and silicate minerals produce the bicarbonate ion $\mathrm{HCO}_{3}^{-}$. The bicarbonate ion further dissociates into the carbonate ion $\mathrm{CO}_{3}^{2-}$ and $\mathrm{H}^{+}$. Water dissociates into $\mathrm{H}^{+}$and $\mathrm{OH}^{-}$. The relations between equilibrium constants of these reactions and thermodynamic activities of reactants and products are given in Appendix B. Thermodynamic activities quantify the energetics of mixing of constituent components in solid or aqueous solutions (DeVoe 2001). Because no nonideal solid-solution behaviors are considered, the endmember compositions of the minerals are used for calculations, and thus, the activities of minerals are set at unity. Furthermore, in a dilute solution, the activity of liquid water is approximately unity.

The activity of an aqueous species (e.g., $\mathrm{HCO}_{3}^{-}(a q)$ ) is given by the product of its concentration $\left[\mathrm{HCO}_{3}^{-}(a q)\right]$ and the activity coefficient $\gamma$ normalized to the standard state of concentration $\left(C_{0}=1 \mathrm{~mol} \mathrm{dm}^{-3}\right), a_{\mathrm{HCO}_{3}^{-}(a q)}=\frac{\gamma\left[\mathrm{HCO}_{3}^{-}(a q)\right]}{C_{0}}$ (DeVoe 2001). In an ideal, dilute solution, $\gamma \rightarrow 1$ and $\left[\mathrm{HCO}_{3}^{-}(a q)\right]=a_{\mathrm{HCO}_{3}^{-}(a q)} C_{0}$, an assumption made throughout the study for all aqueous species. The activity of a gaseous species such as $\mathrm{CO}_{2}(g)$ is given by the ratio of its fugacity in the gas mixture to the fugacity of pure $\mathrm{CO}_{2}(g)$ at the total pressure $P$ (i.e., surface pressure in this study). Thus, $a_{\mathrm{CO}_{2}(g)}=\frac{f_{\mathrm{CO}_{2}}}{f_{\mathrm{CO}_{2}}^{\text {tot }}}=\frac{\Gamma P_{\mathrm{CO}_{2}}}{\Gamma^{\text {tot }} P}$, where $P_{\mathrm{CO}_{2}}$ is the $\mathrm{CO}_{2}$ partial pressure, $P$ is the total surface pressure, and $\Gamma$ and $\Gamma^{\text {tot }}$ are fugacity coefficients for the $\mathrm{CO}_{2}$ component and pure $\mathrm{CO}_{2}$, respectively. The fugacity coefficients give a correction factor for the nonideal behavior due to mixing and/ or pressure effects. For $\mathrm{CO}_{2}(g)$, the fugacity coefficient varies between 0.5 and 1 up to pressures of 200 bar (Spycher \& Reed 1988). Our assumptions of unity fugacity coefficients and $P=1$ bar lead to $a_{\mathrm{CO}_{2}(g)}=P_{\mathrm{CO}_{2}}$.

Equilibrium constants depend on temperature and pressure (see Appendix A). Chemical reactions on continents are characterized by the surface temperature $T$ and surface pressure $P$ (Table 1). Seafloor-weathering reactions are characterized by the seafloor pore-space temperature $T^{\prime}$ and pressure $P^{\prime}$. In the temperature range $273-373 \mathrm{~K}$, data suggest that $T^{\prime}$ is within $1 \%$ of $T$ (Krissansen-Totton \& Catling 2017, and references therein) and hence $T^{\prime}=T$ is assumed. Moreover, pressure in the range of 0.01-1000 bar has a negligible effect on equilibrium constants and resulting concentrations (see Figures A1 and B3). However, seafloor pressure affects carbonate stability. Nonetheless, $P^{\prime}$ is fixed to $200 \mathrm{bar}$, which is the pressure at approximately $2 \mathrm{~km}$ depth in Earth's present-day oceans. When extending the continental weathering model to seafloor weathering, we consider a freshwater ocean, in which ocean chemistry does not limit the production of cations and carbonate alkalinity.

To demonstrate the computation of thermodynamic solute concentrations resulting from fluid-rock reactions, weathering of peridotite is considered. Because two pyroxene endmembers (wollastonite and enstatite) and two olivine endmembers (forsterite and fayalite) are considered to constitute peridotite, dissolution reactions of these four minerals are of interest (Appendix B, Table B1, rows: (a), (b), (d), (e)). Besides, reactions in the water-bicarbonate system are needed (Appendix B, Table B1, rows: (o), (p), (q), (r)). These eight chemical reactions result in 8 equations and 10 unknowns. The eight equations are given by the relations between activities and equilibrium constants (Appendix B). The 10 unknowns are the activities of $\mathrm{CO}_{2}(g), \mathrm{CO}_{2}(a q), \mathrm{SiO}_{2}(a q), \mathrm{Ca}^{2+}, \mathrm{Mg}^{2+}, \mathrm{Fe}^{2+}$, $\mathrm{H}^{+}, \mathrm{OH}^{-}, \mathrm{HCO}_{3}^{-}$, and $\mathrm{CO}_{3}^{2-}$. An additional equation is given by balancing the charges of all cations and anions present in the solution. These 9 equations are further reduced to one polynomial equation with two unknowns, activities of $\mathrm{HCO}_{3}^{-}$ and $\mathrm{CO}_{2}(g)$ (see Appendix B, Table B2). If ferrosilite, the third endmember of pyroxene, is also considered, an additional equation is introduced but the unknowns remain the same and the system is overdetermined. This scenario stems from the assumption of endmember minerals with unity activities instead of solid solutions. In the case of solid solutions, the activities of endmember minerals become unknowns rather than being fixed at unity. This increases the number of unknowns for a given set of equations, and requires more equations that can be derived from additional reactions (e.g., see Galvez et al. 2015, for a treatment of solid solutions). Although mineral solid solutions are commonplace in rocks, endmember considerations allow us to establish a simple framework in which the effects of various lithologies can be explored on the weathering of exoplanets. Therefore, the presence of ferrosilite in peridotite is ignored. Moreover, the presence of $\mathrm{K}$-feldspar and quartz in basalt and anorthite in granite is not considered. For a given $P_{\mathrm{CO}_{2}}, a_{\mathrm{HCO}_{3}^{-}}$is calculated by finding the sole physical root of such a polynomial equation. 
(a)

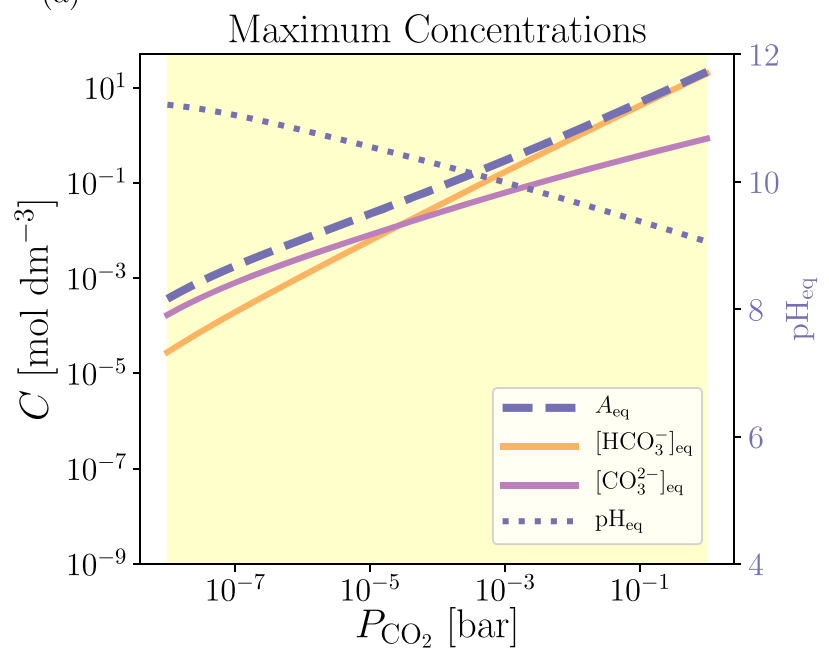

(b)

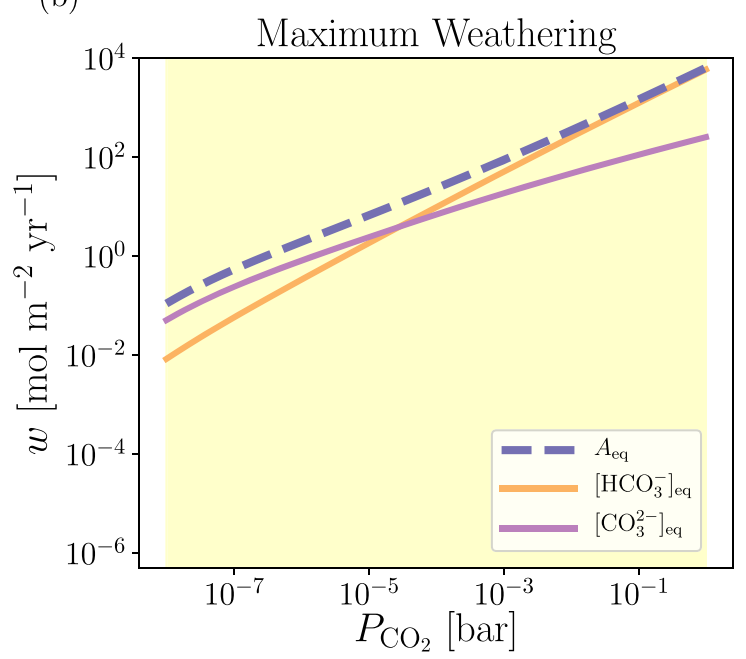

Figure 3. (a) Maximum concentrations of the components of carbonate alkalinity $A$ and the solution $\mathrm{pH}$ of the network of reactions defining peridotite weathering assuming chemical equilibrium as a function of $P_{\mathrm{CO}_{2}}$ at $T=288 \mathrm{~K}$. (b) Maximum weathering flux corresponding to $A,\left[\mathrm{HCO}_{3}^{-}\right]$and $\left[\mathrm{CO}_{3}^{2-}\right]$ at the modern mean runoff of $q=0.3 \mathrm{~m} \mathrm{yr}^{-1}$ (other parameters take reference values). The yellow background denotes the thermodynamic regime of weathering. The scales on vertical and horizontal axes are equal to those in Figure 4.

The bicarbonate ion concentration at chemical equilibrium is obtained from the standard concentration, $\left[\mathrm{HCO}_{3}^{-}\right]_{\mathrm{eq}}=a_{\mathrm{HCO}_{3}^{-}}$ $\times 1 \mathrm{~mol} \mathrm{dm}^{-3}$. Similarly, activities of all aqueous species are converted to concentrations using the standard concentration. Subsequently, all unknowns are calculated from the relations between activities and equilibrium constants (Table B1).

At chemical equilibrium, the carbonate alkalinity increases, and the $\mathrm{pH}$ of the solution decreases with an increase in $P_{\mathrm{CO}_{2}}$ at $T=288 \mathrm{~K}$ (Figure 3(a)). As $P_{\mathrm{CO}_{2}}$ increases, $\left[\mathrm{HCO}_{3}^{-}\right]_{\mathrm{eq}}$ and $\left[\mathrm{CO}_{3}^{2-}\right.$ leq increase monotonically, thereby increasing $A_{\text {eq }}$, whereas $\mathrm{pH}_{\mathrm{eq}}$ decreases monotonically. For all except $P_{\mathrm{CO}_{2}}<20 \mu$ bar, $\left[\mathrm{HCO}_{3}^{-}\right.$ leq contributes significantly to $A_{\mathrm{eq}}$. The weathering flux (Equation (3)) resulting from thermodynamic solute concentrations gives the maximum weathering flux. Because no secondary minerals are modeled for peridotite weathering, the weathering flux for $P_{\mathrm{CO}_{2}}>0.1$ bar is likely an overestimate (e.g., aqueous alteration of olivine produces secondary minerals; Kite \&
Melwani Daswani 2019). Figure 3(b) shows that the thermodynamic weathering flux calculations using $\left[\mathrm{HCO}_{3}^{-}\right]_{\text {eq }}$ and $A_{\mathrm{eq}}$ increase monotonically with $P_{\mathrm{CO}_{2}}$. We follow the same procedure as for peridotite to compute the maximum solute concentrations and the maximum weathering flux for basalt, granite, or individual endmember silicate minerals by solving polynomial equations given in Appendix B and the corresponding charge balance equations.

\subsection{Generalized Weathering Model}

In natural environments, fluid-rock reactions may not have the time to attain chemical equilibrium due to high fluid flow rates. The maximum weathering model (Section 2.3) does not accurately represent the weathering flux when chemical equilibrium for mineral dissolution reactions is not attained. We present the generalized weathering model by extending the fluid-transport-controlled approach of Maher \& Chamberlain (2014). Mineral dissolution reactions, being rate limiting, essentially regulate the concentration of reaction products including $\left[\mathrm{HCO}_{3}^{-}\right]$. In this limit, kinetics plays a more dominant role than thermodynamics. Maher \& Chamberlain (2014) provide a solute transport equation to calculate such a transport-buffered (dilute) solute concentration from its value at chemical equilibrium, fluid flow rate (runoff) $q$, and the Damköhler coefficient $D_{w}$, which gives the "net reaction rate" (see below). The solute transport equation with $\mathrm{HCO}_{3}^{-}$is

$$
\left[\mathrm{HCO}_{3}^{-}\right]=\frac{\left[\mathrm{HCO}_{3}^{-}\right]_{\mathrm{eq}}}{1+\frac{q}{D_{w}}} .
$$

In their formulation, Maher \& Chamberlain (2014) multiply $D_{w}$ by an arbitrary scaling constant $\tau=e^{2} \approx 7.389$ in order to scale up the solute concentration to $88 \%$ of its equilibrium value at $q=D_{w}$. Ibarra et al. (2016) when applying the solute transport equation of Maher \& Chamberlain (2014), use $\tau=1$ without any scaling. For simplicity, we use $\tau=1$, implying $\left[\mathrm{HCO}_{3}^{-}\right]=0.5\left[\mathrm{HCO}_{3}^{-}\right]_{\mathrm{eq}}$ at $q=D_{w}$. The resulting $\left[\mathrm{HCO}_{3}^{-}\right]$of our model at $q=D_{w}$ is about $43 \%$ lower than that of the Maher \& Chamberlain (2014) model, which is a much smaller difference than the 5-10 orders of magnitude range of solute concentrations explored in this study.

The quantity $D_{w} / q$ in Equation (8) is the Damköhler number, the ratio of the fluid residence time and chemical equilibrium timescale (Steefel \& Maher 2009). The $D_{w} / q$ ratio is essentially the ratio of the "net reaction rate" and the fluid flow rate. When the fluid residence time exceeds the chemical equilibrium timescale, or the net reaction rate exceeds the fluid flow rate $\left(q<D_{w}\right),\left[\mathrm{HCO}_{3}^{-}\right] \rightarrow\left[\mathrm{HCO}_{3}^{-}\right]_{\mathrm{eq}}$ and the weathering flux reaches its maximum value for a given $q, w=\left[\mathrm{HCO}_{3}^{-}\right]_{\mathrm{eq}} q$ (Figure 4). This weathering regime is called the thermodynamically limited weathering (hereafter, thermodynamic regime), also known as runoff-limited weathering. When the chemical equilibrium timescale exceeds the fluid residence time, or the fluid flow rate exceeds the net reaction rate $\left(q>D_{w}\right)$, $\left[\mathrm{HCO}_{3}^{-}\right] \rightarrow\left[\mathrm{HCO}_{3}^{-}\right]_{\mathrm{eq}} \frac{D_{w}}{q}$ and $w=\left[\mathrm{HCO}_{3}^{-}\right]_{\mathrm{eq}} D_{w}$, making $w$ independent of $\left[\mathrm{HCO}_{3}^{-}\right]_{\mathrm{eq}}$ because $D_{w}$ is modeled to be inversely proportional to $\left[\mathrm{HCO}_{3}^{-}\right]_{\mathrm{eq}}$ (see below). This regime is known as kinetically limited weathering (hereafter, kinetic regime). The transition between these two regimes occurs at $q=D_{w}$. The comparison of the timescales described here is conceptually identical to the "quenching approximation" 
(a)

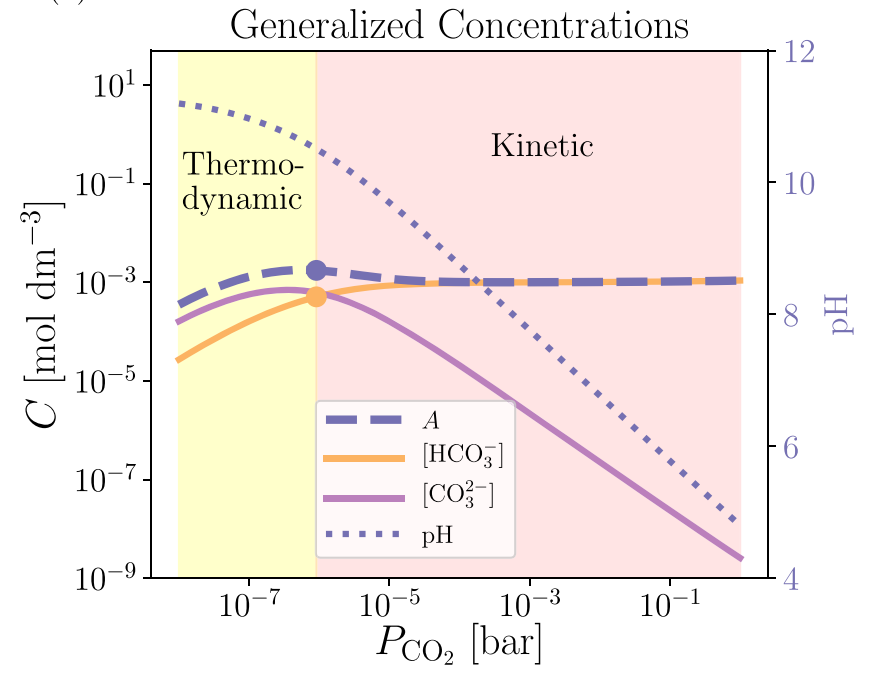

(b)

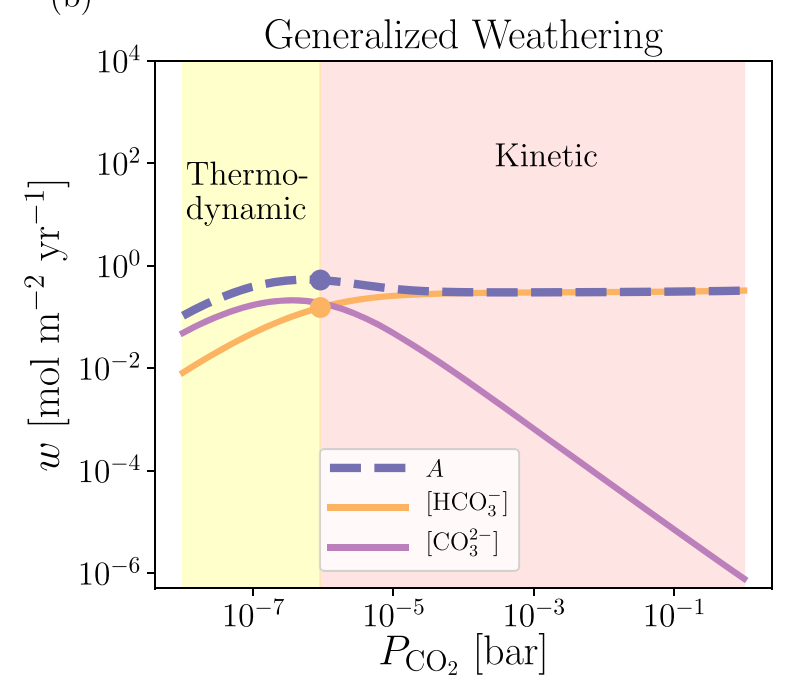

Figure 4. (a) Generalized concentrations of carbonate alkalinity and the solution $\mathrm{pH}$ of peridotite weathering as a function of $P_{\mathrm{CO}_{2}}$ at $T=288 \mathrm{~K}$ and modern mean runoff of $q=0.3 \mathrm{~m} \mathrm{yr}^{-1}$ (other parameters take reference values). From left to right, colored disks mark the transition between thermodynamic and kinetic regimes. (b) The corresponding weathering flux of carbonate alkalinity, $\left[\mathrm{CO}_{3}^{2-}\right]$ and $\left[\mathrm{HCO}_{3}^{-}\right]$. The scales on vertical and horizontal axes are equal to those in Figure 3.

employed in atmospheric chemistry (Prinn \& Barshay 1977; Tsai et al. 2017).

Rewriting the formulation of $D_{w}$ from Maher \& Chamberlain (2014),

$$
D_{w}=\frac{\psi}{\left[\mathrm{HCO}_{3}^{-}\right]_{\mathrm{eq}}\left(k_{\mathrm{eff}}^{-1}+m A_{\mathrm{sp}} t_{\mathrm{s}}\right)},
$$

where $\left[\mathrm{HCO}_{3}^{-}\right]_{\mathrm{eq}}$ is the equilibrium solute concentration, $k_{\mathrm{eff}}$ is the effective kinetic rate coefficient given by kinetics data (Appendix A), $t_{\mathrm{s}}$ is the age of soils or pore space, $A_{\mathrm{sp}}$ is the specific reactive surface area per unit mass of the rock, $m$ is the mean molar mass of the rock, $\psi=L(1-\phi) \rho X_{r} A_{\mathrm{sp}}$ is a dimensionless pore-space parameter that combines five parameters including flow path length $L$, porosity $\phi$, rock density $\rho$, and the fraction of reactive minerals in fresh rock $X_{r}$. Although Maher \& Chamberlain (2014) parameterize $D_{w}$ using nine
Table 3

Fixed Parameters

\begin{tabular}{llc}
\hline \hline Symbol & Description & Value \\
\hline$\phi$ & Porosity & $0.175^{\mathrm{a}}$ \\
$L$ & Flow path length & $1 \mathrm{~m}^{\mathrm{a}}$ \\
$X_{r}$ & Fraction of reactive minerals & $1^{\mathrm{c}}$ \\
& in fresh rock & \\
$A_{\mathrm{sp}}$ & Specific surface area & $100 \mathrm{~m}^{2} \mathrm{~kg}^{-1 \mathrm{a}}$ \\
& of mineral or rock & \\
$\rho$ & Density of mineral or rock & $2700 \mathrm{~kg} \mathrm{~m}^{-3 \mathrm{a}}$ \\
$m$ & Mean molar mass of rock & $0.27 \mathrm{~kg} \mathrm{~mol}^{-1 \mathrm{a}}$ \\
$A_{\mathrm{s}}$ & Planet surface area & $510.1 \mathrm{Mm}^{2 \mathrm{~b}}$ \\
$f$ & Continental area fraction & $0.3^{\mathrm{b}}$ \\
$S$ & Stellar flux & $1360 \mathrm{~W} \mathrm{~m}^{-2 \mathrm{~b}}$ \\
$\alpha$ & Planetary albedo & $0.3^{\mathrm{b}}$ \\
$P^{\prime}$ & Seafloor pore-space pressure & $200 \mathrm{bar}^{\mathrm{b}}$ \\
\hline
\end{tabular}

Notes.

a Maher \& Chamberlain (2014).

${ }^{\mathrm{b}}$ Present-day Earth.

${ }^{c}$ All considered minerals are reactive.

quantities, in Appendix $\mathrm{D}$, we show that $D_{w}$ is mostly sensitive to four of these quantities given their plausible ranges: $\left[\mathrm{HCO}_{3}^{-}\right.$ ]$_{\text {eq }}, k_{\text {eff }}, t_{\mathrm{s}}$, and $L(L$ is absorbed in $\psi$ ). The remaining five parameters are fixed to reference values (Table 3). The parameter $\psi$ scales $k_{\text {eff }}$ with dimensions of moles per unit reactive surface area of rocks per unit time to $w$ with dimensions of moles per unit exposed continental or seafloor area for a given lithology per unit time. In Equation (9), the solid mass to fluid volume ratio $\rho_{\text {sf }}$ given in the $D_{w}$ formulation of Maher \& Chamberlain (2014) is rewritten in terms of solid density and porosity using $\rho_{\text {sf }}=\rho(1-\phi) / \phi$. The kinetic rate coefficients of mineral dissolution reactions are obtained from Palandri \& Kharaka (2004) as a function of $T$ and $\mathrm{pH}$ (see Appendix A). The solution $\mathrm{pH}$ at chemical equilibrium is used to calculate $k_{\text {eff }}$. For minerals with no $k_{\text {eff }}$ data, the $k_{\text {eff }}$ of a corresponding endmember mineral from the same mineral group is adopted. For rocks, we adopt $k_{\text {eff }}$ given by the minimum $k_{\text {eff }}$ among constituent minerals because the slowest reaction is normally rate limiting; but see, e.g., Milliken et al. (2009), where the fastest dissolving mineral sets the pace of rock dissolution.

In Equation (9), when $t_{\mathrm{s}}=0$ (young soils), $D_{w}=\frac{k_{\text {eff }} \psi}{\left[\mathrm{HCO}_{3}^{-}\right]_{\mathrm{eq}}}$ and $w=k_{\text {eff }} \psi$. In this "fast kinetic" regime, the weathering flux is directly proportional to the kinetic rate coefficient, as assumed in traditional kinetic weathering models (e.g., Walker et al. 1981). When $t_{\mathrm{s}} \gg \frac{1}{k_{\text {eff }} m A_{\mathrm{sp}}}$ (old soils), $D_{w}=\frac{\psi}{\left[\mathrm{HCO}_{3}\right]_{\text {eq }} m A_{\mathrm{sp}} t_{\mathrm{s}}}$, and $w=\frac{\psi}{m A_{\mathrm{sp}} t_{\mathrm{s}}}$. This regime may be termed as the "slow kinetic" regime; however, an accepted terminology is supplylimited weathering (hereafter, supply regime), which is limited by the supply of fresh rocks in the weathering zone (Riebe et al. 2003; West et al. 2005). An increase in $t_{\mathrm{s}}$ decreases the influence of chemical kinetics on weathering. Although $t_{\mathrm{s}}$ depends on the soil production and physical erosion rates, which in turn are sensitive to climate, topography, and fluid flow properties, there is no consensus on the formulation of soil production and physical erosion rates (Riebe et al. 2003; West et al. 2005; Gabet \& Mudd 2009; West 2012; Maher \& 
Chamberlain 2014; Foley 2015). Treating $t_{\mathrm{s}}$ as a free parameter makes it possible to model both the age of continental soils and seafloor pore space. The transition between the kinetic and supply regimes can be defined at $t_{\mathrm{s}}=\frac{1}{k_{\text {eff }} m A_{\mathrm{sp}}}$, where the kinetic reaction rate equals the supply rate of fresh rocks (see Equation (9)).

In the fluid-transport-controlled model, the mineral dissolution reactions (Appendix B, rows (a)-(n) in Table B1) do not attain chemical equilibrium, and their reaction products are given by the solute transport equation (Equation (8)). On the other hand, reactions in the water-bicarbonate system (Appendix B, rows (o)-(r) in Table B1), are considered to reach chemical equilibrium. This assumption is justified because the equilibrium timescale of chemical reactions in the water-bicarbonate system is of the order of milliseconds to days, unlike mineral dissolution reactions that may take months to thousands of years (e.g., Palandri \& Kharaka 2004; Schulz et al. 2006). Thus, the generalized concentrations of aqueous species in the water-bicarbonate system such as $\left[\mathrm{CO}_{3}^{2-}\right],\left[\mathrm{H}^{+}\right]$, and $\left[\mathrm{OH}^{-}\right]$are calculated from the transport-buffered $\left[\mathrm{HCO}_{3}^{-}\right]$ and equilibrium constants (see Appendix B, Figure B2 for the flow chart of the methodology). Rewriting $\left[\mathrm{CO}_{3}^{2-}\right]$ in terms of $\left[\mathrm{HCO}_{3}^{-}\right], P_{\mathrm{CO}_{2}}$, and the equilibrium constants in Equation (7),

$$
A=\left[\mathrm{HCO}_{3}^{-}\right]+2 \frac{K_{\mathrm{Car}}\left[\mathrm{HCO}_{3}^{-}\right]^{2}}{K_{\mathrm{Bic}} P_{\mathrm{CO}_{2}}} .
$$

Figure 4(a) shows the carbonate alkalinity and the solution $\mathrm{pH}$ for the generalized model of peridotite weathering as a function of $P_{\mathrm{CO}_{2}}$ at a constant surface temperature $(T=288 \mathrm{~K})$. For $P_{\mathrm{CO}_{2}}<1 \mu \mathrm{bar},\left[\mathrm{HCO}_{3}^{-}\right],\left[\mathrm{CO}_{3}^{2-}\right]$, and $\mathrm{pH}$ in Figure $4(\mathrm{a})$ exhibit the same behavior as in Figure 3(a) because $q<D_{w}$, reiterating that chemical equilibrium calculations are valid in the thermodynamic regime resulting in the maximum weathering flux. The maximum ([ $\left.\mathrm{HCO}_{3}^{-}\right]_{\mathrm{eq}}$ and $A_{\mathrm{eq}}$, Figure $\left.3(\mathrm{~b})\right)$ and generalized $\left(\left[\mathrm{HCO}_{3}^{-}\right]\right.$and $A$, Figure $\left.4(\mathrm{~b})\right)$ weathering fluxes diverge from each other beyond the thermodynamic to kinetic regime transition that occurs at $P_{\mathrm{CO}_{2}} \sim 1 \mu$ bar. The choice of $q$ determines this transition. At a higher $q$, the regime transition would shift to a lower $P_{\mathrm{CO}_{2}}$ and vice versa. For $P_{\mathrm{CO}_{2}}>1 \mu \mathrm{bar}$, $\left[\mathrm{HCO}_{3}^{-}\right]$becomes independent of $P_{\mathrm{CO}_{2}}$ in the kinetic weathering regime. This is because the kinetic rate coefficient of the slowest reaction (fayalite dissolution) is constant at a fixed $T$ and does not vary when the $\mathrm{pH}$ is basic (see Appendix A). However, the results shown in Figure 4 are expected to change when the temperature is not held constant and depends on $P_{\mathrm{CO}_{2}}$, where the relation between the two is given by a climate model (Section 2.5).

In the kinetic weathering regime, $\left[\mathrm{CO}_{3}^{2-}\right]$ decreases with $P_{\mathrm{CO}_{2}}$ (Figure $4(\mathrm{a})$ ) because $\left[\mathrm{CO}_{3}^{2-}\right]$ is directly proportional to $\left[\mathrm{HCO}_{3}^{-}\right]$and inversely proportional to $P_{\mathrm{CO}_{2}}$ (Equation (10)). Because $\left[\mathrm{HCO}_{3}^{-}\right]$is constant in the kinetic regime, $\left[\mathrm{CO}_{3}^{2-}\right]$ shows a strong decrease because of its sole dependence on $P_{\mathrm{CO}_{2}}$. We follow the same procedure as for peridotite to compute the generalized concentrations for the weathering of basalt, granite, or individual minerals and find that lithology strongly impacts the occurrence of weathering regimes (Appendix B, Figure B3).

\subsection{Climate Model}

The greenhouse effect of $\mathrm{CO}_{2}$ exerts a strong control on the planetary surface temperature. A climate model enables one to express the surface temperature $T$ as a function of the $\mathrm{CO}_{2}$ partial pressure $P_{\mathrm{CO}_{2}}$ for a given planetary albedo $\alpha$ and top-ofatmosphere stellar flux $S$. Such a climate model is essential to assess the role of climate in weathering on temperate planets. CHILI provides the functionality to couple $T$ and $P_{\mathrm{CO}_{2}}$ using any climate model. Previous studies provide formulations of climate models (e.g., Walker et al. 1981; Kasting et al. 1993). Recently, Kopparapu et al. (2013, 2014) performed 1D radiative-convective calculations to obtain $T$ as a function of $P_{\mathrm{CO}_{2}}, \alpha$, and $S$. Studies such as Haqq-Misra et al. (2016) and Kadoya \& Tajika (2019) provide fitting functions to the models of Kopparapu et al. (2013, 2014). We use the fitting function provided by Kadoya \& Tajika (2019) to couple $T$ in the range $150-350 \mathrm{~K}$ with $P_{\mathrm{CO}_{2}}$ in the range $10^{-5}-10$ bar. For $\alpha=0.3$ (present-day albedo of Earth) and $S=1360 \mathrm{~W} \mathrm{~m}^{-2}$ (presentday solar flux), the Kadoya \& Tajika (2019) fitting function results in $T$ between 280 and $350 \mathrm{~K}$ for $P_{\mathrm{CO}_{2}}$ between $10 \mu \mathrm{bar}$ and 0.5 bar (see Appendix E for details).

\section{Weathering on Temperate Planets}

\subsection{Maximum Weathering for Various Lithologies}

The thermodynamic solute concentrations provide an upper limit to weathering (e.g., peridotite weathering; Figure 3). To evaluate the case of maximum weathering on temperate planets, in Figure 5, we provide the $\left[\mathrm{HCO}_{3}^{-}\right]_{\mathrm{eq}}$ weathering flux of three common rocks (basalt, peridotite, granite) as a function of climate properties, $P_{\mathrm{CO}_{2}}$ and $T$, at the present-day mean runoff of $0.3 \mathrm{~m} \mathrm{yr}^{-1}$. The dependence of weathering on total surface pressure is negligible (see Appendix B). The $\left[\mathrm{HCO}_{3}^{-}\right]_{\mathrm{eq}}$ weathering flux for all rocks increases monotonically with $P_{\mathrm{CO}_{2}}$ at a constant temperature because weathering intensifies as $P_{\mathrm{CO}_{2}}$ increases (Figure 5(a)). This is a direct consequence of the calculations of solute concentrations at chemical equilibrium (Section 2.3). Table 4 gives fitting parameters of the thermodynamic weathering flux of $\left[\mathrm{HCO}_{3}^{-}\right]_{\mathrm{eq}}$ to the kinetic weathering expression (Equation (2)) for the silicate rocks and minerals considered in this study. Such a fit, although not the best approximation of the calculated values, provides a way to compare the sensitivity of thermodynamic weathering to climate properties with studies assuming kinetic weathering (e.g., Walker et al. 1981; Sleep \& Zahnle 2001; Foley 2015).

Fluid-rock reactions produce both monovalent (e.g., $\mathrm{K}^{+}$, $\mathrm{Na}^{+}$) and divalent cations (e.g., $\mathrm{Ca}^{2+}, \mathrm{Mg}^{2+}$ ). The sensitivity of $\left[\mathrm{HCO}_{3}^{-}\right]_{\text {eq }}$ flux to $P_{\mathrm{CO}_{2}}$ depends on the capacity of a rock to produce divalent cations. More divalent cations in the solution require more $\mathrm{HCO}_{3}^{-}$and $\mathrm{CO}_{3}^{2-}$ ions to balance the charges. Consequently, the higher the fraction of divalent cations in a rock, the higher the thermodynamic $P_{\mathrm{CO}_{2}}$ sensitivity $\left(\beta_{\text {th }}\right)$. For instance, peridotite, which produces only divalent cations, exhibits the highest $\beta_{\text {th }}$ among the three rocks (Figure 3). Granite produces more monovalent cations than peridotite and basalt, and therefore has the lowest $\beta_{\mathrm{th}}$. This effect has been discussed for feldspar minerals by Ibarra et al. (2016); Winnick \& Maher (2018).

The $\beta_{\text {th }}$ values for endmember minerals within the same mineral group (pyroxene, olivine, mica, and amphibole), with the exception of feldspars, are similar to each other (Table 4). This result is again attributed to the presence of monovalent or divalent cations. The divalent-cation-producing pyroxene, olivine, mica, and amphibole endmembers exhibit $\beta_{\mathrm{th}} \sim 0.5$, and monovalent-cation-producing albite and K-feldspar exhibit 
(a)

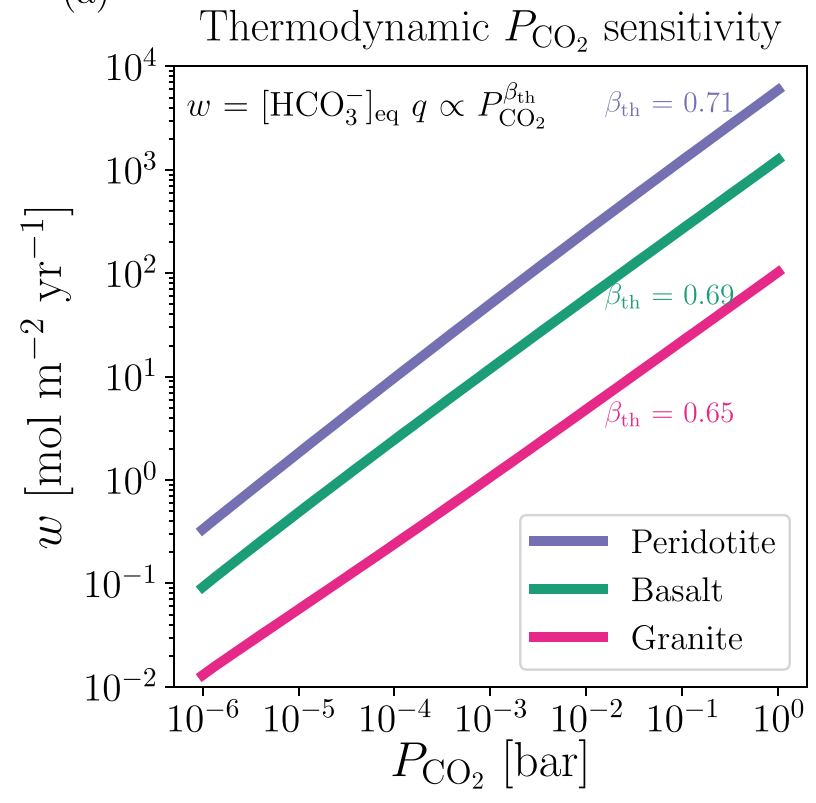

(b)

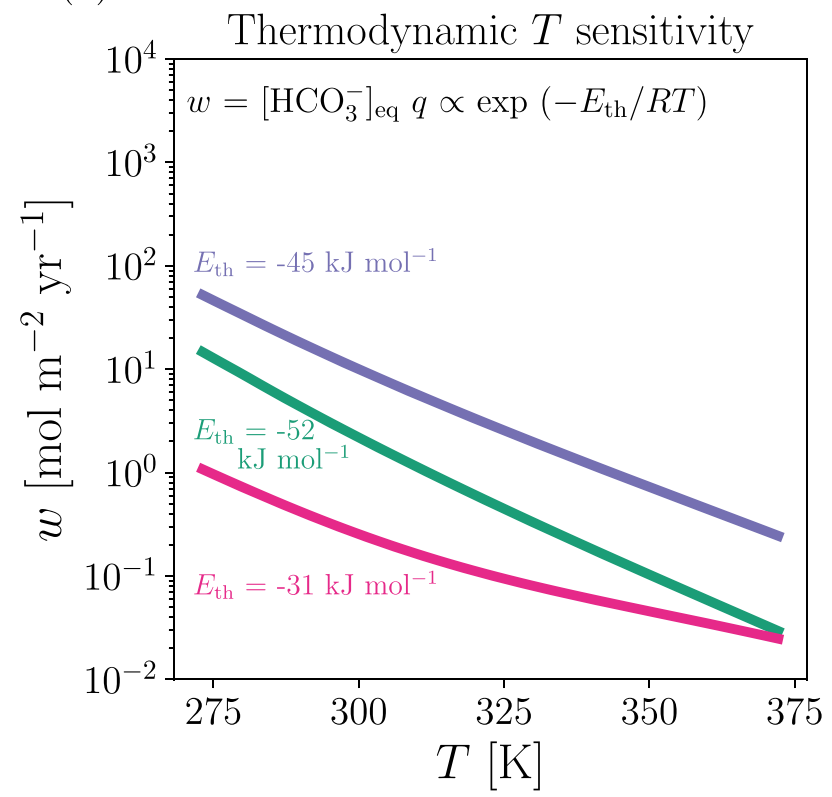

Figure 5. Sensitivity of thermodynamic $\left[\mathrm{HCO}_{3}^{-}\right]_{\mathrm{eq}}$ flux (maximum weathering) of rocks to (a) $P_{\mathrm{CO}_{2}}$ at $T=288 \mathrm{~K}$ and (b) $T$ at $P_{\mathrm{CO}_{2}}=280 \mu$ bar, at present-day mean runoff $q=0.3 \mathrm{~m} \mathrm{yr}^{-1}$. The labeled fitting parameters are obtained by fitting the thermodynamic weathering flux to the kinetic weathering expression (Equation (2)).

$\beta_{\text {th }} \sim 0.25$. The deviation from these ideal values of 0.5 and 0.25 is a result of the simultaneous consideration of the mineral dissolution reaction and the water-bicarbonate reactions. For instance, Winnick \& Maher (2018) show that reaction stoichiometry controls $\beta_{\text {th }}$ values by considering the dissolution reactions of individual feldspar minerals and find $\beta_{\mathrm{th}}=0.25$ for albite and K-feldspar. However, we find that the presence of ions produced by the water-bicarbonate system makes $\beta_{\text {th }}$ dependent on equilibrium constants of all reactions considered in addition to stoichiometry and hence $\beta_{\text {th }}=0.26$ for albite and K-feldspar (Table 4). The $\beta_{\text {th }}$ value of the divalent-cationproducing anorthite is 0.69 , considerably higher than other divalent-cation-producing minerals. This is again attributed to reaction stoichiometry as demonstrated by Winnick \& Maher (2018), although their study results in a slightly smaller $\beta_{\text {th }}=0.67$ because reactions in the water-bicarbonate system are ignored.

The weathering flux produced by the rock with a higher $\beta_{\text {th }}$ is higher (Figure 3(a)). However, the choice of secondary minerals produced during weathering influences this result. For instance, if kaolinite is considered instead of halloysite, the weathering flux of basalt is higher by more than an order of magnitude, which is even higher than that of peridotite (see Table 4). The effect of a secondary mineral on the weathering flux of granite is smaller than that of basalt. This difference is attributed to the impact of the secondary mineral on weathering reactions of feldspar endmember minerals. Anorthite, a constituent of basalt in our model, exhibits an order of magnitude increase in the weathering flux when kaolinite is used instead of halloysite (Table 4), whereas the weathering flux of albite and K-feldspar, constituents of granite in our model, increases by a factor of 3 for the same change. Moreover, the nonconsideration of secondary minerals for peridotite weathering results in high weathering flux at high $P_{\mathrm{CO}_{2}}$, which in reality may be lower (e.g., Kite \& Melwani Daswani 2019). Thus, the choice of secondary mineral strongly affects the $w$ and $\beta_{\text {th }}$ of rocks. However, this effect is small for the weathering of individual minerals (Table 4).

Contrary to observations of the increase in kinetic weathering flux with temperature (e.g., Walker et al. 1981), the thermodynamic weathering flux for rocks decreases with the temperature at a fixed $P_{\mathrm{CO}_{2}}$ (Figure 5(b)). The fitting parameter, the activation energy of thermodynamic weathering, provides a scaling relation between weathering and temperature. Unlike kinetic weathering, $E_{\mathrm{th}}$ is negative for the weathering of all rocks and minerals except albite and K-feldspar (Table 4). This result is a consequence of the decrease in equilibrium constants as a function of temperature for all mineral dissolution reactions except those of albite and K-feldspar (see Appendix A). The choice of secondary mineral influences the magnitude of $E_{\text {th }}$ but not its sign. Winnick \& Maher (2018) observe this effect for plagioclase feldspars, which contain anorthite in addition to albite. This effect is discussed further in Section 4.2.

The fitting parameters provided in Table 4 should be used with caution as $\beta_{\mathrm{th}}$ depends on $T$ and $E_{\mathrm{th}}$ depends on $P_{\mathrm{CO}_{2}}$. For example, $\beta_{\text {th }}$ for peridotite at $P_{\mathrm{CO}_{2}}=280 \mu$ bar varies between 0.71 at $T=273 \mathrm{~K}$ and 0.77 at $T=373 \mathrm{~K}$, whereas $E_{\text {th }}$ for peridotite at $T=288 \mathrm{~K}$ varies between $-55 \mathrm{~kJ} \mathrm{~mol}^{-1}$ at $P_{\mathrm{CO}_{2}}=1 \mu \mathrm{bar}$ and $-46 \mathrm{~kJ} \mathrm{~mol}^{-1}$ at $P_{\mathrm{CO}_{2}}=1$ bar. This provides further reason to calculate thermodynamic concentrations consistently by considering all necessary reactions simultaneously, as formulated in this study.

\subsection{Climate Sensitivity of Peridotite Weathering}

Figure 6 shows the sensitivity of both maximum and generalized weathering fluxes of peridotite to $\mathrm{CO}_{2}$ partial pressure and surface temperature. The maximum weathering model gives an upper limit to the weathering flux. The generalized weathering flux is either equal to or smaller than the maximum weathering flux depending on if the generalized model encounters the thermodynamic regime or not. The generalized weathering flux in the kinetic regime is lower than that in the thermodynamic regime and higher than that in the supply regime. Because the weathering 
Table 4

Parameters for Fitting Thermodynamic Weathering Flux to Kinetic Weathering Expression (Equation (2))

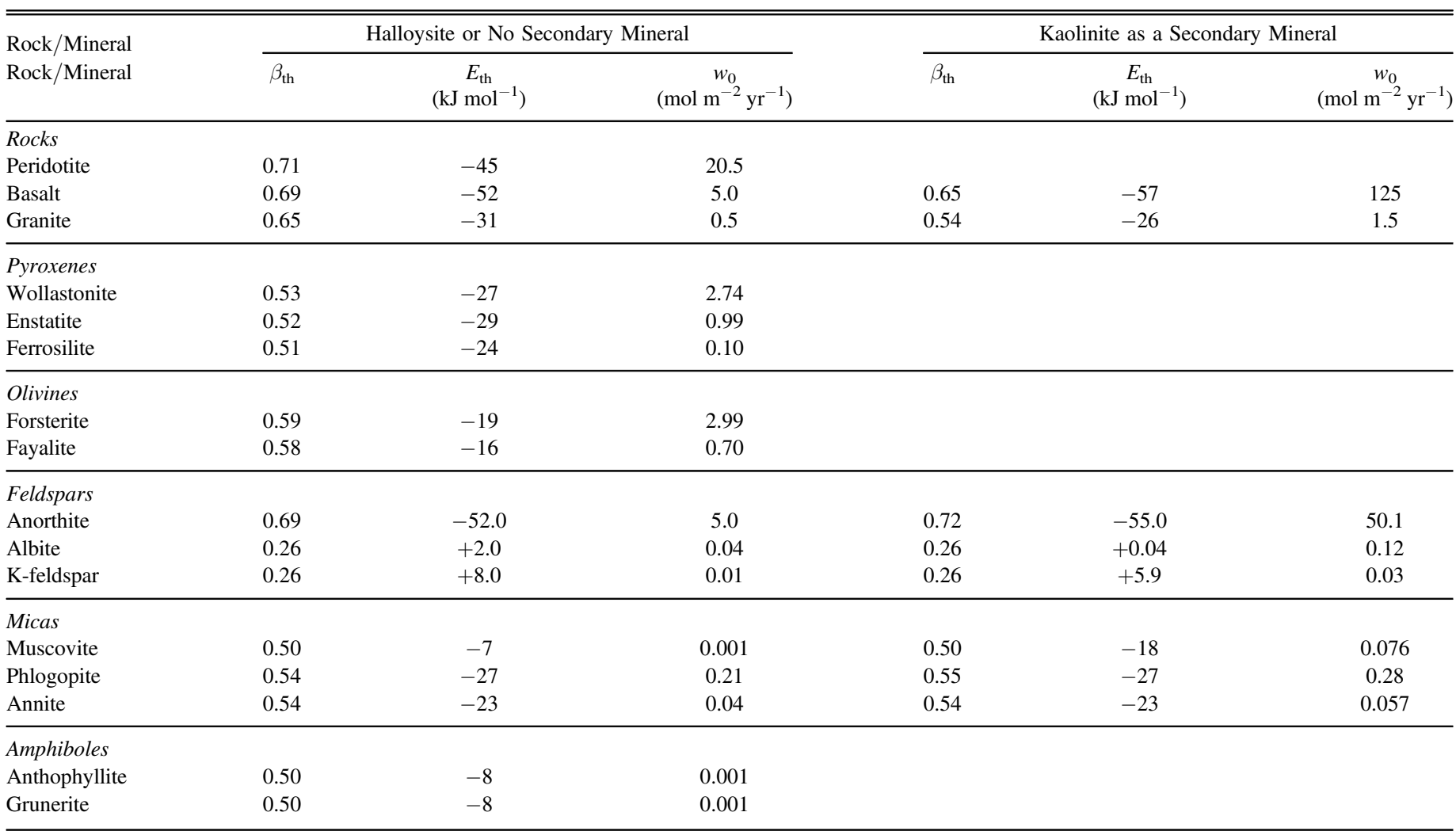

Note. $w_{0}$ is not a fitting parameter but the value of $w$ at $P_{\mathrm{CO}_{2}}=280 \mu \mathrm{bar}, T=288 \mathrm{~K}$, and $q=0.3 \mathrm{~m} \mathrm{yr}^{-1}$. No secondary minerals are assumed to be produced during the weathering of peridotite, pyroxenes, olivines, and amphiboles.

flux in the thermodynamic regime is an upper limit to weathering, the kinetic flux cannot exceed the thermodynamic flux. To isolate the effect of $P_{\mathrm{CO}_{2}}$ on weathering, we present the peridotiteweathering flux as a function of $P_{\mathrm{CO}_{2}}$ at a fixed surface temperature (Figure 6(a)). The sensitivity of weathering to temperature is demonstrated at two $P_{\mathrm{CO}_{2}}$ values (Figures 6(b) and (d)). In reality, $T$ depends on $P_{\mathrm{CO}_{2}}$ due to the greenhouse effect of $\mathrm{CO}_{2}$, which is normally modeled using a climate model (Section 2.5). The strength of the coupling between $T$ and $P_{\mathrm{CO}_{2}}$ is sensitive to numerous parameters including incident solar flux and planetary albedo that are fixed to present-day values (Table 3). Because the solar flux is held constant, the coupling between $T$ and $P_{\mathrm{CO}_{2}}$ becomes stronger than that during Earth's early history where the solar flux dropped to about $70 \%$ of its present-day value. Figure 6(c) demonstrates peridotite weathering under the limit of strong coupling between $T$ and $P_{\mathrm{CO}_{2}}$.

The maximum (thermodynamic) carbonate alkalinity and bicarbonate ion fluxes increase monotonically with $P_{\mathrm{CO}_{2}}$ at $T=288 \mathrm{~K}$ (Figure 6(a)). This monotonic behavior is a direct result of chemical equilibrium calculations with $P_{\mathrm{CO}_{2}}$ as a free parameter at a fixed temperature. The difference between the maximum $A$ and $\left[\mathrm{HCO}_{3}^{-}\right]$fluxes at low $P_{\mathrm{CO}_{2}}$ is due to the excess contribution of $\left[\mathrm{CO}_{3}^{2-}\right]$ to $A$ when the solution $\mathrm{pH}$ is basic (see Figure 3 ). The thermodynamic weathering flux decreases with $T$ at a fixed $P_{\mathrm{CO}_{2}}$ (Figures 6(b) and (d)). As explained in Section 3.1 and later discussed in Section 4.2, this decrease is a result of the decrease in equilibrium constants of mineral dissolution reactions as a function of temperature (see Appendix A). The thermodynamic flux at $P_{\mathrm{CO}_{2}}=0.1 \mathrm{bar}$ is higher than that at $P_{\mathrm{CO}_{2}}=280 \mu$ bar by about a factor of 30 . Unlike at $P_{\mathrm{CO}_{2}}=280 \mu \mathrm{bar}$, at $P_{\mathrm{CO}_{2}}=0.1 \mathrm{bar}$, there is a negligible difference between the thermodynamic $A$ and $\left[\mathrm{HCO}_{3}^{-}\right]$fluxes. When $T$ depends on $P_{\mathrm{CO}_{2}}$ via a climate model, the behavior of thermodynamic weathering as a function of $P_{\mathrm{CO}_{2}}$ depends on the trade-off between the individual effects of $T$ and $P_{\mathrm{CO}_{2}}$ (Figure 6(c)). Up to $P_{\mathrm{CO}_{2}}=0.01$ bar, the thermodynamic fluxes increase with $P_{\mathrm{CO}_{2}}$ because the $P_{\mathrm{CO}_{2}}$ effect dominates, whereas beyond $P_{\mathrm{CO}_{2}}=0.05$ bar, there is a small decrease in the thermodynamic fluxes because the effect of $T$ takes over.

When soils are young (soil age is zero, $t_{\mathrm{s}}=0$ ), the generalized $\left[\mathrm{HCO}_{3}^{-}\right]$flux at $T=288 \mathrm{~K}$, which is in the kinetic regime, is almost constant for the given $P_{\mathrm{CO}_{2}}$ range (Figure 6(a)). The kinetic rate coefficient depends on $T$ as well as the solution $\mathrm{pH}$ which in turn depends on $P_{\mathrm{CO}_{2}}$ (Section 2.4). However, the kinetic weathering flux is independent of $P_{\mathrm{CO}_{2}}$ at a fixed temperature because $k_{\mathrm{eff}}$ of peridotite is independent of $P_{\mathrm{CO}_{2}}$ when the solution $\mathrm{pH}$ is basic (Figure 6(a)). This $k_{\text {eff }}$ is determined by the fayalite dissolution reaction as it is rate limiting among the considered mineral dissolution reactions for peridotite (see Appendix A). As a function of $T$ at constant $P_{\mathrm{CO}_{2}}$, kinetic weathering exhibits a strong dependence on temperature as seen in Figures 6(b) and (d). For the $P_{\mathrm{CO}_{2}}=280 \mu$ bar case, the generalized $\left(t_{\mathrm{s}}=0\right)$ model switches from the kinetic to the thermodynamic regime at $\sim 310 \mathrm{~K}$ where the limit of maximum weathering is encountered. For the $P_{\mathrm{CO}_{2}}=0.1$ bar case, this transition temperature increases to $\sim 340 \mathrm{~K}$. The transition from kinetic 
(a)

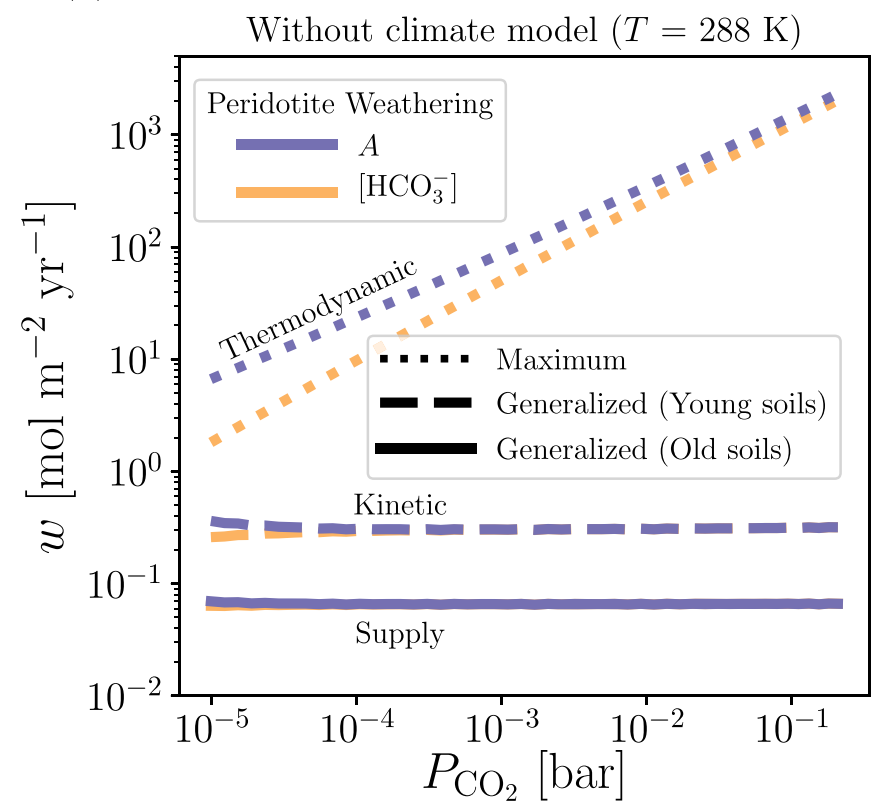

(c)

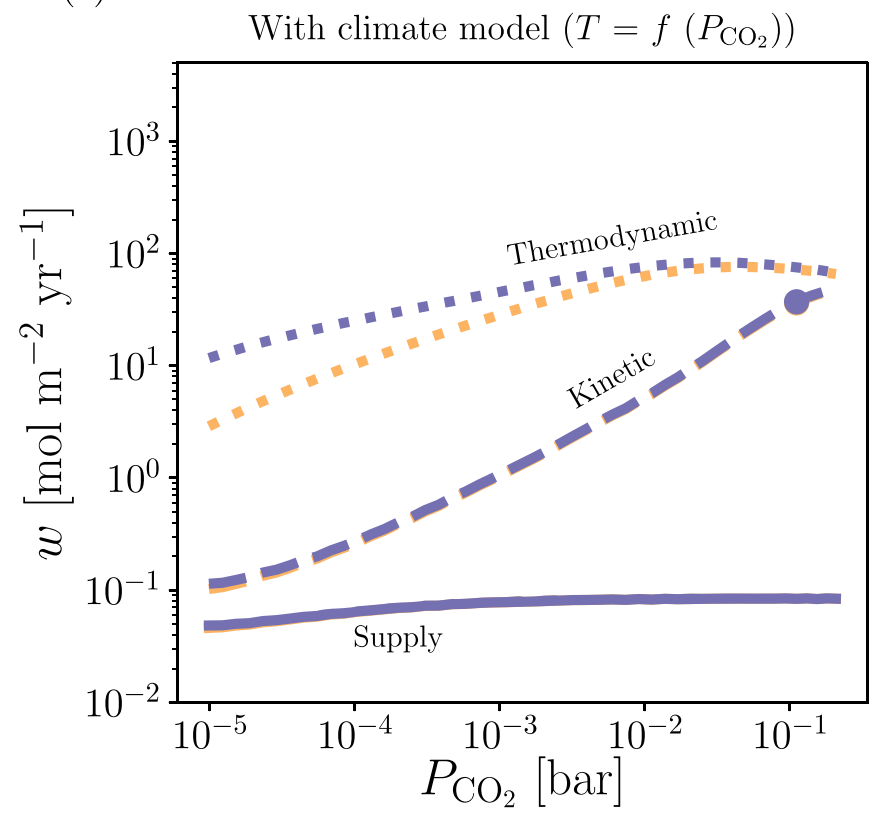

(b)

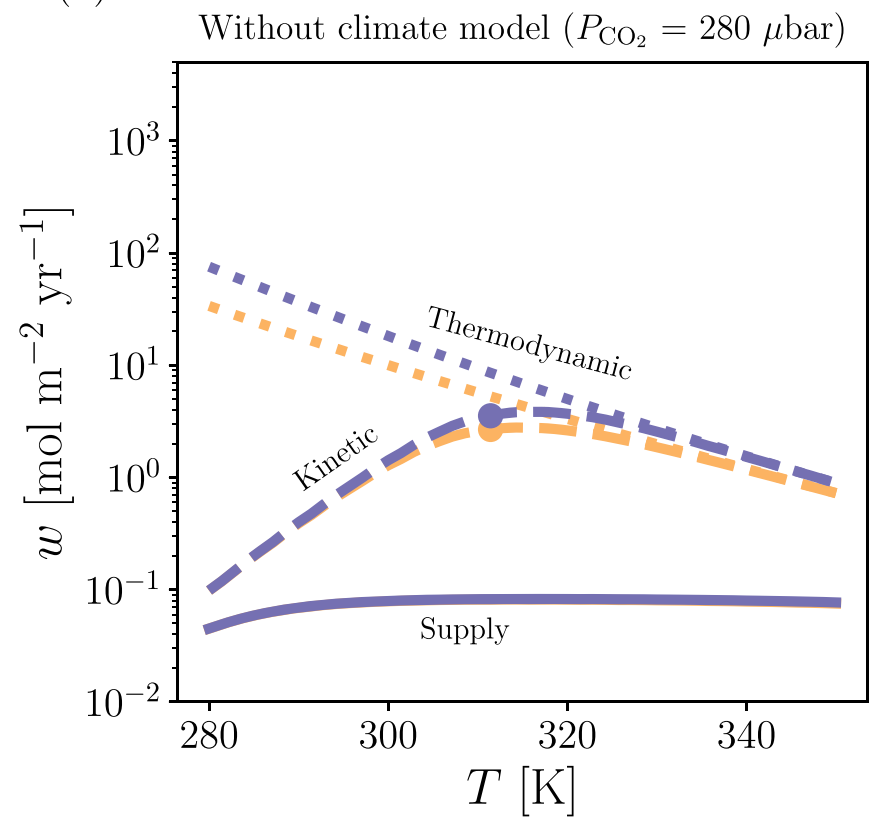

(d)

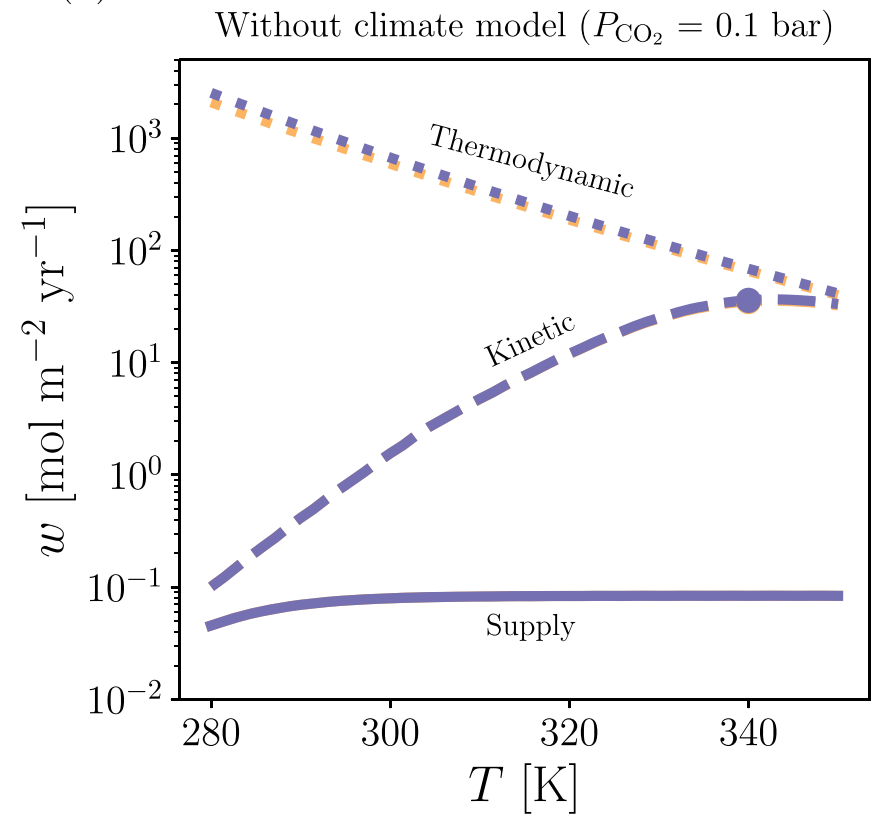

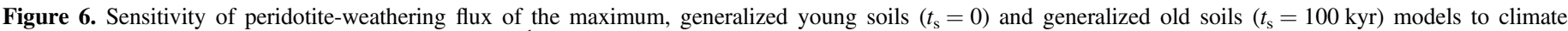

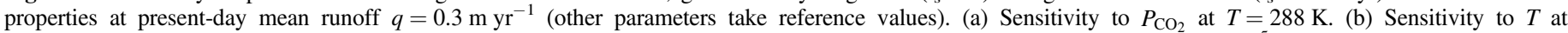

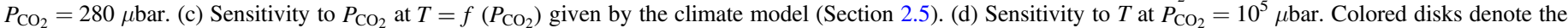
transition between kinetic and thermodynamic regimes.

to thermodynamic regime occurs at high $T$ and low $P_{\mathrm{CO}_{2}}$. The sequence of this transition is in contrast to the switch from the thermodynamic to the kinetic regime that occurs at $P_{\mathrm{CO}_{2}}=1 \mu \mathrm{bar}$ as a function of $P_{\mathrm{CO}_{2}}$ (see Figure 4). If the climate model is invoked, the generalized $\left(t_{\mathrm{s}}=0\right)$ weathering flux increases steeply with $P_{\mathrm{CO}_{2}}$ and encounters the thermodynamic regime at about $P_{\mathrm{CO}_{2}}=0.1 \mathrm{bar}$, a result of the kinetic temperature dependence (Figure 6(c)). When $T$ is strongly coupled to $P_{\mathrm{CO}_{2}}$, the generalized model may switch from the thermodynamic to kinetic regime at low $P_{\mathrm{CO}_{2}}$ and from the kinetic regime back to the thermodynamic regime at high $P_{\mathrm{CO}_{2}}$.
When soils are old (present-day characteristic soil age, $\left.t_{\mathrm{S}}=100 \mathrm{kyr}\right)$, the $\left[\mathrm{HCO}_{3}^{-}\right]$flux at $T=288 \mathrm{~K}$ as a function of $P_{\mathrm{CO}_{2}}$ is constant and in the supply regime (Figure 6(a)). This regime is limited by the supply of fresh rocks, and the influence of chemical kinetics on weathering is small compared to when soils are young $\left(t_{\mathrm{s}}\right.$ is small). This regime is almost independent of $T$ (Figures 6(b) and (d)). Consequently, unlike the kinetic weathering flux, the supply-limited weathering flux is independent of $P_{\mathrm{CO}_{2}}$ when $T$ dependence via the climate model is invoked (Figure 6(c)). In the supply regime, the weathering flux depends on the age of soils, which is held constant. There 
(a)

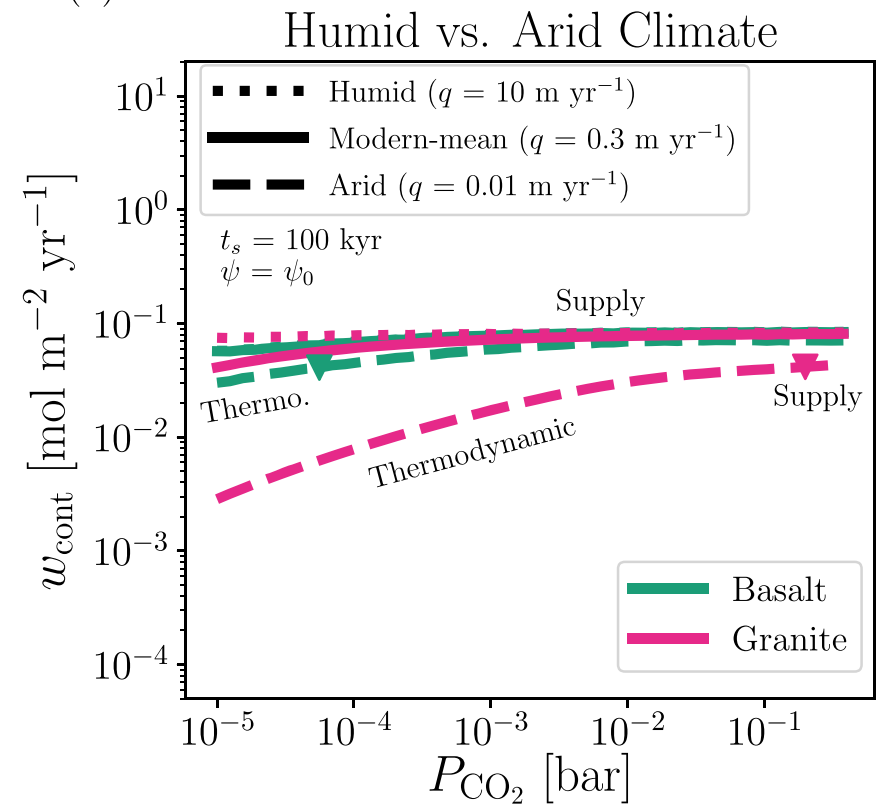

(c)

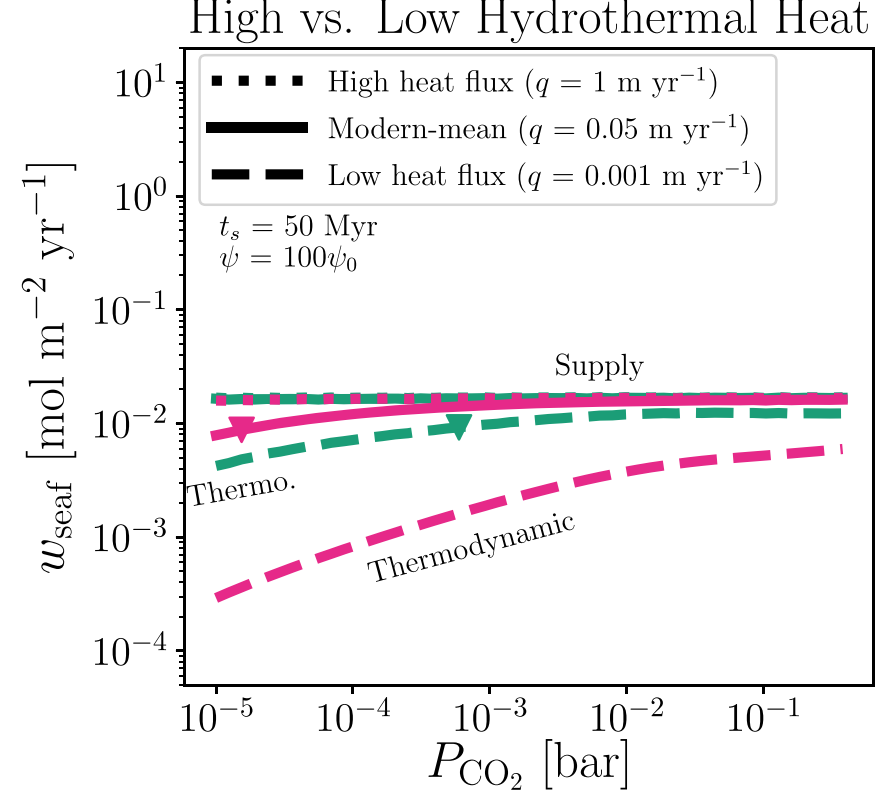

(b)

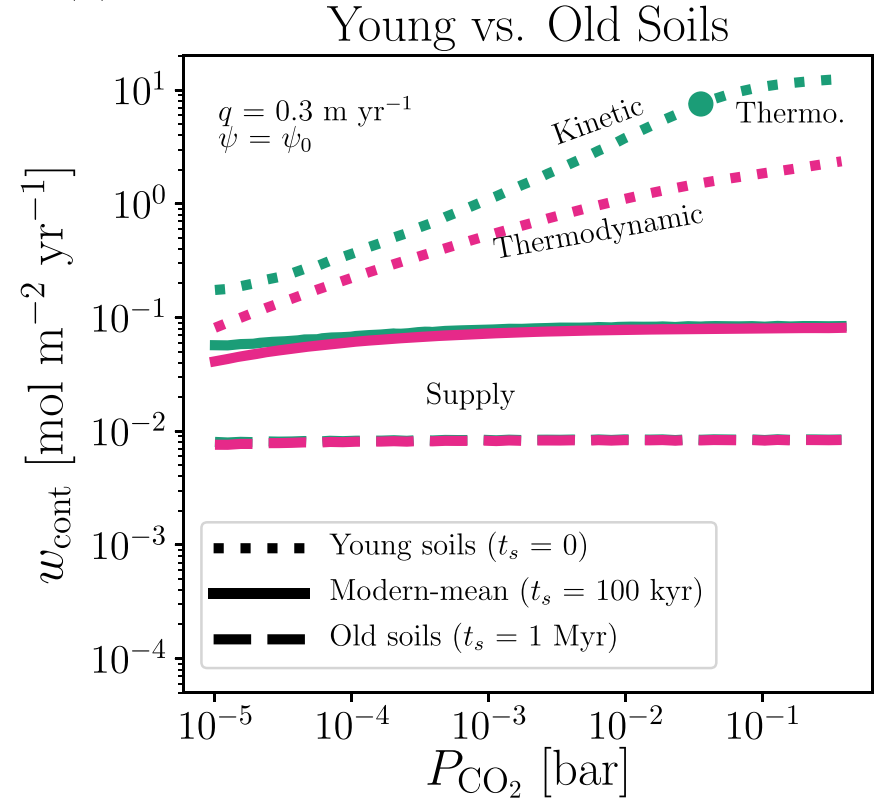

(d)

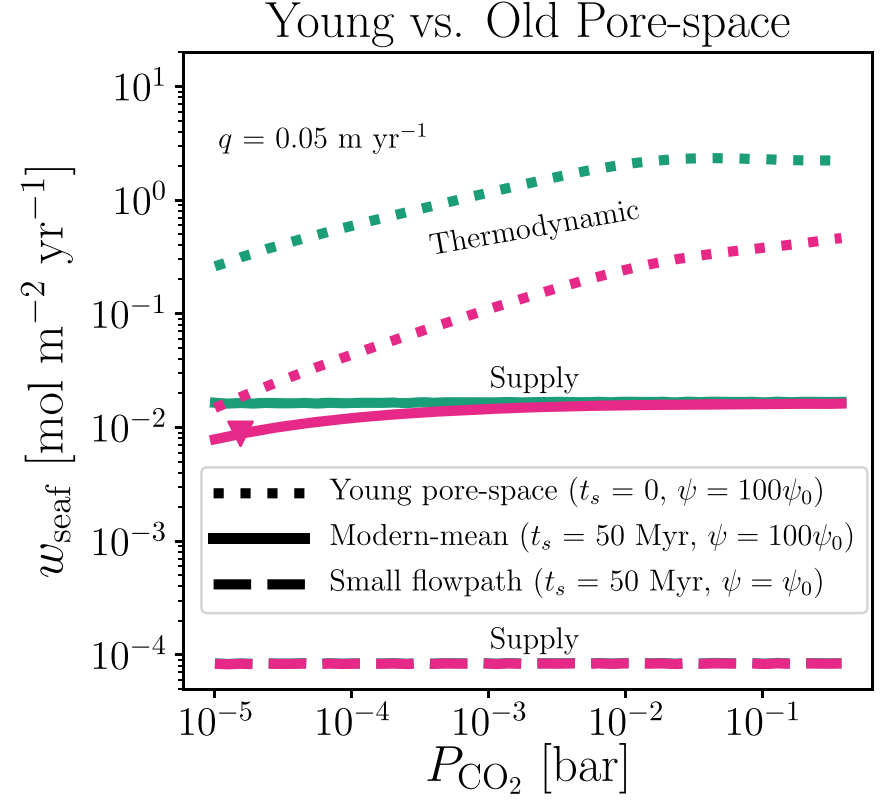

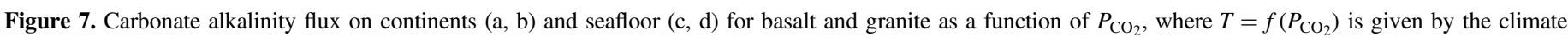

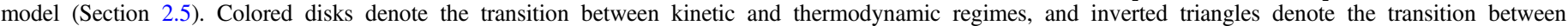
thermodynamic and supply regimes.

is almost no difference between the generalized ( $\left.t_{\mathrm{s}}=100 \mathrm{kyr}\right)$ $A$ and $\left[\mathrm{HCO}_{3}^{-}\right]$fluxes between Figures 6(a) and (c) because the inclusion of the $T$ effect via the climate model is not strong enough to escape from the supply regime. In contrast, for the generalized $\left(t_{\mathrm{s}}=0\right)$ model, invoking the climate model increases the weathering fluxes in the kinetic regime enough to enter the thermodynamic regime at about $P_{\mathrm{CO}_{2}}=0.1$ bar.

\subsection{Endmember Cases of Continental and Seafloor Weathering}

We apply the generalized weathering model to both continental (Figures 7(a) and (b)) and seafloor silicate weathering
(Figures 7(c) and (d)) for diverse cases that may represent weathering scenarios on temperate rocky exoplanets. The climate model is used to couple $T$ with $P_{\mathrm{CO}_{2}}$ by fixing the stellar flux and planetary albedo to present-day Earth values (Section 2.5). This implies a strong coupling between $T$ and $P_{\mathrm{CO}_{2}}$ such that $T$ varies from 280 to $350 \mathrm{~K}$ when $P_{\mathrm{CO}_{2}}$ varies from $10 \mu \mathrm{bar}$ to $0.5 \mathrm{bar}$. The lithology and pore-space properties of continents and seafloor on present-day Earth are different from each other. This presents an opportunity to test the generalized weathering model in an extended parameter space beyond applications to continental weathering. We show the results for basalt and granite in Figure 7. The sensitivity of the carbonate alkalinity weathering flux to $P_{\mathrm{CO}_{2}}$ 
is a complex function of climate, fluid flow rate, and rock and pore-space properties. This result implies that the weathering flux cannot be simply approximated by Equation (2) assuming either kinetic weathering (e.g., Walker et al. 1981; Berner et al. 1983; Sleep \& Zahnle 2001; Foley 2015) or thermodynamic weathering (Winnick \& Maher 2018, and Section 3.1, this study).

In Figure 7(a), the continental $A$ flux is calculated for three values of runoff that are representative of arid, modern mean, and humid climates. Gaillardet et al. (1999) report regional variations in the present-day runoff from 0.01 to $3 \mathrm{~m} \mathrm{yr}^{-1}$. Because the choice of humid runoff in our model is higher than the arid runoff by three orders of magnitude, the corresponding weathering fluxes should differ by the same amount if the weathering fluxes are in the thermodynamic regime. However, the differences are smaller in the given $P_{\mathrm{CO}_{2}}$ range. This is because nonthermodynamic regimes exhibit smaller weathering fluxes than the thermodynamic regime. For example, up to $P_{\mathrm{CO}_{2}}=0.2$ bar, the arid model of granite is in the thermodynamic regime (upper limit for this model), whereas the humid model of granite is in the supply regime (lower limit for this model). Thus, the differences between the two models are smaller than the maximum possible differences. For more arid climates, lithology plays an even more important role as the weathering becomes thermodynamically limited for the whole $P_{\mathrm{CO}_{2}}$ range. In contrast, the supply regime is largely independent of lithology. For this reason, lithology has a negligible impact on the modern mean and humid cases.

The age of soils is a key parameter that determines if the weathering is limited by reaction kinetics or limited by the supply of fresh rocks. Figure 7(b) shows that lithology has no influence on the weathering flux of old soils $\left(t_{\mathrm{s}}=100 \mathrm{kyr}\right.$ and $\left.t_{\mathrm{s}}=1 \mathrm{Myr}\right)$ as opposed to young soils $\left(t_{\mathrm{s}}=0\right)$. The old-soil models are in the supply regimes. Granite and basalt in young soils are in different weathering regimes. Granite is in the thermodynamic regime for the whole $P_{\mathrm{CO}_{2}}$ range because the net reaction rate $\left(D_{w}=1-3 \mathrm{~m} \mathrm{yr}^{-1}\right)$ is higher than the fluid flow rate $\left(q=0.3 \mathrm{~m} \mathrm{yr}^{-1}\right)$. In contrast, $D_{w}\left(0.05-4.5 \mathrm{~m} \mathrm{yr}^{-1}\right)$ of basalt is lower than $q=0.3 \mathrm{~m} \mathrm{yr}^{-1}$ up to $P_{\mathrm{CO}_{2}}=0.5 \mathrm{bar}$, implying a transition from kinetic to thermodynamic regime above this $P_{\mathrm{CO}_{2}}$.

On Earth, the continental and seafloor pore space differ in terms of pore-space properties besides the differences in lithology. The dimensionless pore-space parameter $\psi$ depends on the flow path length $L$ that is normally assumed to be of the order of the regolith thickness (Section 2.4). Because the thickness of the oceanic crust where seafloor weathering occurs is of the order of $100 \mathrm{~m}$ (e.g., Alt et al. 1986; Coogan \& Gillis 2018), we assume $L=100 \mathrm{~m}$ and $\psi=100 \psi_{0}$. Moreover, the average age of the oceanic crust on Earth at the present day is approximately equal to $50 \mathrm{Myr}$, about 500 times the characteristic age of continental soils.

In Figure 7(d), we compare the seafloor $A$ flux for characteristic seafloor values of $t_{\mathrm{s}}=50 \mathrm{Myr}$ and $\psi=100 \psi_{0}$ with two models, one with $t_{\mathrm{s}}=0$ and another with $\psi=\psi_{0}$. The present-day seafloor $A$ flux is in the supply regime, making it independent of lithology. The supply-limited fluxes of seafloor weathering are smaller than those of continental weathering by a factor of 5 because $w \propto \psi / t_{\mathrm{s}}$ in this regime. When $\psi$ is lowered from $100 \psi_{0}$ to $\psi_{0}$, the supply-limited weathering flux decreases by two orders of magnitude at a much lower $P_{\mathrm{CO}_{2}}$. For the young seafloor pore-space case, the $A$ fluxes of basalt and granite are in the thermodynamic regime, and consequently, the impact of lithology is pronounced. Compared to the $t_{\mathrm{s}}=0$ basalt model in Figure 7(b) that is in the kinetic regime, the $t_{\mathrm{s}}=0$ basalt model in Figure $7(\mathrm{~d})$ is in the thermodynamic regime. This difference arises due to the choice of $\psi$ that makes the net reaction rate $\left(D_{w}\right)$ higher than the fluid flow rate, pushing basalt into the thermodynamic regime. Being in the thermodynamic regime, chemical equilibrium controls the weathering flux of basalt. At high $P_{\mathrm{CO}_{2}}$, the thermodynamic weathering flux of basalt decreases slightly as the decreasing effect of $T$ takes over the increasing effect of $P_{\mathrm{CO}_{2}}$. This decreasing effect of $T$ is due to the decrease in equilibrium constants of weathering reactions as a function of temperature (Appendix A). The effect of $T$ on the weathering flux of granite is small and hence there is no net decrease in the weathering flux at high $P_{\mathrm{CO}_{2}}$.

In Figure 7(c), we calculate the seafloor $A$ flux for three hydrothermal fluid flow rates, where the two extreme $q$ values differ by three orders of magnitude, similar to the strategy in Figure 7(a). Because the fluid flow rates are directly proportional to the hydrothermal heat flux (Stein \& Stein 1994; Coogan \& Gillis 2013), a variation in the hydrothermal heat flux implies a variation in the fluid flow rate. Depending on the age of oceanic crust, present-day non-porosity-corrected fluid flow rates are observed between 0.001 and $0.7 \mathrm{~m} \mathrm{yr}^{-1}$ (Johnson \& Pruis 2003). The three cases of seafloor weathering shown in Figure 7(c) are broadly similar to their continental counterparts. The modern mean and high fluid flow rates result in lithologyindependent weathering fluxes that are in the supply-limited regimes. The low hydrothermal fluid flow rate causes the granite model to be in the thermodynamic regime for the full $P_{\mathrm{CO}_{2}}$ range, although the basalt model transitions from the thermodynamic to supply regime at $P_{\mathrm{CO}_{2}}=0.6 \mathrm{mbar}$.

\section{Discussion and Implications}

\subsection{Weathering Regimes and the Role of Lithology}

In this study, silicate-weathering rates are computed by the simultaneous consideration of dissolution reactions of all minerals present in a rock as well as reactions in the waterbicarbonate system. Three common silicate rocks (peridotite, basalt, and granite) are examined. We develop the maximum weathering model (Section 2.3) presuming chemical equilibrium and the generalized weathering model (Section 2.4) that applies to both equilibrium and nonequilibrium conditions. The generalized weathering model allows us to explore weathering in three different regimes (Figure 8). To simulate the transportbased dilution of equilibrium concentrations of weathering products, the solute transport equation of Maher \& Chamberlain (2014) is implemented. This equation is based on the interplay between the fluid flow rate $(q)$ and the net reaction rate $\left(D_{w}\right)$. When $q<D_{w}$, reactions are limited by thermodynamics or transport (runoff) and the weathering is thermodynamically limited (Figure 8(a)). In contrast, when $q>D_{w}$, reactions are limited by kinetics (and independent of runoff), and the weathering is kinetically limited. Another parameter, the age of soils $\left(t_{\mathrm{s}}\right)$, is introduced by Maher \& Chamberlain (2014) to model the effect of a limited supply of fresh rocks on the net reaction rate. The higher the $t_{\mathrm{s}}$, the lower is the $D_{w}$. This gives rise to another regime, supply-limited weathering (Figure 8(a)).

As a function of transport and climate properties, the carbonate alkalinity weathering flux shows a strong dependence on lithology 
(a)

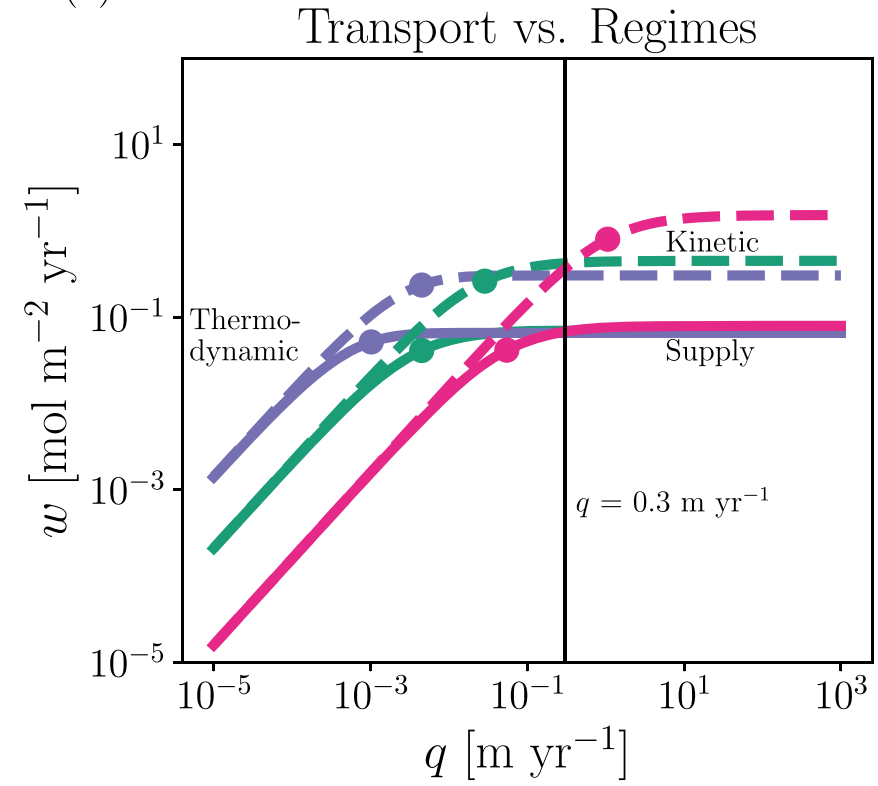

(b)

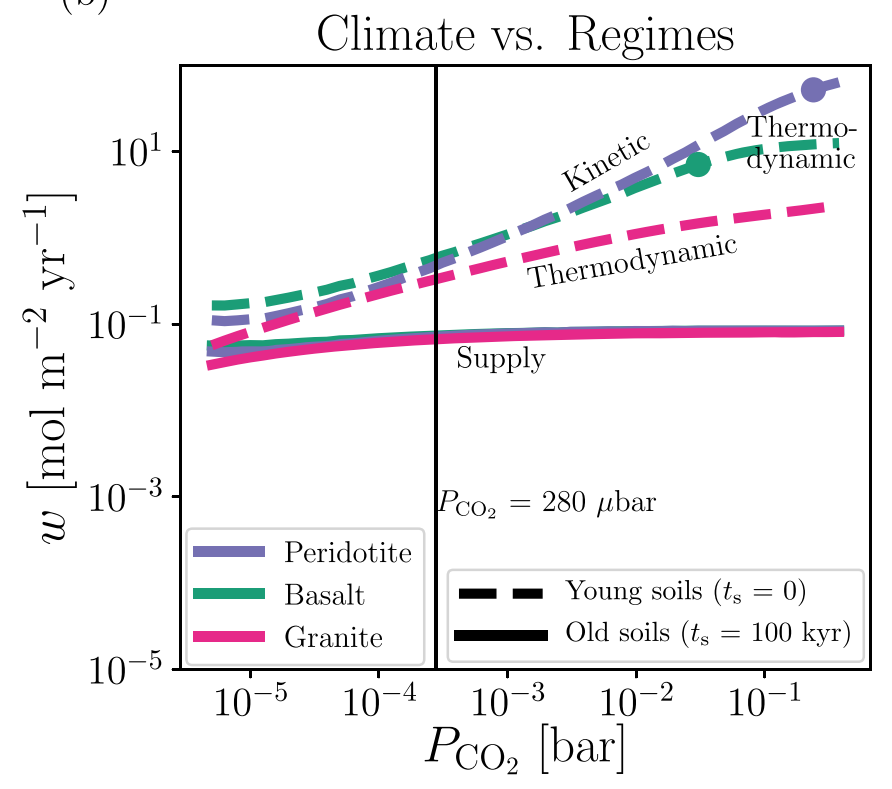

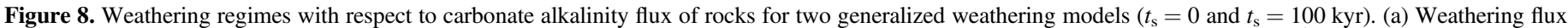

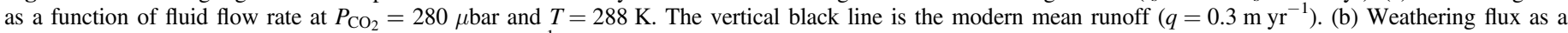

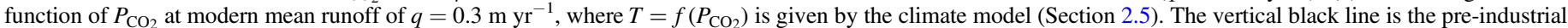
$\mathrm{CO}_{2}$ partial pressure $\left(P_{\mathrm{CO}_{2}}=280 \mu\right.$ bar $)$. Colored disks mark the transition between the thermodynamic and kinetic/supply regimes.

in the thermodynamic and kinetic regimes and a weak dependence on lithology in the supply regime (Figure 8). This impact of lithology for the three weathering regimes as a function of $q$ is seen in Figure 8(a). There is approximately an order of magnitude difference between the thermodynamic fluxes of peridotite and basalt as well as those of basalt and granite. The thermodynamic weathering flux is proportional to the equilibrium carbonate alkalinity, which is strongly sensitive to the mineralogy considered for a given rock. In the kinetic regime, the differences are smaller but significant. The kinetic weathering flux is proportional to the effective rate coefficient of a given rock. In contrast, in the supply-limited regime, the $A$ fluxes almost overlap with each other because there is no impact of lithology. The supply regime is strongly sensitive to pore-space properties that are held constant.

The climate sensitivity of the weathering flux showcases how the weathering regime may depend on lithology. Figure $8(\mathrm{~b})$ shows that the generalized $t_{\mathrm{s}}=0$ model of the weathering fluxes of peridotite and basalt increase steeply with $P_{\mathrm{CO}_{2}}$ up to $\sim 0.1$ bar where $T=f\left(P_{\mathrm{CO}_{2}}\right)$ is obtained from the climate model. Beyond this $P_{\mathrm{CO}_{2}}$ value, peridotite and basalt enter the thermodynamic regime. This is because the weathering flux in the kinetic regime cannot keep increasing indefinitely. As soon as the model hits the thermodynamic upper limit, the model follows the thermodynamic sensitivities of weathering that are independent of pore-space properties and depend on chemical equilibrium and lithology. It is important to note that extrapolations of kinetic weathering expressions (Equation (2)) used in previous studies (e.g., Walker et al. 1981; Berner et al. 1983; Sleep \& Zahnle 2001; Foley 2015; Krissansen-Totton \& Catling 2017) may incorrectly predict the weathering flux to be higher than the upper limit provided by the thermodynamic flux.

Unlike basalt and peridotite, the generalized young-soil $\left(t_{\mathrm{s}}=0\right)$ model of granite is in the thermodynamic regime for the given $P_{\mathrm{CO}_{2}}$ range (Figure $8(\mathrm{~b})$ ). This is also evident from
Figure 8(a) where the vertical line $\left(q=0.3 \mathrm{~m} \mathrm{yr}^{-1}\right)$ falls right before the thermodynamic to kinetic regime transition for granite. Thus, the climate sensitivity of the weathering of fresh granite at $q=0.3 \mathrm{~m} \mathrm{yr}^{-1}$ is determined largely by thermodynamics instead of kinetics. On the other hand, for the generalized models at the present-day characteristic soil age of $t_{\mathrm{s}}=100 \mathrm{kyr}$, the weathering fluxes of the three rocks overlap with each other. This is because this $t_{\mathrm{s}}$ value is so high that the effect of $k_{\text {eff }}$ on the "net reaction rate" $D_{w}$ is negligible in pushing the model out of the supply regime. In this regime, the weathering flux is independent of the climate and transport properties.

Because most laboratory measurements of kinetic rate coefficients are available for individual minerals, previous studies discuss the weathering of individual minerals instead of rocks (e.g., Walker et al. 1981; Berner et al. 1983). In reality, all minerals in rocks undergo weathering contemporaneously, rendering consideration of individual minerals in isolated systems less informative. Because the minerals in a rock are in contact with the aqueous solution, solute concentrations are buffered by the dissolution reactions of these minerals. It is essential to consider these reactions simultaneously to solve for solute concentrations. The generalized weathering model shows that the choice of individual minerals or rocks determines the weathering regime. For example, the feldspar endmember minerals (anorthite, albite, and $\mathrm{K}$-feldspar) are in the thermodynamic regime for the $P_{\mathrm{CO}_{2}}$ range considered, whereas rocks exhibit both thermodynamic and kinetic regimes (see Figure B3). In their implementation of the fluid-transportcontrolled model, Graham \& Pierrehumbert (2020) find that weathering is largely independent of kinetics because of their choice of oligoclase (a type of plagioclase feldspar mineral) to model weathering, which is in the thermodynamic regime of weathering for a wide range of $\mathrm{CO}_{2}$ partial pressures similar to the feldspar endmembers shown in Figure B3. 


\subsection{Positive Feedback of Weathering at High Temperature}

It is widely accepted that weathering intensifies with surface temperature (e.g., Walker et al. 1981; Berner et al. 1983; Kump et al. 2000; Brantley et al. 2008); but see Gaillardet et al. (1999) and Kite et al. (2011) for alternate viewpoints. This $T$ dependence of weathering is due to the increase in kinetic rate coefficients of mineral dissolution reactions as a function of $T$ (see Appendix A). Laboratory and field measurements of kinetic rate coefficients are fitted to the Arrhenius law, $w \propto \exp (-E / R T)$, where $E$ is the activation energy and $R$ is the universal gas constant (Palandri \& Kharaka 2004). The generalized weathering model based on the fluid-transportcontrolled approach (Maher \& Chamberlain 2014) captures the diversity of weathering regimes in a generic formulation, which is particularly useful for applications to exoplanets with potentially diverse surface environments. Studies applying the fluid-transport-controlled model find that $T$ has a small effect on weathering (Winnick \& Maher 2018; Graham \& Pierrehumbert 2020). This statement holds in the thermodynamic regime of weathering for certain plagioclase feldspars including oligoclase, which coincidentally exhibits a small $T$ sensitivity, although Winnick \& Maher (2018) find that the equilibrium $\left[\mathrm{HCO}_{3}^{-}\right]$resulting from plagioclase feldspars decreases with $T$.

To isolate the effect of temperature on weathering from that of the $P_{\mathrm{CO}_{2}}$ effect, we first present weathering as a function of $T$ at a fixed $P_{\mathrm{CO}_{2}}$ in Figure 9(a). The generalized weathering model at $t_{\mathrm{s}}=0, q=0.3 \mathrm{~m} \mathrm{yr}^{-1}$, and $P_{\mathrm{CO}_{2}}=280 \mu \mathrm{bar}$ (no climate model) shows that the carbonate alkalinity flux of rocks is in the kinetic regime at low temperatures and in the thermodynamic regime at high temperatures. In the kinetic regime, there is a steep increase in the weathering flux of granite up to $\sim 285 \mathrm{~K}$, basalt up to $\sim 310 \mathrm{~K}$, and peridotite up to $\sim 320 \mathrm{~K}$ because the effective kinetic rate coefficients show an exponential increase with temperature. Beyond these transition temperatures (where the net reaction rate equals the fluid flow rate), the models enter their respective thermodynamic regimes. This transition implies a switch from the negative feedback of silicate weathering to the carbon cycle to a potential positive feedback. As the thermodynamic regime gives the maximum possible weathering flux, the kinetic weathering flux cannot exceed the thermodynamic weathering flux in the generalized model. Importantly, the kinetic weathering flux of granite is higher than that of basalt and peridotite because the slowest kinetic reaction among the constituent endmember minerals of granite has a higher kinetic rate coefficient than those of basalt and peridotite. This result is based on the choice of endmember minerals to define rocks and is expected to change with the choice of other endmember minerals or mineral solid solutions.

The kinetic weathering flux increases with $T$ as expected; however, the thermodynamic weathering flux decreases with $T$ (Figure 9(a)). As described in Section 3.1, if fitted to a kinetic weathering expression (Equation (2)), the thermodynamic model gives a negative value for the activation energy $\left(E_{\mathrm{th}}\right)$ for the weathering of rocks and most minerals. Such a negative value highlights that thermodynamic weathering exhibits a negative slope as a function of $T$. This negative exponential decrease in weathering is a result of the negative slope exhibited by equilibrium constants of mineral dissolution reactions as a function of $T$ except for albite and $\mathrm{K}$-feldspar (see Appendix A). This $T$ dependence is a thermodynamic property of mineral dissolution reactions in the aqueous system. For rocks, constituent minerals determine the overall (a)

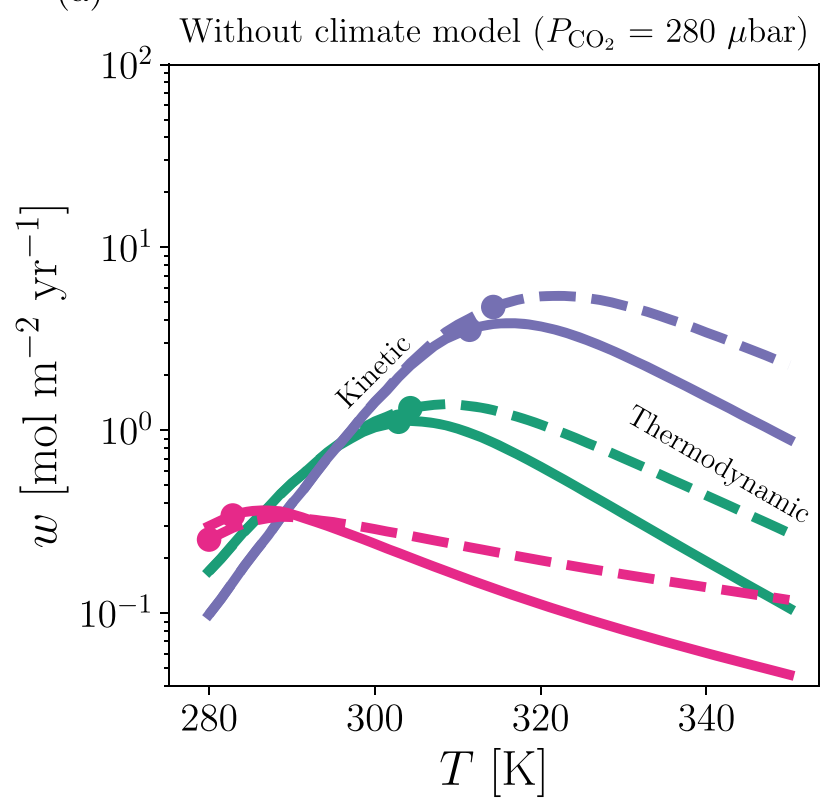

(b)

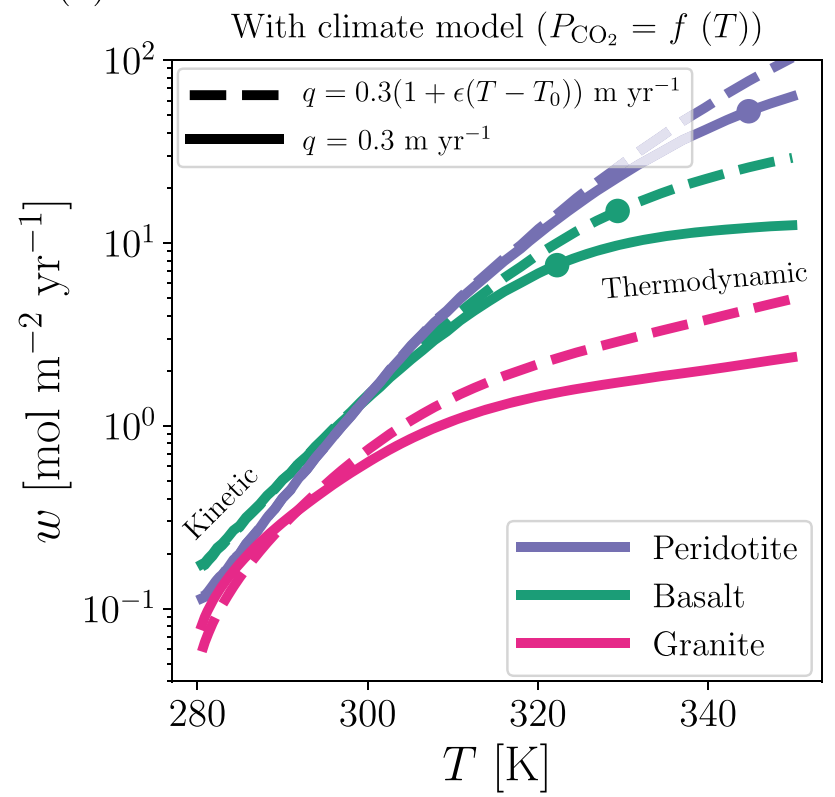

Figure 9. Generalized carbonate alkalinity flux of rocks as a function of temperature at $t_{\mathrm{s}}=0, P_{\mathrm{CO}_{2}}=280 \mu$ bar for a constant $q=0.3 \mathrm{~m} \mathrm{yr}^{-1}$ and a $T$ dependent $q$ with $\epsilon=0.03 \mathrm{~K}^{-1}$ and $T_{0}=288 \mathrm{~K}$. Colored disks mark the transition from kinetic to thermodynamic regimes.

dependence of thermodynamic weathering on $T$. For example, for a rock consisting of only albite and K-feldspar, the thermodynamic weathering flux is expected to increase with $T$, similar to the prevalent understanding of the $T$ dependence of kinetic weathering. However, apart from these two minerals, all other minerals considered in this study show a negative slope. Because granite consists of both albite and K-feldspar in addition to quartz, phlogopite, and annite, granite shows the least negative slope among the three rocks considered (Figure 9(a)). Moreover, the weathering of basalt in the thermodynamic regime decreases with $T$ more steeply than peridotite because of the presence of anorthite in basalt which 
exhibits the most negative slope in the equilibrium constant -temperature parameter space.

When the climate model is invoked assuming present-day solar flux and present-day planetary albedo, $P_{\mathrm{CO}_{2}}$ increases from $10 \mu$ bar to 0.5 bar as a function of $T$ varying from 280 to $350 \mathrm{~K}$, and the decreasing effect of $T$ on weathering disappears (Figure 9(b)). This is because, in the thermodynamic regime, the weathering flux shows a positive power-law dependence on $P_{\mathrm{CO}_{2}}$, which is stronger than the exponential decrease in weathering with temperature. And in the kinetic regime, the exponential increase in weathering with temperature dominates. It is interesting to note that basalt and peridotite enter the thermodynamic regime only at $\sim 325 \mathrm{~K}$ and $\sim 345 \mathrm{~K}$, respectively, whereas granite is in the thermodynamic regime for the given temperature range. For this climate model, assuming a constant stellar flux results in a strong coupling between $T$ and $P_{\mathrm{CO}_{2}}$, in contrast to the behavior when $P_{\mathrm{CO}_{2}}$ is held constant. Depending on the stellar flux and planetary albedo, the strength of coupling between $T$ and $P_{\mathrm{CO}_{2}}$ is probably in between the two panels shown in Figure 9, pushing the thermodynamic to kinetic transition temperature given in Figure 9(a) to higher values. The supply-limited weathering flux, on the other hand, is independent of $T$ (e.g., Figures 6(c) and (d)). This is because the supply-limited weathering flux depends on pore-space parameters including $t_{\mathrm{s}}$ and $\psi$ that are assumed to be constant for a given model. In reality, the age of soils may indirectly depend on temperature through the effect of precipitation and runoff on physical erosion rates (e.g., West et al. 2005; West 2012; Foley 2015).

Previous studies have argued that because runoff depends on precipitation, which in turn depends on $T$, the weathering flux should increase even more strongly with $T$ when a $T$-dependent runoff is assumed (e.g., Berner \& Kothavala 2001). Figure 9 shows that this statement does not hold in the kinetic regime of weathering. This is because the kinetic regime is independent of runoff in the fluid-transport-controlled model (Maher \& Chamberlain 2014). Considering a linear dependence of runoff on temperature (e.g., Equations (41) and (42) in Graham \& Pierrehumbert 2020) instead of a constant runoff, there is no impact on weathering because the kinetic regime is independent of runoff in the generalized model.

\subsection{Global Silicate Weathering Rates}

During the Archean (2.5-4 Ga), the incident solar radiation was about $70 \%-80 \%$ of its present-day value, not high enough to maintain a temperate climate with present-day atmospheric $\mathrm{CO}_{2}$ levels (Sagan \& Mullen 1972; Charnay et al. 2020). Although there are no direct measurements of historical weathering rates, the Archean geological record suggests a steady decrease in $P_{\mathrm{CO}_{2}}$ from the order of 0.1 bar to modern values while maintaining surface temperatures between $280 \mathrm{~K}$ and $315 \mathrm{~K}$ (Krissansen-Totton et al. 2018, and references therein). The lower insolation during the Archean was compensated by the greenhouse effect of $\mathrm{CO}_{2}$. As the insolation increased, climates should have become warmer than the observations suggest. Without a negative feedback of silicate weathering that allowed a decrease in $\mathrm{CO}_{2}$ levels as insolation increased, modern climates would not have been temperate (Walker et al. 1981; Berner et al. 1983; Kasting et al.

1993). The extent of silicate weathering during the history of Earth and the contribution of seafloor weathering are debated (e.g., Sleep \& Zahnle 2001; Berner \& Kothavala 2001;
Foley 2015; Coogan \& Gillis 2018; Krissansen-Totton et al. 2018). By applying the generalized weathering model to Earth, we lay the foundation for understanding climate regulation on temperate planets.

Because present-day continents on Earth are largely felsic and the seafloor is mafic, we approximate the lithology of continents by granite and the seafloor by basalt. Continental and seafloor-weathering rates on Earth are calculated up to $4 \mathrm{Ga}$ (Figures 10(c) and (d)). This is the first application of the fluid-transport-controlled weathering model of Maher \& Chamberlain (2014) to seafloor weathering on Earth. Because there are no direct measurements of historical weathering rates on Earth, we compare the generalized model developed in this study with a model from Krissansen-Totton et al. (2018, hereafter KT18, their Figure 3). Instead of using a climate model, time-dependent median models of $P_{\mathrm{CO}_{2}}$ and $T$ from the same KT18 model are used as inputs to the generalized model. The same inputs are used to obtain the continental weathering rate from Walker et al. (1981) and the seafloor weathering from Brady \& Gíslason (1997), where the present-day weathering rates of both models are normalized to those of KT18 models.

To first order, one may expect that continental and seafloorweathering rates depend on the continental surface area $\left(f A_{\mathrm{s}}\right)$ and the seafloor surface area $\left((1-f) A_{\mathrm{s}}\right)$, respectively (Equation (4)). However, not all continental and seafloor surface area undergoes weathering on Earth. Fekete et al. (2002) report the value of the continental weatherable area to be equal to $93 \mathrm{Mm}^{2}$, about $60 \%$ of the modern continental area $\left(=0.6 f A_{\mathrm{s}}\right)$. About $147 \mathrm{Mm}^{2}$ of the seafloor area $(=0.41(1-$ f) $A_{\mathrm{s}}$ ) is expected to contribute to seafloor weathering (given by the exposed area of low-temperature hydrothermal systems; Johnson \& Pruis 2003). Therefore, in Figure 10, the continental and seafloor-weathering rates are given by $W_{\text {cont }}=w_{\text {cont }} \times$ $93 \mathrm{Mm}^{2}$ and $W_{\text {seaf }}=w_{\text {seaf }} \times 147 \mathrm{Mm}^{2}$, respectively. A more precise definition of continental weatherable area is the area susceptible to precipitation and runoff, and that of seafloor weatherable area is the area covered by low-temperature hydrothermal systems that are younger than approximately 60 Myr (Stein \& Stein 1994; Johnson \& Pruis 2003; Coogan \& Gillis 2018). Nonetheless, the definition given in Equation (4) assumes all surfaces are weatherable, thereby giving upper estimates of the global weathering rates on exoplanets.

The present-day continental weathering rate for young soils $\left(t_{\mathrm{s}}=0\right)$ in Figure $10(\mathrm{c})$ is in the thermodynamic regime (see also Figure 8(a)). Similarly, the present-day seafloor-weathering rate for young pore space is in the thermodynamic regime (Figure $10(\mathrm{~d})$ ). As the $\mathrm{CO}_{2}$ levels increase (prior to $0.5 \mathrm{Ga}$ ), continental weathering for young soils is driven by kinetics (Figure 10(c)), whereas seafloor weathering for young pore space is in the thermodynamic regime even at high $P_{\mathrm{CO}_{2}}$. The weathering rate of the young-soil granite model decreases between 1 and $2 \mathrm{Ga}$. This is because the effective kinetic rate coefficient of granite is almost constant as a function of $\mathrm{pH}$ in basic solutions resulting from our calculations and depends mostly on $T$, which decreases between 1 and $2 \mathrm{Ga}$. Seafloor weathering in the thermodynamic regime increases monotonically because the effect of $P_{\mathrm{CO}_{2}}$ on weathering wins over the $T$ effect. In the thermodynamic regime, the choice of secondary minerals also affects the weathering rates. For example, on one hand, the granite and basalt weathering rates for $t_{\mathrm{s}}=0$ models would be higher by a factor of 20 and 3 when kaolinite is used as a secondary 
(a)

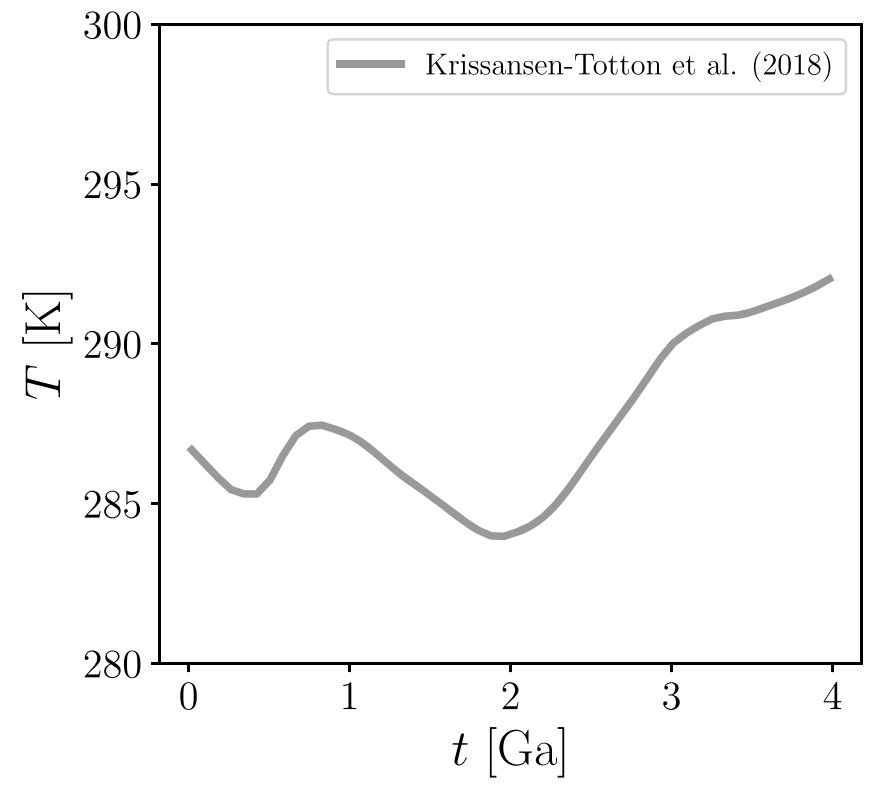

(c)

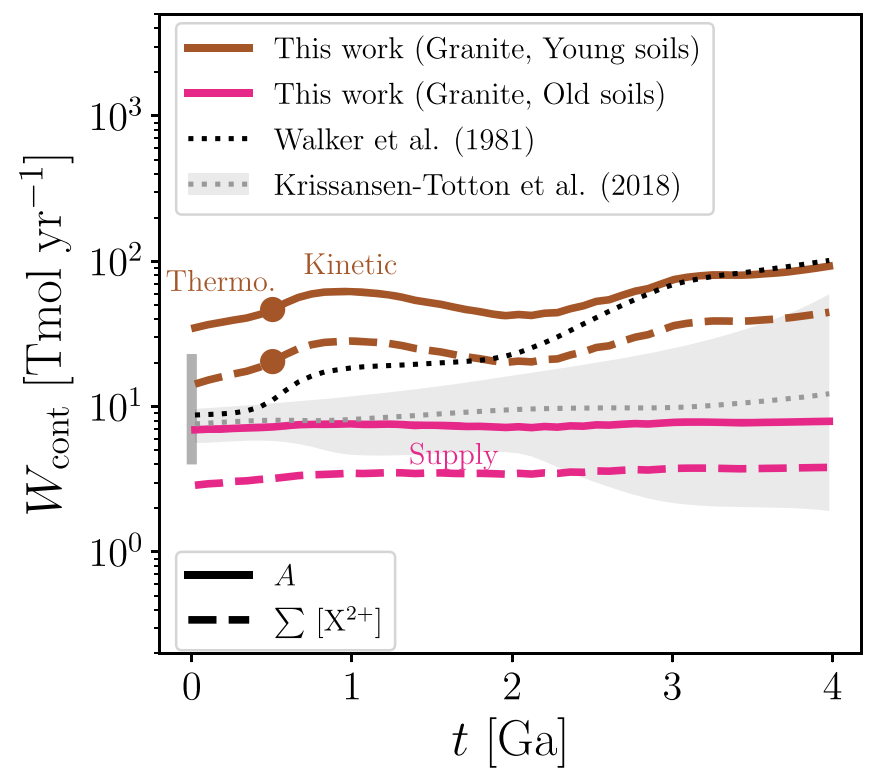

(b)

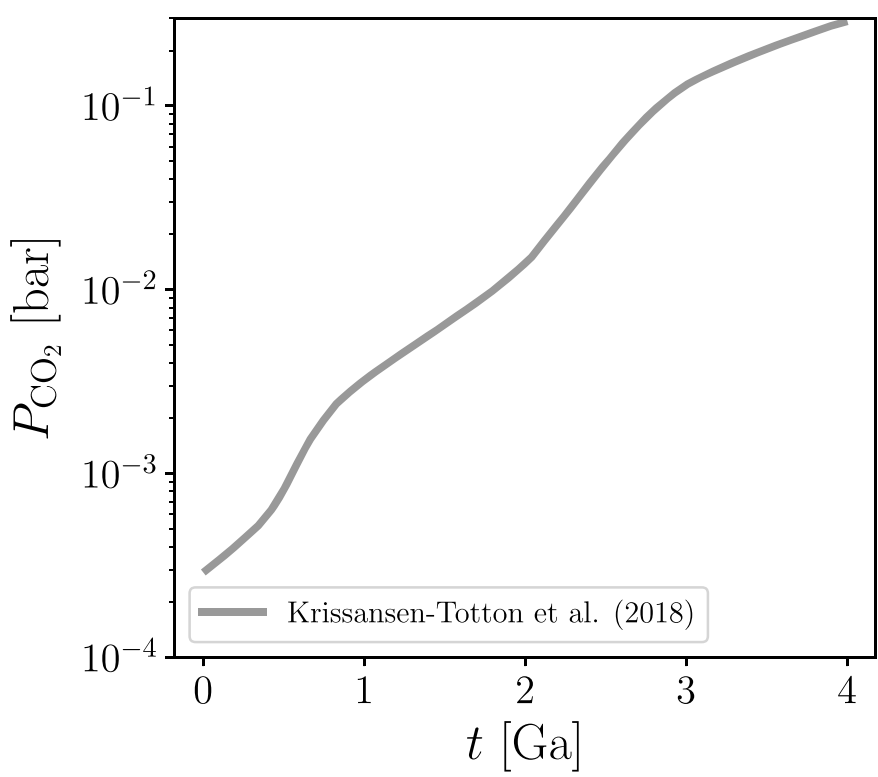

(d)

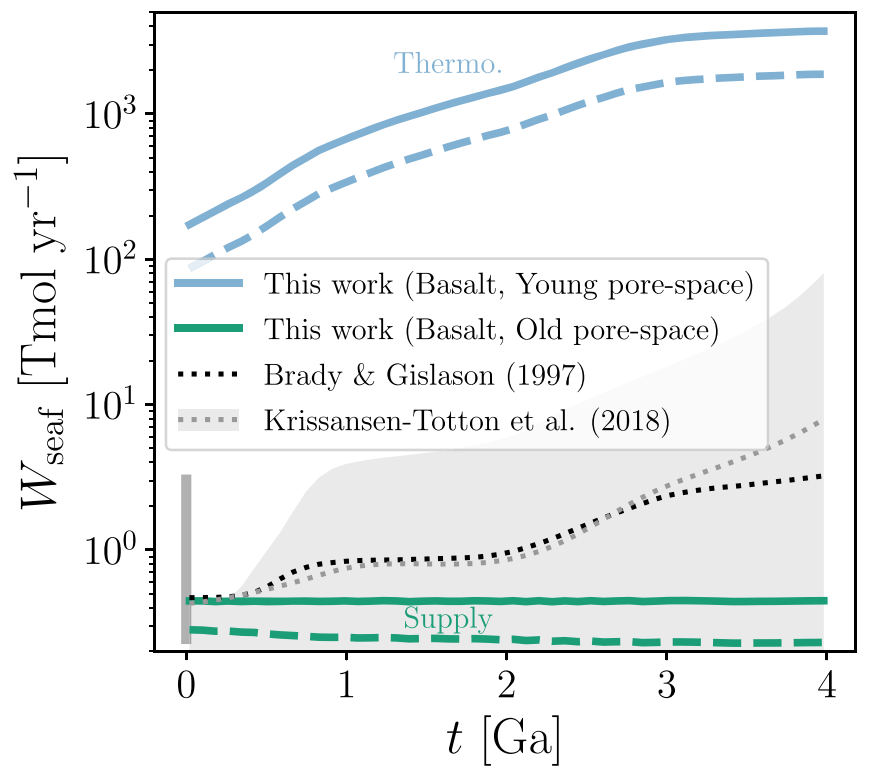

Figure 10. Continental granite and seafloor basalt weathering rates derived from carbonate alkalinity $A$ and the sum of concentrations of divalent cations $\sum\left[\mathrm{X}^{2+}\right]$ compared with a model from KT18 (their Figures 3(E) and (F),) for the past $4 \mathrm{Ga}$ on Earth. (a) $T$ and (b) $P_{\mathrm{CO}_{2}}$ are the median values of the same model from KT18 that are used as inputs to the weathering models in (c) and (d). (c) Generalized young-soil $\left(t_{\mathrm{s}}=0\right)$ and old-soil $\left(t_{\mathrm{s}}=100\right.$ kyr) granite models take the same values for $\psi=\psi_{0}, q=0.3 \mathrm{~m} \mathrm{yr}^{-1}$ (modern mean runoff), and continental weatherable area of $93 \mathrm{Mm}^{2}$ (Fekete et al. 2002). (d) Generalized young pore-space ( $\left.t_{\mathrm{s}}=0\right)$ and old pore-space $\left(t_{\mathrm{s}}=50 \mathrm{Myr}\right.$ ) basalt models take different values for $\psi\left(\psi=100 \psi_{0}\right.$ and $\psi=18 \psi_{0}$, respectively) but the same value for $q=0.05 \mathrm{~m}^{-1}$ (modern mean $^{-}$ hydrothermal fluid flow rate) and seafloor weatherable area of $147 \mathrm{Mm}^{2}$ (Johnson \& Pruis 2003). Gray shaded regions are 95\% confidence intervals of KT18 models. Vertical gray lines are uncertainties in the estimates of present-day silicate-weathering rates given by geological measurements and models. Colored disks denote the transition between thermodynamic and kinetic regimes.

mineral instead of halloysite. On the other hand, if secondary minerals incorporating divalent cations are modeled, the weathering rates would be lower because bicarbonate and carbonate ions equivalent to cations locked up in secondary minerals would be removed from the solution (e.g., Kite \& Melwani Daswani 2019).

The continental weathering rate derived from carbonate alkalinity for young soils and the seafloor-weathering rate derived from carbonate alkalinity for young pore space are, respectively, about an order of magnitude and up to three orders of magnitude higher than that of KT18 models (Figures 10(c) and (d)). The Walker et al. (1981) continental weathering rate and the Brady \& Gíslason (1997) seafloorweathering rate exhibit a monotonic rise $(\beta=0.3$ and $\beta=0.23$, respectively). There are multiple reasons for the discrepancy between our $t_{\mathrm{s}}=0$ models and other models in Figure 10. Our 
models are designed to provide absolute weathering rates for generality and are therefore not intrinsically calibrated to present-day weathering rates, unlike other studies. The entire exposed planetary surface area may not contain fresh rocks for weathering, and continents do not necessarily have a uniform lithology and topography. On Earth's continents, orogeny (mountain building) exposes fresh rocks to the surface that are highly susceptible to weathering (low $t_{\mathrm{s}}$ ), whereas the contribution of cratons (ancient continental crust, high $t_{\mathrm{s}}$ ) to weathering is smaller than mountains (Maher \& Chamberlain 2014). Similarly, ridge volcanism exposes fresh basalt at midocean ridges but the majority of the seafloor area is older than a million years.

For a planet with surface conditions where all divalent and monovalent cations react with carbonate and bicarbonate ions to produce carbonates, carbonate alkalinity is a proxy for the flux of $\mathrm{CO}_{2}$ out of the atmosphere-ocean system. However, carbonate alkalinity overestimates the global weathering rate on modern Earth, which is limited by the flux of divalent cations instead of carbonate alkalinity (France-Lanord \& Derry 1997). This is because monovalent cations do not contribute to the carbonate precipitation in the present-day ocean. Figure 10(c) shows that the weathering rate derived from divalent cations in our granite-weathering model is smaller than the carbonate alkalinity weathering rate by up to a factor of 5. Alternatively, a planet with no rivers but only coastal springs that are isolated from the atmosphere would produce divalent cations but no carbonate alkalinity and effectively no $\mathrm{CO}_{2}$ flux out of the atmosphere-ocean system. Therefore, care should be taken when extrapolating a single weathering proxy to diverse planetary conditions.

The present-day continental weathering rate derived from carbonate alkalinity matches that of KT18 when the soil age is set to the characteristic soil age $(100 \mathrm{kyr})$. The soil age encapsulates several processes including tectonics, erosion, and soil production (Heimsath et al. 1997; Riebe et al. 2003; West et al. 2005; Maher \& Chamberlain 2014). For example, the soil age decreases with increasing erosion or increasing mineral supply rates (Maher \& Chamberlain 2014). On continents, the dimensionless pore-space parameter varies with topography, and its mean value for present-day continents is not well constrained as previous studies adopt values that span an order of magnitude on either side of the reference value used in this study (Maher 2010, 2011; Maher \& Chamberlain 2014; Winnick \& Maher 2018). Given the validity range in parameters and weathering proxies, our model allows the present-day global continental weathering on Earth to either be in the thermodynamic, kinetic, or supply-limited regimes of weathering.

To match the present-day seafloor-weathering rate derived from carbonate alkalinity with that of KT18, the pore-space age is increased to $50 \mathrm{Myr}$ (characteristic seafloor age) and the dimensionless pore-space parameter is decreased from $100 \psi_{0}$ to $18 \psi_{0}$. Because these two pore-space parameters have never been discussed in the context of seafloor weathering, future studies must evaluate their magnitude and extent of validity. For the same parameters, the seafloor-weathering rate derived from divalent cations is smaller by less than a factor of 2 . Both of these models are in the supply-limited regime of weathering and therefore exhibit almost constant weathering rates.
The present-day regional variation in continental runoff (0.01-3 $\mathrm{m} \mathrm{yr}^{-1}$, Gaillardet et al. 1999; Fekete et al. 2002) and seafloor fluid flow rate (0.001-0.7 $\mathrm{m} \mathrm{yr}^{-1}$, Stein \& Stein 1994; Johnson \& Pruis 2003; Hasterok 2013) is more than two orders of magnitude. At fluid flow rates lower than the mean values (arid climates or low hydrothermal heat flux; see Figure 7), the models might escape kinetic/supply regimes and enter the thermodynamic regime. These models rely on characteristic values of $t_{\mathrm{s}}, \psi$, and $q$ to be suitable proxies for calculating global weathering rates, which are not necessarily appropriate for present-day Earth. For example, mountains contribute an order of magnitude more weathering flux than cratons (Maher \& Chamberlain 2014). Additionally, basaltic regions on continents (omitted in our calculations) may contribute a weathering flux (weathering rate per unit area) higher than that of granitic regions by a factor of 5 (Ibarra et al. 2016). On Earth, local weathering rates can be estimated from data and integrated to compute the global weathering rate for the planetary surface. However, exoplanets lack (Earth-independent) data constraints on global properties such as fluid flow rates and pore-space parameters, let alone their potential regional variations. Hence, we propose to study exoplanets by implementing the generalized weathering model to various lithologies using characteristic values of fluid flow rates and pore-space parameters.

Holding modeling parameters constant throughout Earth's dynamic history is another critical approximation. The uplift of the Himalayan-Tibetan Plateau in the past 40 million years has decreased the characteristic soil age, which has likely increased the global weathering rates (Kump et al. 2000). The lithology of continents has also evolved over time and therefore the application of one type of lithology may result in inaccurate weathering rates for certain periods of Earth's history. The continental area fraction (and consequently, the weatherable area) was smaller in the Archean than today (Dhuime et al. 2017). Even if the strength of continental weathering flux was similar at the beginning of the Archean compared to today but the continental area was significantly smaller, then the continental weathering rate must have been significantly smaller. The true contribution of the silicate-weathering flux to the carbon cycle also depends on the carbonate compensation depth in the oceans (Pytkowicz 1970; Ridgwell \& Zeebe 2005) as well as reverse weathering (Mackenzie \& Garrels 1966; Isson \& Planavsky 2018; Krissansen-Totton \& Catling 2020) that requires knowledge of ocean salinity and ocean $\mathrm{pH}$, which suggests that an ocean chemistry model should form the basis of future research.

\subsection{Weathering Regimes and the Habitable Zone}

It has been proposed that measuring the gaseous abundance of $\mathrm{CO}_{2}$ in the atmospheres of Earth-sized exoplanets will allow one to statistically distinguish between Venus-like and Earthlike climates (Bean et al. 2017; Checlair et al. 2019; Graham \& Pierrehumbert 2020). Negative feedback associated with weathering is necessary to control the climatic impact of $\mathrm{CO}_{2}$ over geological timescales on an Earth-like planet (Walker et al. 1981). One-dimensional, radiative-convective atmospheric models used to study the boundaries of the classical habitable zone usually assume the presence of the negative weathering feedback to justify the assumption of $\mathrm{CO}_{2}$ being present as a greenhouse gas at the outer boundary of the 
habitable zone and having only a minor abundance at its inner edge (Kasting et al. 1993; Kopparapu et al. 2013). The effects of $\mathrm{CO}_{2}$ on the runaway greenhouse effect associated with water are debated (Nakajima et al. 1992; Abe 1993). Moreover, if weathering is limited by the supply of fresh rocks, the negative feedback is lost (West 2012; Foley 2015). This is evident from Figure 8, where supply-limited weathering flux is seen to be insensitive to changes in $T$ and $P_{\mathrm{CO}_{2}}$. However, if soil age indirectly depends on $T$ and $P_{\mathrm{CO}_{2}}$ on geological timescales, the negative feedback may reinstate. Our models of thermodynamic weathering flux show that the weathering flux decreases with $T$ and increases with $P_{\mathrm{CO}_{2}}$ (Figure 9). In the parameter space where the effect of $T$ dominates, it is possible to have a positive climate feedback associated with weathering for lithologies tested in this study. Such a scenario may have implications on the boundaries of the habitable zone. Future studies should combine the climate and weathering models to investigate these possibilities.

\section{Summary and Conclusions}

Silicate weathering is a key process in the carbon cycle that transfers $\mathrm{CO}_{2}$ from the atmosphere to the surface of a planet. The intensity of silicate weathering has previously been attributed to the kinetics of fluid-rock reactions (e.g., Walker et al. 1981; Berner et al. 1983; Kump et al. 2000). Maher (2011) and Maher \& Chamberlain (2014) show that if the reaction rate exceeds the fluid flow rate, thermodynamics of fluid-rock reactions at chemical equilibrium drives weathering instead of kinetics. This fluid-transport-controlled approach models both thermodynamic and kinetic regimes of weathering with a single formulation. Moreover, if there is a limited supply of fresh rocks, the weathering is supply limited. The applications of this approach to continental weathering on Earth (Winnick \& Maher 2018) and temperate exoplanets (Graham \& Pierrehumbert 2020) consider weathering reactions of individual minerals.

In this study, we extend this approach to the weathering of any rock type (lithology) and apply it to seafloor weathering in addition to continental weathering. We find that the simultaneous consideration of weathering reactions of the major minerals present in a rock as well as the reactions in the waterbicarbonate system instead of weathering reactions of individual minerals impacts weathering rates as well as weathering regimes. Moreover, this model allows the calculation of absolute weathering rates instead of weathering rates normalized to present-day values as most previous weathering studies. In addition to climate properties $\left(T\right.$ and $\left.P_{\mathrm{CO}_{2}}\right)$ and runoff or fluid flow rate $(q)$, this model is mainly sensitive to the age of soils $\left(t_{\mathrm{s}}\right)$ and a dimensionless scaling parameter $(\psi)$ based on pore-space and rock properties. The equilibrium constants and kinetic rate coefficients are effectively a function of $T$ and $P_{\mathrm{CO}_{2}}$. Depending on these five parameters, the weathering for a given lithology is in the thermodynamic, kinetic, or supply regimes. Close to the regime transition points, the contribution of both regimes to weathering is similar.

Weathering reactions at chemical equilibrium give the maximum concentrations of weathering products. We use this approach to calculate the maximum weathering flux for a given lithology. The larger the fraction of divalent cations in rocks, the higher the sensitivity of maximum weathering flux to $\mathrm{CO}_{2}$ partial pressure. This thermodynamic $P_{\mathrm{CO}_{2}}$ sensitivity (powerlaw exponent $\beta_{\text {th }}$ ) is $0.71,0.69$, and 0.65 for peridotite, basalt, and granite, respectively. These values are subject to change depending on the choice of minerals to define a rock type as well as secondary minerals produced during weathering. For example, the consideration of kaolinite as a secondary mineral instead of halloysite changes $\beta_{\text {th }}$ to 0.65 and 0.54 for basalt and granite, respectively. The thermodynamic $P_{\mathrm{CO}_{2}}$ sensitivity of these rocks is stronger than the kinetic $P_{\mathrm{CO}_{2}}$ sensitivity implemented in previous studies (0.22-0.55, Walker et al. 1981; Berner 1991; Driscoll \& Bercovici 2013). However, the combined effect of $P_{\mathrm{CO}_{2}}$ and $T$ results in a weaker thermodynamic $P_{\mathrm{CO}_{2}}$ sensitivity.

The fluid-transport-controlled model demonstrates that the weathering flux cannot necessarily be approximated by the kinetic weathering expression (Equation (2)). In our model, planets with arid climates (low runoff) and elevated topography (young soils) are likely in the thermodynamic regime of weathering, exhibiting weathering rates higher than that of modern Earth by three to four orders of magnitude. Moreover, the limited supply of fresh rocks mitigates the role of kinetics. The thermodynamic $T$ sensitivity of weathering of rocks is negative, implying that the weathering flux decreases with $T$. This is in contrast with the prevalent understanding that weathering intensifies with an increase in $T$, which is attributed to an increase in kinetic rate coefficients of mineral dissolution reactions with $T$ (Lagache 1965; Palandri \& Kharaka 2004; Brantley et al. 2008). An important implication of this finding is that when $T$ increases without a strong variation in $P_{\mathrm{CO}_{2}}$, silicate weathering has the potential to instigate a positive feedback in the carbon cycle. The focus of future studies should be on applying a generalized weathering model encompassing multiple weathering regimes to model the carbon cycle.

We thank Edwin Kite and an anonymous reviewer for their constructive comments that helped to improve this manuscript. We thank Eric Gaidos for stimulating discussions. We acknowledge financial support from the European Research Council via Consolidator grant ERC-2017-CoG-771620EXOKLEIN (awarded to K. Heng) and Center for Space and Habitability, University of Bern. D.J.B. acknowledges the Swiss National Science Foundation (SNSF) Ambizione grant 173992. C.D. acknowledges the SNSF Ambizione grant 174028. We thank the financial support of the National Centre of Competence in Research PlanetS supported by the SNSF.

Software: astropy (Astropy Collaboration et al. 2013, 2018), CHNOSz (Dick 2019), ipython (Perez \& Granger 2007), matplotlib (Hunter 2007), numpy (van der Walt et al. 2011), scipy (Virtanen et al. 2020).

\section{Appendix A Thermodynamics and Kinetics Data}

The equilibrium constant $K$ of a reaction is given by the difference of the Gibbs energy of formation of products and reactants as follows:

$$
-R T \ln K=\sum_{i}^{\text {products }} \nu_{i} \Delta_{f} G_{P, T, i}-\sum_{j}^{\text {reactants }} \nu_{j} \Delta_{f} G_{P, T, j},
$$

where $\Delta_{f} G_{P, T, i}$ is the Gibbs energy of formation of $i^{\text {th }}$ species at pressure $P$ and temperature $T, \nu_{i}$ is the stoichiometric coefficient, and $R$ is the universal gas constant. The Gibbs energy of formation of each species is computed at any $P$ and $T$ in terms of the Gibbs energy of formation at reference pressure 
(a)

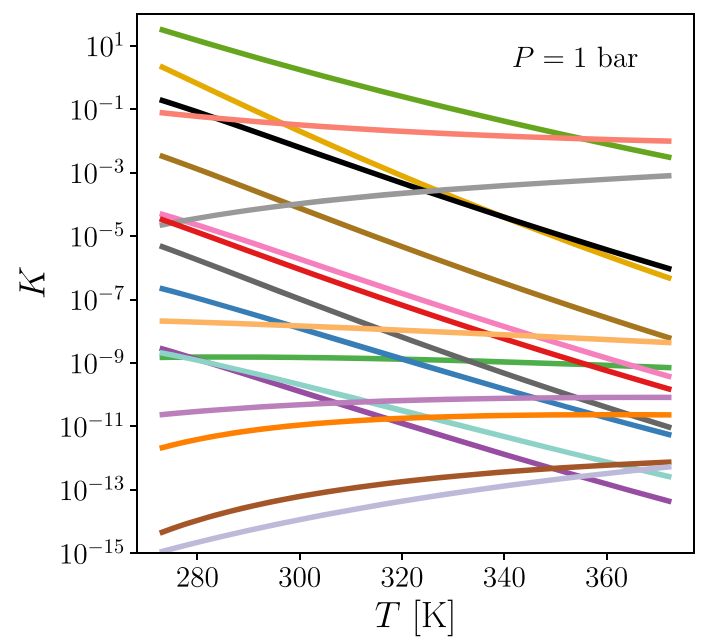

(b)

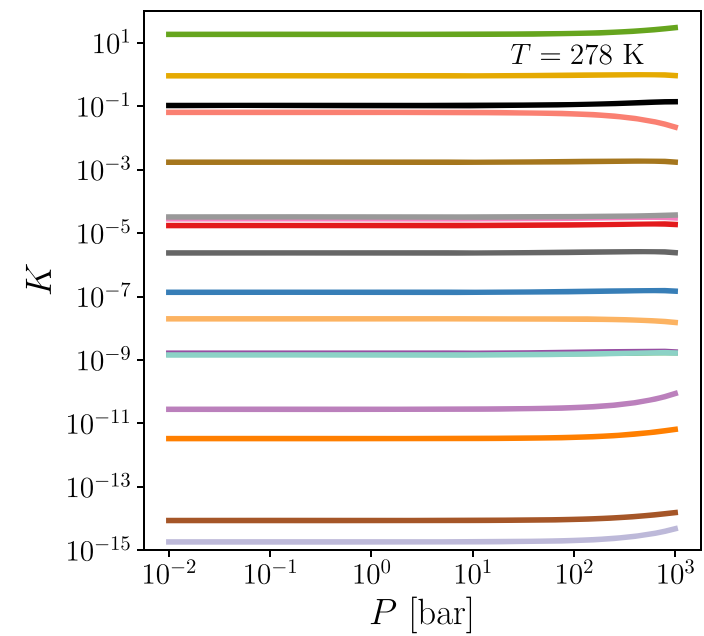

Figure A1. Equilibrium constants for the reactions listed in Table B1 obtained from CHNOSZ (Dick 2019). (a) $K$ as a function of $T$. (b) $K$ as a function of $P$. Please note that some reactions have fractional stoichiometry in order to ensure high numerical precision.

$P_{0}$ and reference temperature $T_{0}$ by

$$
\begin{aligned}
\Delta_{f} G_{P, T}= & \Delta_{f} G_{P_{0}, T_{0}}-S_{P_{0}, T_{0}}\left(T-T_{0}\right) \\
& +\int_{T_{0}}^{T} C_{P} d T-T \int_{T_{0}}^{T} C_{P} d \ln T+\int_{P_{0}}^{P} V d P,
\end{aligned}
$$

where $S_{P_{0}, T_{0}}$ is the entropy at the reference pressure and temperature, $C_{P}$ is the heat capacity at constant pressure as a function of temperature, and $V$ is the volume as a function of pressure. In this study, $\Delta_{f} G$ values are obtained from the CHNOSZ database (Dick 2019). The equilibrium constants of reactions given in Table $\mathrm{B} 1$ are shown as a function of $P$ and $T$ in Figure A1.

The kinetic rate coefficients $k_{\text {eff }}$ of mineral dissolution reactions are obtained from the compilation of Palandri \& Kharaka (2004). This compilation (Table 5) is based on the fitting of the following equation to experimental kinetics data,

$$
\begin{aligned}
k_{\text {eff }}= & A_{\text {acid }} \exp \left(\frac{-E_{\text {acid }}}{R T}\right) 10^{-\mathrm{pH} n_{\text {acid }}} \\
& +A_{\text {neut }} \exp \left(\frac{-E_{\text {neut }}}{R T}\right) \\
& +A_{\text {base }} \exp \left(\frac{-E_{\text {base }}}{R T}\right) 10^{-\mathrm{pH} n_{\text {base }}},
\end{aligned}
$$

Table 5

Kinetics Data from Palandri \& Kharaka (2004)

\begin{tabular}{lccccc}
\hline \hline Mineral & $\begin{array}{c}E_{\text {acid }} \\
\left(\mathrm{kJ} \mathrm{mol}^{-1}\right)\end{array}$ & $n_{\text {acid }}$ & $\begin{array}{c}E_{\text {neut }} \\
\left(\mathrm{kJ} \mathrm{mol}^{-1}\right)\end{array}$ & $\begin{array}{c}E_{\text {base }} \\
\left(\mathrm{kJ} \mathrm{mol}^{-1}\right)\end{array}$ & $n_{\text {base }}$ \\
\hline Wollastonite & 54.7 & 0.400 & 54.7 & $\ldots$ & $\ldots$ \\
Enstatite & 80.0 & 0.600 & 80.0 & $\ldots$ & $\ldots$ \\
Forsterite & 67.2 & 0.470 & 79.0 & $\ldots$ & $\ldots$ \\
Fayalite & 94.4 & $\ldots$ & 94.4 & $\ldots$ & $\ldots$ \\
Anorthite & 16.6 & 1.411 & 17.8 & $\ldots$ & $\ldots$ \\
Albite & 65.0 & 0.457 & 69.8 & 71.0 & -0.572 \\
K-feldspar & 51.7 & 0.500 & 38.0 & 94.1 & -0.823 \\
Muscovite & 22.0 & 0.370 & 22.0 & 22.0 & -0.220 \\
Phlogopite & $\ldots$ & $\ldots$ & 29.0 & $\ldots$ & $\ldots$ \\
Anthophyllite & 51.0 & 0.440 & 51.0 & $\ldots$ & $\ldots$ \\
Quartz & $\cdots$ & $\ldots$ & 90.1 & 108.4 & -0.5 \\
\hline
\end{tabular}

Note. For minerals that are not listed, data from a corresponding endmember mineral from the same mineral group is adopted.

where $E_{\text {acid }}, E_{\text {neut }}$, and $E_{\text {base }}$ are the activation energies at acidic, neutral, and basic $\mathrm{pH} ; A_{\text {acid }}, A_{\text {neut }}$, and $A_{\text {base }}$ are the preexponential factors at acidic, neutral, and basic $\mathrm{pH}$; and $n_{\text {acid }}$ and $n_{\text {base }}$ are the neutral and basic power-law exponents. Figure A2 shows the variation of $k_{\text {eff }}$ with $T$ and $\mathrm{pH}$ for a number of mineral dissolution reactions. For minerals not present in this compilation (ferrosilite, annite, grunerite), the kinetic rate coefficients are obtained from the respective 
(a)

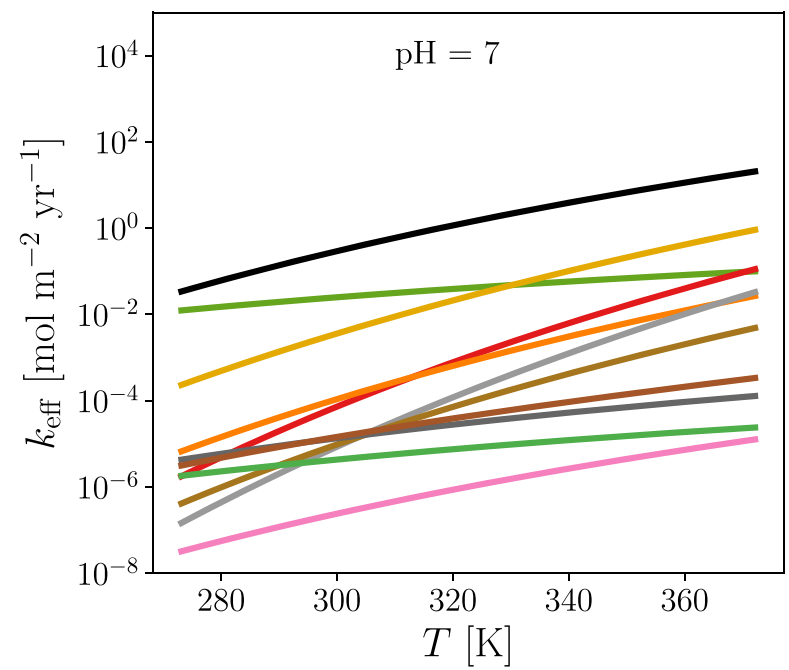

(a)

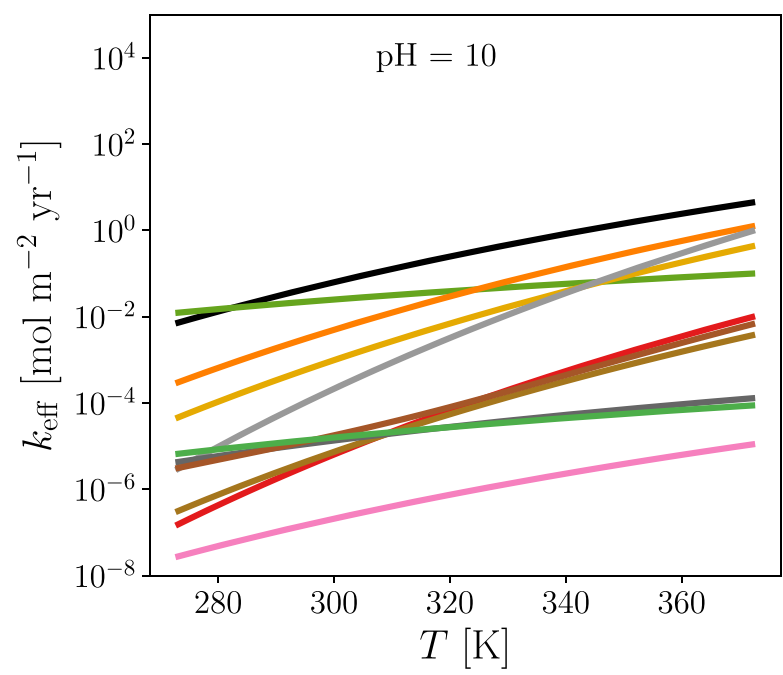

(b)

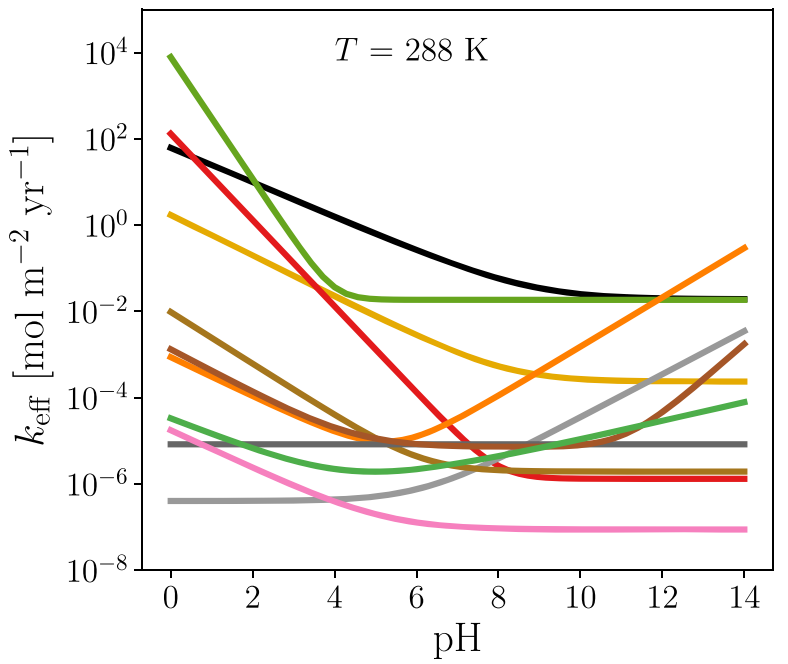

(b)

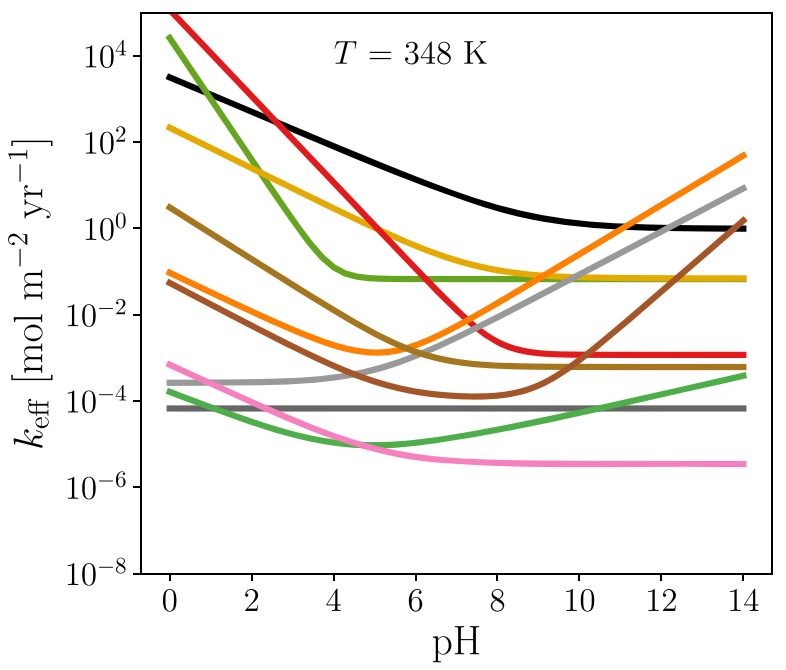

\begin{tabular}{lll}
\hline Wollastonite $\left(\mathrm{CaSiO}_{3}\right)$ & Enstatite $\left(\mathrm{MgSiO}_{3}\right)$ \\
- Anorthite $\left(\mathrm{CaAl}_{2} \mathrm{Si}_{2} \mathrm{O}_{8}\right)$ & - Phlogopite $\left(\mathrm{KMg}_{3} \mathrm{AlSi}_{3} \mathrm{O}_{10}(\mathrm{OH})_{2}\right)$ \\
- Forsterite $\left(\mathrm{Mg}_{2} \mathrm{SiO}_{4}\right)$ & K-Feldspar $\left(\mathrm{KAlSi}_{3} \mathrm{O}_{8}\right)$ \\
- Fayalite $\left(\mathrm{Fe}_{2} \mathrm{SiO}_{4}\right)$ & Muscovite $\left(\mathrm{KAl}_{3} \mathrm{Si}_{3} \mathrm{O}_{10}(\mathrm{OH})_{2}\right)$ \\
Albite $\left(\mathrm{NaAlSi}_{3} \mathrm{O}_{8}\right)$ & - Anthophyllite $\left(\mathrm{Mg}_{7} \mathrm{Si}_{8} \mathrm{O}_{22}(\mathrm{OH})_{2}\right)$ \\
Quartz $\left(\mathrm{SiO}_{2}\right)$ &
\end{tabular}

Figure A2. Kinetic rate coefficients for the dissolution of minerals obtained from Palandri \& Kharaka (2004). (a) $k_{\text {eff }}$ as a function of $T$ at $\mathrm{pH}=7$. (b) $k_{\mathrm{eff}}$ as a function of $\mathrm{pH}$ at $T=288 \mathrm{~K}$. (c) $k_{\mathrm{eff}}$ as a function of $T$ at $\mathrm{pH}=10$. (d) $k_{\mathrm{eff}}$ as a function of $\mathrm{pH}$ at $T=348 \mathrm{~K}$.

endmember minerals of the same mineral group (enstatite, phlogopite, anthophyllite).

\section{Appendix B Maximum and Generalized Concentrations of Rocks and Minerals}

Sections 2.3 and 2.4 introduce the methods to compute maximum (thermodynamic) and generalized solute concentrations for peridotite weathering. Table B1 lists the mineral dissolution (reactions (a)-(n)) and water-bicarbonate reactions (reactions (o) $-(\mathrm{r})$ ), and the relation between equilibrium constants of these reactions and thermodynamic activities. Table $\mathrm{B} 2$ gives the polynomial equations to calculate the activity of $\mathrm{HCO}_{3}^{-}$at chemical equilibrium as a function of $P_{\mathrm{CO}_{2}}$ for the weathering of all rocks and minerals considered. As an example, the maximum $\left[\mathrm{HCO}_{3}^{-}\right]$ for peridotite weathering is obtained as a function of $\mathrm{CO}_{2}$ partial pressure, surface temperature, and total pressure in 
Table B1

Reactions and Relations between Equilibrium Constants and Activities of Reactants and Products

\begin{tabular}{|c|c|c|c|}
\hline Index & Symbol & Reaction & 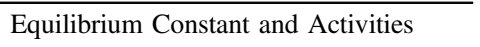 \\
\hline $\begin{array}{l}\text { (a) } \\
\text { (b) } \\
\text { (c) }\end{array}$ & $\begin{array}{l}\text { Wo } \\
\text { En } \\
\text { Fs }\end{array}$ & $\begin{array}{l}\text { Pyroxene } \\
\mathrm{CaSiO}_{3}(s)+2 \mathrm{CO}_{2}(g)+\mathrm{H}_{2} \mathrm{O}(l) \stackrel{K_{\mathrm{Wo}_{\mathrm{o}}}^{\rightleftharpoons}}{\rightleftharpoons} 2 \mathrm{HCO}_{3}^{-}+\mathrm{Ca}^{2+}+\mathrm{SiO}_{2}(a q) \\
\mathrm{MgSiO}_{3}(s)+2 \mathrm{CO}_{2}(g)+\mathrm{H}_{2} \mathrm{O}(l) \stackrel{K_{\mathrm{En}}}{\rightleftharpoons} 2 \mathrm{HCO}_{3}^{-}+\mathrm{Mg}^{2+}+\mathrm{SiO}_{2}(a q) \\
\mathrm{FeSiO}_{3}(s)+2 \mathrm{CO}_{2}(g)+\mathrm{H}_{2} \mathrm{O}(l) \stackrel{K_{\mathrm{Fs}}}{\rightleftharpoons} 2 \mathrm{HCO}_{3}^{-}+\mathrm{Fe}^{2+}+\mathrm{SiO}_{2}(a q) \\
\end{array}$ & $\begin{array}{l}K_{\mathrm{Wo}}=a_{\mathrm{HCO}_{3}^{-}}^{2} a_{\mathrm{Ca}^{2+}} a_{\mathrm{SiO}_{2}(a q)} P_{\mathrm{CO}_{2}}^{-2} \\
K_{\mathrm{En}}=a_{\mathrm{HCO}_{3}^{-}}^{2} a_{\mathrm{Mg}^{2+}} a_{\mathrm{SiO}_{2}(a q)} P_{\mathrm{CO}_{2}}^{-2} \\
K_{\mathrm{Fs}}=a_{\mathrm{HCO}_{3}^{-}}^{2} a_{\mathrm{Fe}^{2+}} a_{\mathrm{SiO}_{2}(a q)} P_{\mathrm{CO}_{2}}^{-2}\end{array}$ \\
\hline (d) & $\begin{array}{l}\text { Fo } \\
\text { Fa }\end{array}$ & $\begin{array}{l}\text { Olivine } \\
\frac{1}{2} \mathrm{Mg}_{2} \mathrm{SiO}_{4}(s)+2 \mathrm{CO}_{2}(g)+\mathrm{H}_{2} \mathrm{O}(l) \stackrel{K_{\mathrm{Fo}}}{\rightleftharpoons} 2 \mathrm{HCO}_{3}^{-}+\mathrm{Mg}^{2+}+\frac{1}{2} \mathrm{SiO}_{2}(a q) \\
\frac{1}{2} \mathrm{Fe}_{2} \mathrm{SiO}_{4}(s)+2 \mathrm{CO}_{2}(g)+\mathrm{H}_{2} \mathrm{O}(l) \stackrel{K_{\mathrm{Fa}}}{\rightleftharpoons} 2 \mathrm{HCO}_{3}^{-}+\mathrm{Fe}^{2+}+\frac{1}{2} \mathrm{SiO}_{2}(a q)\end{array}$ & $\begin{array}{l}K_{\mathrm{Fo}}=a_{\mathrm{HCO}_{3}^{-}}^{2} a_{\mathrm{Mg}^{2+}} a_{\mathrm{SiO}_{2}(a q)}^{1 / 2} P_{\mathrm{CO}_{2}}^{-2} \\
K_{\mathrm{Fa}}=a_{\mathrm{HCO}_{3}^{-}}^{2} a_{\mathrm{Fe}^{2+}} a_{\mathrm{SiO}_{2}(a q)}^{1 / 2} P_{\mathrm{CO}_{2}}^{-2}\end{array}$ \\
\hline (h) & $\begin{array}{l}\text { An } \\
\text { Alb } \\
\text { Kfs }\end{array}$ & $\begin{array}{l}\text { Feldspar } \\
\frac{1}{2} \mathrm{CaAl}_{2} \mathrm{Si}_{2} \mathrm{O}_{8}(s)+\mathrm{CO}_{2}(g)+\frac{3}{2} \mathrm{H}_{2} \mathrm{O}(l) \stackrel{K_{\mathrm{An}}}{\rightleftharpoons} \mathrm{HCO}_{3}^{-}+\frac{1}{2} \mathrm{Ca}^{2+}+\frac{1}{2} \mathrm{Al}_{2} \mathrm{Si}_{2} \mathrm{O}_{5}(\mathrm{OH})_{4}(s) \\
\mathrm{NaAlSi}_{3} \mathrm{O}_{8}(s)+\mathrm{CO}_{2}(g)+\frac{3}{2} \mathrm{H}_{2} \mathrm{O}(l) \stackrel{K_{\mathrm{Alb}}}{\rightleftharpoons} \mathrm{HCO}_{3}^{-}+\mathrm{Na}^{+}+\frac{1}{2} \mathrm{Al}_{2} \mathrm{Si}_{2} \mathrm{O}_{5}(\mathrm{OH})_{4}(s)+2 \mathrm{SiO}_{2}(a q) \\
\mathrm{KAlSi}_{3} \mathrm{O}_{8}(s)+\mathrm{CO}_{2}(g)+\frac{3}{2} \mathrm{H}_{2} \mathrm{O}(l) \stackrel{K_{\mathrm{Kfs}}}{\rightleftharpoons} \mathrm{HCO}_{3}^{-}+\mathrm{K}^{+}+\frac{1}{2} \mathrm{Al}_{2} \mathrm{Si}_{2} \mathrm{O}_{5}(\mathrm{OH})_{4}(s)+2 \mathrm{SiO}_{2}(a q)\end{array}$ & $\begin{array}{l}K_{\mathrm{An}}=a_{\mathrm{HCO}_{3}^{-}} a_{\mathrm{Ca}^{2+}}^{1 / 2} P_{\mathrm{CO}_{2}}^{-1} \\
K_{\mathrm{Alb}}=a_{\mathrm{HCO}_{3}^{-}} a_{\mathrm{Na}^{+}}^{+} a_{\mathrm{SiO}_{2}(a q)}^{2} P_{\mathrm{CO}_{2}}^{-1} \\
K_{\mathrm{Kfs}}=a_{\mathrm{HCO}_{3}^{-}} a_{\mathrm{K}^{+}} a_{\mathrm{SiO}_{2}(a q)}^{2} P_{\mathrm{CO}_{2}}^{-1}\end{array}$ \\
\hline (i) & Ms & $\begin{array}{l}\text { Mica } \\
\mathrm{KAl}_{3} \mathrm{Si}_{3} \mathrm{O}_{10}(\mathrm{OH})_{2}(s)+\mathrm{CO}_{2}(g)+\frac{5}{2} \mathrm{H}_{2} \mathrm{O}(l) \stackrel{K_{\mathrm{Ms}}}{\rightleftharpoons} \mathrm{HCO}_{3}^{-}+\mathrm{K}^{+}+\frac{3}{2} \mathrm{Al}_{2} \mathrm{Si}_{2} \mathrm{O}_{5}(\mathrm{OH})_{4}(s)\end{array}$ & $K_{\mathrm{Ms}}=a_{\mathrm{HCO}_{3}} a_{\mathrm{K}^{+}} P_{\mathrm{CO}_{2}}^{-1}$ \\
\hline (k) & Ann & $\begin{array}{l}\frac{1}{3} \mathrm{KMg}_{3} \mathrm{AlSi}_{3} \mathrm{O}_{10}(\mathrm{OH})_{2}(s)+\frac{7}{3} \mathrm{CO}_{2}(g)+\frac{7}{6} \mathrm{H}_{2} \mathrm{O}(l) \stackrel{K_{\mathrm{Phl}}}{\rightleftharpoons} \\
\frac{7}{3} \mathrm{HCO}_{3}^{-}+\frac{1}{3} \mathrm{~K}^{+}+\mathrm{Mg}^{2+}+\frac{1}{6} \mathrm{Al}_{2} \mathrm{Si}_{2} \mathrm{O}_{5}(\mathrm{OH})_{4}(s)+\frac{2}{3} \mathrm{SiO}_{2}(a q) \\
\frac{1}{3} \mathrm{KFe}_{3} \mathrm{AlSi}_{3} \mathrm{O}_{10}(\mathrm{OH})_{2}(s)+\frac{7}{3} \mathrm{CO}_{2}(g)+\frac{7}{6} \mathrm{H}_{2} \mathrm{O}(l) \stackrel{K_{\mathrm{Ann}}}{\rightleftharpoons} \\
\frac{7}{3} \mathrm{HCO}_{3}^{-}+\frac{1}{3} \mathrm{~K}^{+}+\mathrm{Fe}^{2+}+\frac{1}{6} \mathrm{Al}_{2} \mathrm{Si}_{2} \mathrm{O}_{5}(\mathrm{OH})_{4}(s)+\frac{2}{3} \mathrm{SiO}_{2}(a q)\end{array}$ & $\begin{array}{l}K_{\mathrm{Phl}}=a_{\mathrm{HCO}_{3}^{-}}^{7 / 3} a_{\mathrm{K}^{+}}^{1 / 3} a_{\mathrm{Mg}^{2+}}+a_{\mathrm{SiO}_{2}(a q)}^{2 / 3} P_{\mathrm{CO}_{2}}^{-7 / 3} \\
K_{\mathrm{Ann}}=a_{\mathrm{HCO}_{3}^{-}}^{7 / 3} a_{\mathrm{K}^{+}}^{1 / 3} a_{\mathrm{Fe}^{2+}} a_{\mathrm{SiO}_{2}(a q)}^{2 / 3} P_{\mathrm{CO}_{2}}^{-7 / 3}\end{array}$ \\
\hline $\begin{array}{l}\text { (l) } \\
\text { (m) }\end{array}$ & $\begin{array}{l}\text { Ath } \\
\text { Gru }\end{array}$ & $\begin{array}{l}\text { Amphibole } \\
\frac{1}{7} \mathrm{Mg}_{7} \mathrm{Si}_{8} \mathrm{O}_{22}(\mathrm{OH})_{2}(s)+2 \mathrm{CO}_{2}(g)+\frac{6}{7} \mathrm{H}_{2} \mathrm{O}(l) \stackrel{K_{\text {Ath }}}{\rightleftharpoons} 2 \mathrm{HCO}_{3}^{-}+\mathrm{Mg}^{2+}+\frac{8}{7} \mathrm{SiO}_{2}(a q) \\
\frac{1}{7} \mathrm{Fe}_{7} \mathrm{Si}_{8} \mathrm{O}_{22}(\mathrm{OH})_{2}(s)+2 \mathrm{CO}_{2}(g)+\frac{6}{7} \mathrm{H}_{2} \mathrm{O}(l) \stackrel{K_{\text {Gru }}}{\rightleftharpoons} 2 \mathrm{HCO}_{3}^{-}+\mathrm{Fe}^{2+}+\frac{8}{7} \mathrm{SiO}_{2}(a q)\end{array}$ & $\begin{array}{l}K_{\mathrm{Ath}}=a_{\mathrm{HCO}_{3}^{-}}^{2} a_{\mathrm{Mg}^{2+}} a_{\mathrm{SiO}_{2}(a q)}^{8 / 7} P_{\mathrm{CO}_{2}}^{-2} \\
K_{\mathrm{Gru}}=a_{\mathrm{HCO}_{3}^{-}}^{2} a_{\mathrm{Fe}^{2+}} a_{\mathrm{SiO}_{2}(a q)}^{8 / 7} P_{\mathrm{CO}_{2}}^{-2}\end{array}$ \\
\hline (n) & Qz & $\begin{array}{l}\text { Quartz } \\
\mathrm{SiO}_{2}(s) \stackrel{K_{\mathrm{Qz}}}{\rightleftharpoons} \mathrm{SiO}_{2}(a q)\end{array}$ & $K_{\mathrm{Qz}}=a_{\mathrm{SiO}_{2}(a q)}$ \\
\hline $\begin{array}{l}\text { (o) } \\
\text { (p) } \\
\text { (q) } \\
\text { (r) }\end{array}$ & $\begin{array}{l}\mathrm{CO}_{2} \\
\mathrm{Bic} \\
\mathrm{Car} \\
\text { Wat }\end{array}$ & $\begin{array}{l}\text { Water-Bicarbonate System } \\
\mathrm{CO}_{2}(g) \stackrel{K_{\mathrm{CO}}}{\rightleftharpoons} \mathrm{CO}_{2}(a q) \\
\mathrm{CO}_{2}(g)+\mathrm{H}_{2} \mathrm{O} \stackrel{K_{\text {Bic }}}{\rightleftharpoons} \mathrm{HCO}_{3}^{-}+\mathrm{H}^{+} \\
\mathrm{HCO}_{3}^{-} \stackrel{K_{\text {Car }}}{\rightleftharpoons} \mathrm{CO}_{3}^{2-}+\mathrm{H}^{+} \\
\mathrm{H}_{2} \mathrm{O} \stackrel{K_{\text {Wat }}}{\rightleftharpoons} \mathrm{OH}^{-}+\mathrm{H}^{+}\end{array}$ & $\begin{array}{l}K_{\mathrm{CO}_{2}}=a_{\mathrm{CO}_{2}(a q)} P_{\mathrm{CO}_{2}}^{-1} \\
K_{\mathrm{Bic}}=a_{\mathrm{HCO}_{3}^{-}} a_{\mathrm{H}^{+}} P_{\mathrm{CO}_{2}}^{-1} \\
K_{\mathrm{Car}}=a_{\mathrm{CO}_{3}^{2}-} a_{\mathrm{H}^{+}} a_{\mathrm{HCO}_{3}^{-}}^{-1} \\
K_{\mathrm{Wat}}=a_{\mathrm{OH}^{-}} a_{\mathrm{H}^{+}}\end{array}$ \\
\hline
\end{tabular}

Note. Moles of several species are fractional so that the equilibrium constants do not exceed computational numerical precision. See Figure A1 for the dependence of $K$ on $P$ and $T$. 
Weathering of a mineral/rock

(Reaction indices from Table B1)

Peridotite (a, b, d, e, o, p, q, r)

Basalt (a, b, c, f, g, o, p, q, r)

Granite (g, h, j, k, n, o, p, q, r)

Wollastonite (a, o, p, q, r)

Enstatite (b,o, p, q, r)

Ferrosilite (c, o, p, q, r)

Forsterite (d, o, p, q, r)

Fayalite (e, o, p, q, r)

Anorthite (f, o, p, q, r)

Albite (g, o, p, q, r)

K-feldspar (h, o, p, q, r)

N Muscovite (i, o, p, q, r)

Phlogopite (j, o, p, q, r)

Annite (k, o, p, q, r)

Anthophyllite (l, o, p, q, r)

Grunerite (m, o, p, q, r)
Table B2

Polynomial Equations in and for Minerals and Rocks

Polynomial in $a_{\mathrm{HCO}_{3}^{-}}$and $P_{\mathrm{CO}_{2}}$

$\left(2 K_{\mathrm{Car}} K_{\mathrm{En}}^{2}\right) a_{\mathrm{HCO}}^{4}+K_{\mathrm{En}}^{2}\left(K_{\mathrm{Wat}}+K_{\mathrm{Bic}} P_{\mathrm{CO}_{2}}\right) a_{\mathrm{HCO}_{3}^{-}}^{3}-K_{\mathrm{Bic}}^{2} K_{\mathrm{En}}^{2} P_{\mathrm{CO}_{2}}^{2} a_{\mathrm{HCO}}^{-}-2 K_{\mathrm{Bic}} K_{\mathrm{Fo}}\left(K_{\mathrm{Fo}} K_{\mathrm{En}}+K_{\mathrm{Fa}} K_{\mathrm{En}}+K_{\mathrm{Wo}_{0}} K_{\mathrm{Fo}}\right) P_{\mathrm{CO}_{2}}^{3}=0$

$\left(2 K_{\mathrm{Car}} K_{\mathrm{Wo}}^{2}\right) a_{\mathrm{HCO}}^{4}+K_{\mathrm{Wo}}^{2}\left(K_{\mathrm{Wat}}+K_{\mathrm{Bic}} P_{\mathrm{CO}_{2}}\right) a_{\mathrm{HCO}_{3}^{-}}^{3}-K_{\mathrm{Bic}}\left(K_{\mathrm{Bic}} K_{\mathrm{Wo}}^{2}+K_{\mathrm{An}}^{4} K_{\mathrm{Alb}}\right) P_{\mathrm{CO}_{2}}^{2} a_{\mathrm{HCO}_{3}}-2 K_{\mathrm{Bic}} K_{\mathrm{An}}^{2} K_{\mathrm{Wo}}\left(K_{\mathrm{Wo}}+K_{\mathrm{En}}+K_{\mathrm{Fs}}\right) P_{\mathrm{CO}_{2}}^{3}=0$

$\left(2 K_{\mathrm{Car}} K_{\mathrm{Qz}_{2}}^{2} K_{\mathrm{Kfs}}^{1 / 3}\right) a_{\mathrm{HCO}}^{4}+K_{\mathrm{Qz}_{2}}^{2} K_{\mathrm{Kfs}}^{1 / 3}\left(K_{\mathrm{Wat}}+K_{\mathrm{Bic}} P_{\mathrm{CO}_{2}}\right) a_{\mathrm{HCO}_{3}^{-}}^{3}-K_{\mathrm{Bic}} K_{\mathrm{Kfs}}^{1 / 3}\left[K_{\mathrm{Bic}} K_{\mathrm{Qz}^{2}}^{2}+\left(K_{\mathrm{Alb}}+K_{\mathrm{Kfs}}\right)\right] P_{\mathrm{CO}_{2}}^{2} a_{\mathrm{HCO}_{3}^{-}}-2 K_{\mathrm{Bic}} K_{\mathrm{Qz}^{2}}^{2}\left(K_{\mathrm{Phl}}+K_{\mathrm{Ann}}\right) P_{\mathrm{CO}_{2}}^{3}=0$

$\left(2 K_{\mathrm{Car}}\right) a_{\mathrm{HCO}_{3}^{-}}^{3}+\left(K_{\mathrm{Wat}}+K_{\mathrm{Bic}} P_{\mathrm{CO}_{2}}\right) a_{\mathrm{HCO}}^{2}-\left(K_{\mathrm{Bic}}^{2}+2 K_{\mathrm{Bic}} \sqrt{K_{\mathrm{Wo}}}\right) P_{\mathrm{CO}_{2}}^{2}=0$

$\left(2 K_{\mathrm{Car}}\right) a_{\mathrm{HCO}_{3}^{3}}^{3}+\left(K_{\mathrm{Wat}}+K_{\mathrm{Bic}} P_{\mathrm{CO}_{2}}\right) a_{\mathrm{HCO}_{3}^{2}}^{2}-\left(K_{\mathrm{Bic}}^{2}+2 K_{\mathrm{Bic}} \sqrt{K_{\mathrm{En}}}\right) P_{\mathrm{CO}_{2}}^{2}=0$

$\left(2 K_{\mathrm{Car}}\right) a_{\mathrm{HCO}}^{3}+\left(K_{\mathrm{Wat}}+K_{\mathrm{Bic}} P_{\mathrm{CO}_{2}}\right) a_{\mathrm{HCO}}^{2}-\left(K_{\mathrm{Bic}}^{2}+2 K_{\mathrm{Bic}} \sqrt{K_{\mathrm{Fs}}}\right) P_{\mathrm{CO}_{2}}^{2}=0$

$\left.\left(2 K_{\mathrm{Car}}\right) a_{\mathrm{HCO}_{3}^{-10 / 3}}^{10 /(} K_{\mathrm{Wat}}+K_{\mathrm{Bic}} P_{\mathrm{CO}_{2}}\right) a_{\mathrm{HCO}_{3}^{-}}^{7 / 3}-\left(K_{\mathrm{Bic}}^{2} P_{\mathrm{CO}_{2}}^{2}\right) a_{\mathrm{HCO}_{3}^{-}}^{1 / 3}-2^{4 / 3} K_{\mathrm{Bic}} K_{\mathrm{Fo}}^{2 / 3} P_{\mathrm{CO}_{2}}^{7 / 3}=0$

$\left(2 K_{\mathrm{Car}}\right) a_{\mathrm{HCO}_{3}^{-1}}^{10 / 3}+\left(K_{\mathrm{Wat}}+K_{\mathrm{Bic}} P_{\mathrm{CO}_{2}}\right) a_{\mathrm{HCO}_{3}^{-}}^{7 / 3}-\left(K_{\mathrm{Bic}}^{2} P_{\mathrm{CO}_{2}}^{2}\right) a_{\mathrm{HCO}_{3}^{-}}^{1 / 3}-2^{4 / 3} K_{\mathrm{Bic}} K_{\mathrm{Fa}}^{2 / 3} P_{\mathrm{CO}_{2}}^{7 / 3}=0$

$\left(2 K_{\mathrm{Car}}\right) a_{\mathrm{HCO}_{3}^{-}}^{4}+\left(K_{\mathrm{Wat}}+K_{\mathrm{Bic}} P_{\mathrm{CO}_{2}}\right) a_{\mathrm{HCO}_{3}^{-}}^{3}-\left(K_{\mathrm{Bic}}^{2} P_{\mathrm{CO}_{2}}^{2}\right) a_{\mathrm{HCO}_{3}^{-}}-2 K_{\mathrm{Bic}} K_{\mathrm{An}}^{2} P_{\mathrm{CO}_{2}}^{3}=0$

$\left(2 K_{\mathrm{Car}}\right) a_{\mathrm{HCO}_{3}^{-}}^{3}+\left(K_{\mathrm{Wat}}+K_{\mathrm{Bic}} P_{\mathrm{CO}_{2}}\right) a_{\mathrm{HCO}_{3}^{-}}^{2}-\left(2^{-2 / 3} K_{\mathrm{Bic}} K_{\mathrm{Alb}^{1 / 3}}^{1 / 3} P_{\mathrm{CO}_{2}}^{4 / 3}\right) a_{\mathrm{HCO}_{3}^{-}}^{2 / 3}-\left(K_{\mathrm{Bic}^{2}}^{2} P_{\mathrm{CO}_{2}}^{2}\right)=0$

$\left(2 K_{\mathrm{Car}}\right) a_{\mathrm{HCO}_{3}^{-}}^{3}+\left(K_{\mathrm{Wat}}+K_{\mathrm{Bic}} P_{\mathrm{CO}_{2}}\right) a_{\mathrm{HCO}_{3}^{-}}^{2}-\left(2^{-2 / 3} K_{\mathrm{Bic}} K_{\mathrm{Kfs}}^{1 / 3} P_{\mathrm{CO}_{2}}^{4 / 3}\right) a_{\mathrm{HCO}_{3}^{-}}^{2 / 3}-\left(K_{\mathrm{Bic}^{2}}^{2} P_{\mathrm{CO}_{2}}^{2}\right)=0$

$\left(2 K_{\mathrm{Car}}\right) a_{\mathrm{HCO}_{3}^{-}}^{3}+\left(K_{\mathrm{Wat}}+K_{\mathrm{Bic}} P_{\mathrm{CO}_{2}}\right) a_{\mathrm{HCO}_{3}^{-}}^{2}-\left(K_{\mathrm{Bic}}^{2}+K_{\mathrm{Bic}} K_{\mathrm{Ms}}\right) P_{\mathrm{CO}_{2}}^{2}=0$

$\left(2 K_{\mathrm{Car}}\right) a_{\mathrm{HCO}_{3}^{-} / 6}^{19 /}+\left(K_{\mathrm{Wat}}+K_{\mathrm{Bic}} P_{\mathrm{CO}_{2}}\right) a_{\mathrm{HCO}_{3}^{-1}}^{13 / 6}-\left(K_{\mathrm{Bic}}^{2} P_{\mathrm{CO}_{2}}^{2}\right) a_{\mathrm{HCO}_{3}^{-}}^{1 / 6}-2^{2 / 3} 3^{1 / 2} K_{\mathrm{Bic}} K_{\mathrm{Phl}}^{1 / 2} P_{\mathrm{CO}_{2}}^{13 / 6}=0$

$\left(2 K_{\mathrm{Car}}\right) a_{\mathrm{HCO}_{3}^{-}}^{19 / 6}+\left(K_{\mathrm{Wat}}+K_{\mathrm{Bic}} P_{\mathrm{CO}_{2}}\right) a_{\mathrm{HCO}_{3}^{-}}^{13 / 6}-\left(K_{\mathrm{Bic}}^{2} P_{\mathrm{CO}_{2}}^{2}\right) a_{\mathrm{HCO}_{3}^{-}}^{1 / 6}-2^{2 / 3} 3^{1 / 2} K_{\mathrm{Bic}} K_{\mathrm{Ann}^{1 / 2}}^{1 / 2} \mathrm{CO}_{2}^{13 / 6}=0$

$\left(2 K_{\mathrm{Car}}\right) a_{\mathrm{HCO}_{3}^{3}}^{3}+\left(K_{\mathrm{Wat}}+K_{\mathrm{Bic}} P_{\mathrm{CO}_{2}}\right) a_{\mathrm{HCO}_{3}^{-}}^{2}-\left(2^{-3 / 5} 7^{8 / 15} K_{\mathrm{Bic}} K_{\mathrm{Anth}}^{7} P_{\mathrm{CO}_{2}}^{29 / 15}\right) a_{\mathrm{HCO}_{3}^{-}}^{1 / 15}-\left(K_{\mathrm{Bic}^{2}}^{2} P_{\mathrm{CO}_{2}}^{2}\right)=0$

$\left(2 K_{\mathrm{Car}}\right) a_{\mathrm{HCO}_{3}^{-}}^{3}+\left(K_{\mathrm{Wat}}+K_{\mathrm{Bic}} P_{\mathrm{CO}_{2}}\right) a_{\mathrm{HCO}_{3}^{-}}^{2}-\left(2^{-3 / 5} 7^{8 / 15} K_{\mathrm{Bic}} K_{\mathrm{Gru}}^{7} P_{\mathrm{CO}_{2}}^{29 / 15}\right) a_{\mathrm{HCO}_{3}^{-}}^{1 / 15}-\left(K_{\mathrm{Bic}}^{2} P_{\mathrm{CO}_{2}}^{2}\right)=0$ 
(a)

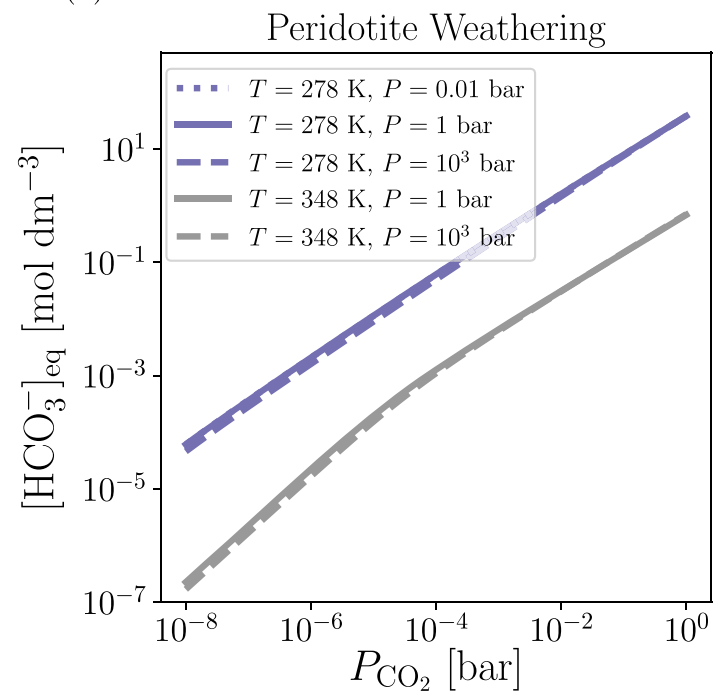

(b)

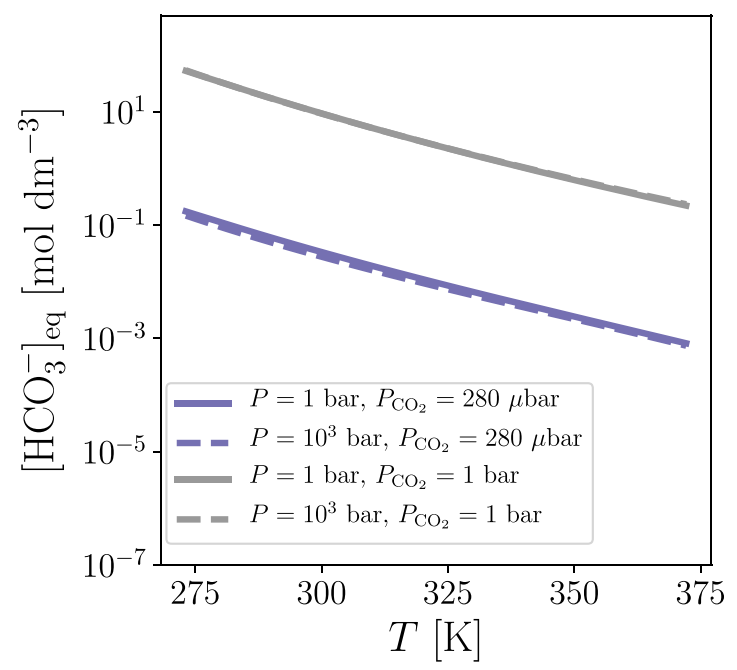

(c)

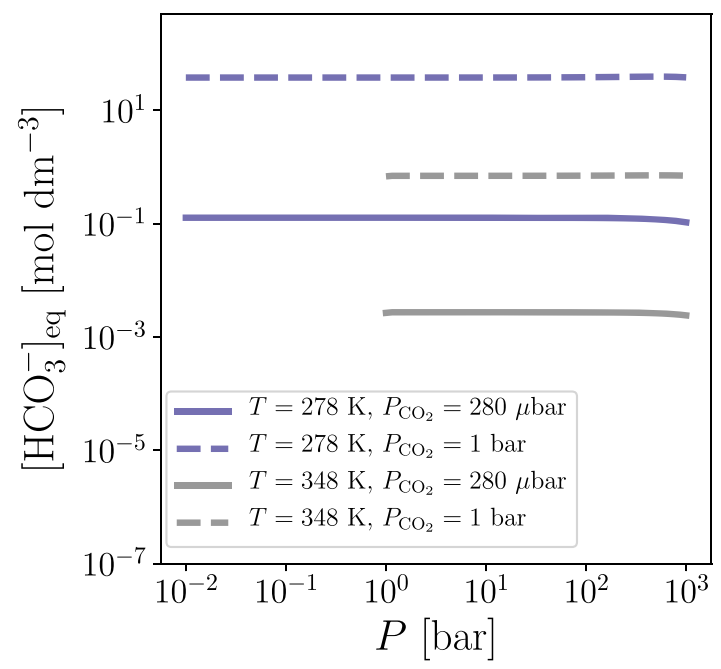

Figure B1. Impact of climate properties on the equilibrium bicarbonate concentration produced as a result of peridotite weathering. (a) $\mathrm{CO}_{2}$ partial pressure. (b) Temperature. (c) Total Pressure.

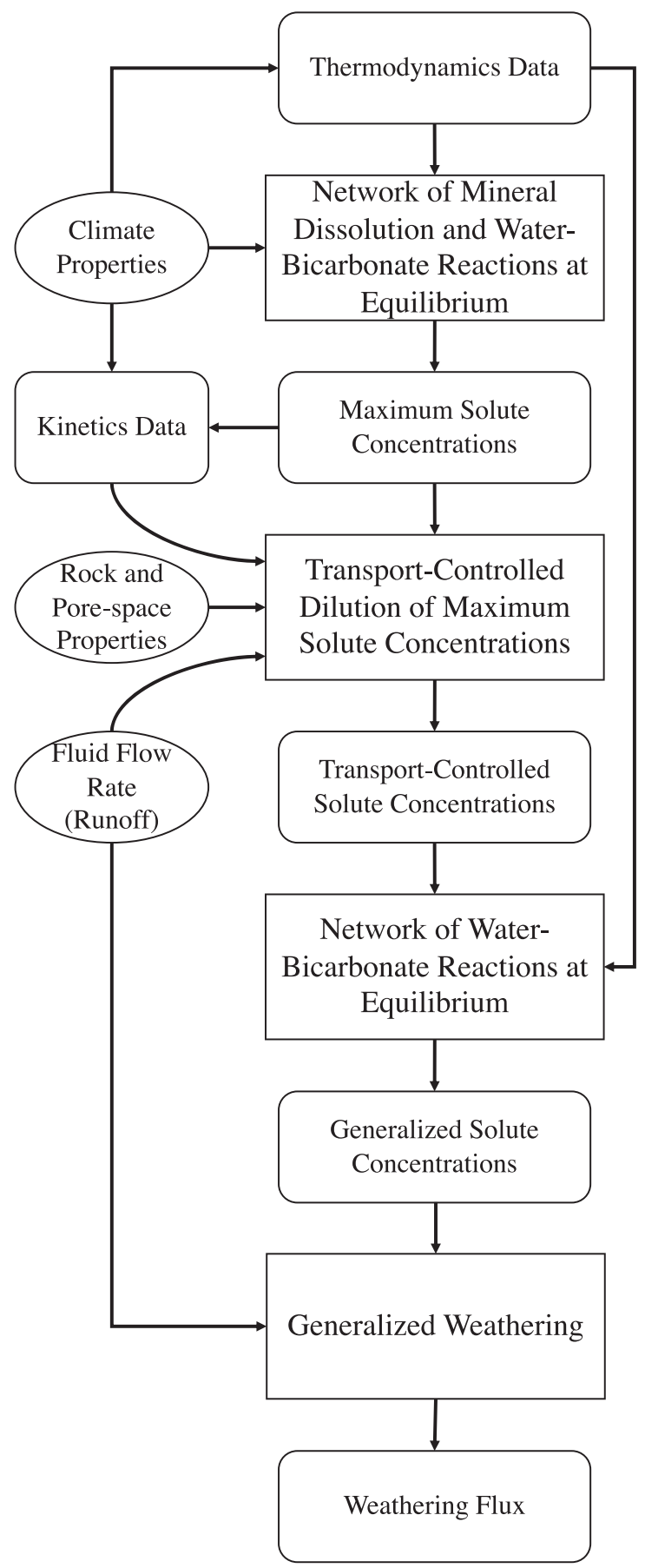

Figure B2. Schematic describing the methodology of the weathering model CHILI. Square boxes represent software modules, ovals denote parameters (Tables 1 and 3), and rounded squares represent computed quantities (Table 2). The solute transport equation of Maher \& Chamberlain (2014) is implemented to calculate diluted solute concentrations. Thermodynamics and kinetics data are obtained from Dick (2019) and Palandri \& Kharaka (2004), respectively (see Appendix A).

Figure B1. As described in Section 2.3, $\left[\mathrm{HCO}_{3}^{-}\right]_{\text {eq }}$ is strongly sensitive to $P_{\mathrm{CO}_{2}}$ and $T$. However, $P$ has a negligible effect on $\left[\mathrm{HCO}_{3}^{-}\right]_{\text {eq }}$ because the equilibrium constants of reactions are largely unchanged up to 1000 bar (Appendix A). This figure demonstrates that the total pressure plays a negligible role in determining the solute concentrations of aqueous species. The effect of precipitation of amorphous silica (Winnick \& Maher 2018) 


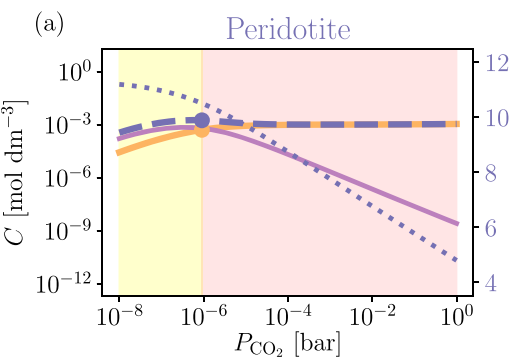

(d)
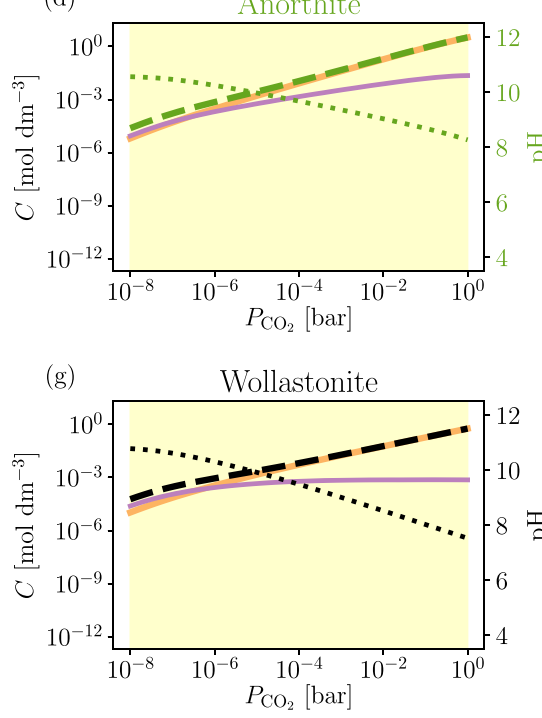

(j)
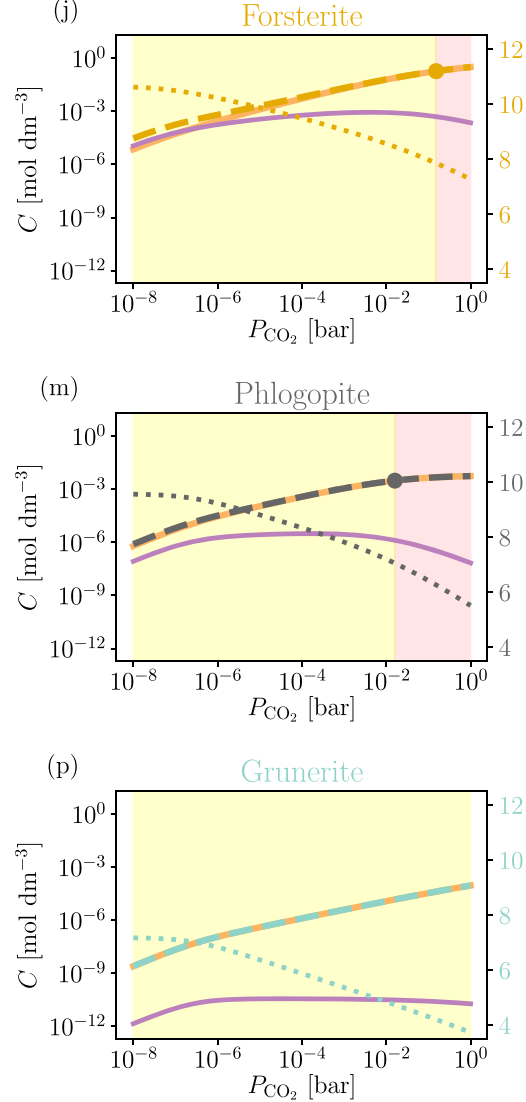

(b)

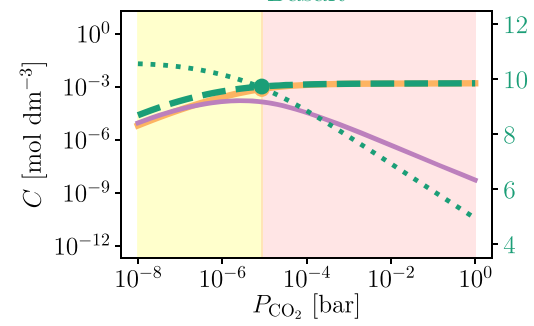

(e)

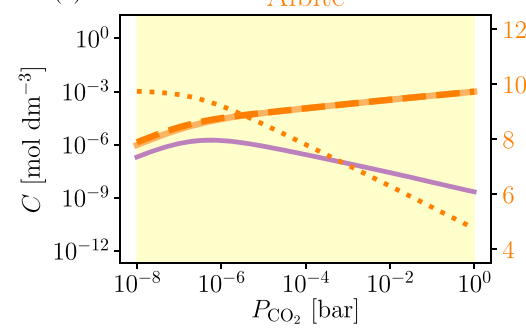

(h)

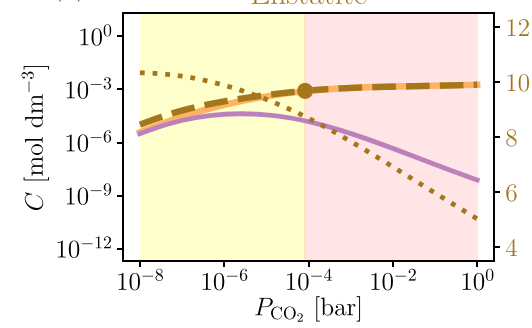

(k)

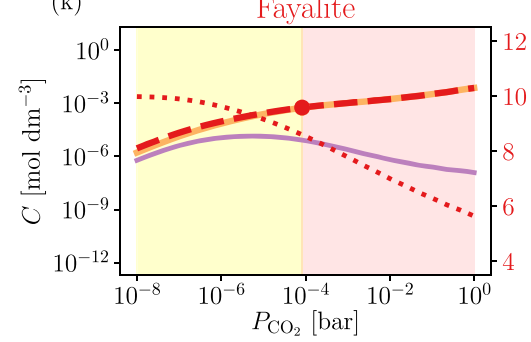

(n)

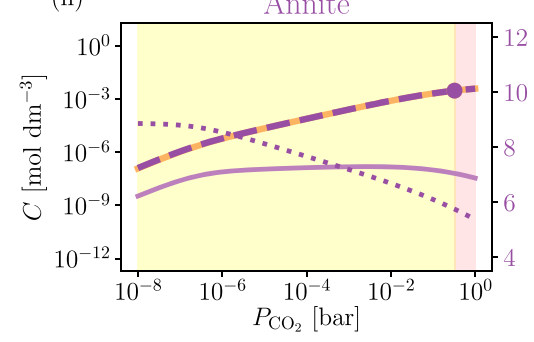

(c)

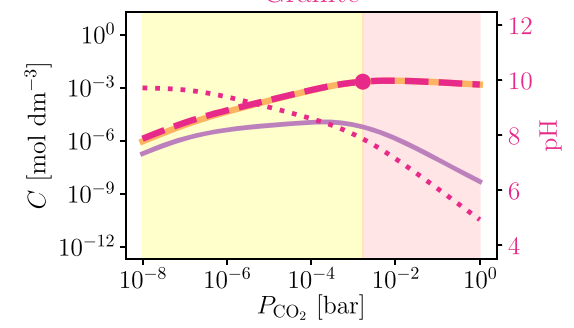

(f)

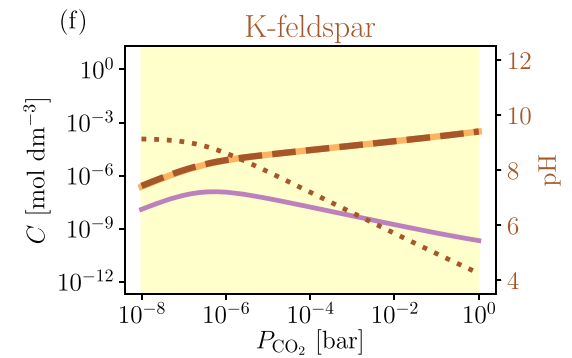

(i)

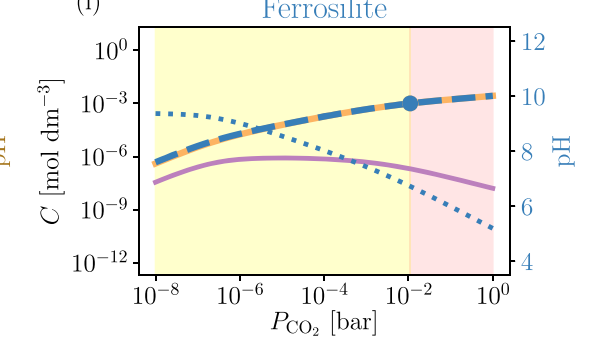

$(1)$

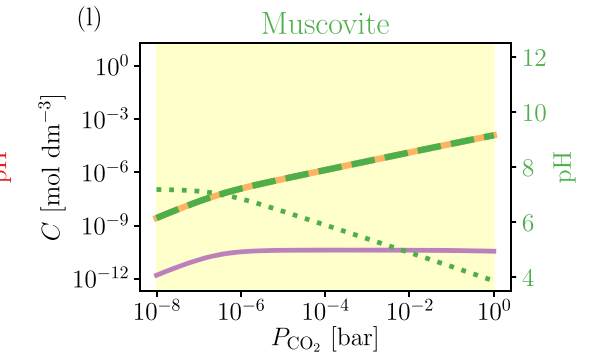

(o)

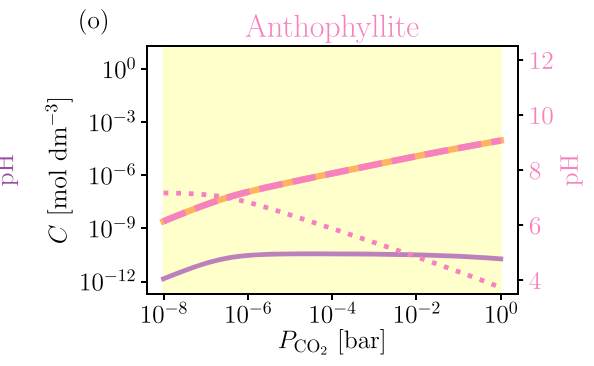

Figure B3. Carbonate alkalinity and $\mathrm{pH}$ as a function of $P_{\mathrm{CO}_{2}}$ at $T=288 \mathrm{~K}$ (modern surface temperature), $q=0.3 \mathrm{~m} \mathrm{yr}^{-1}$ (modern mean runoff), and $t_{\mathrm{s}}=0$ (young soils). From left to right, colored disks mark the transition between the thermodynamic and kinetic regimes. 
is not modeled because this effect changes the weathering flux by less than an order of magnitude (only at high $P_{\mathrm{CO}_{2}}$ ), which is smaller than the 5-10 order of magnitude spread in the weathering fluxes discussed in this study.

Once the maximum $\left[\mathrm{HCO}_{3}^{-}\right]$is determined for a given rock or mineral, the solute transport equation of Maher \& Chamberlain (2014) is implemented to dilute the equilibrium value of $\left[\mathrm{HCO}_{3}^{-}\right]$as a function of runoff or fluid flow rate $q$ (Figure B2). This equation allows the nonequilibrium concentrations to be calculated using equilibrium concentrations. The higher the fluid flow rate, the more diluted is the resulting $\left[\mathrm{HCO}_{3}^{-}\right]$(Equation (8)). This diluted $\left[\mathrm{HCO}_{3}^{-}\right]$is then used as an input to solve for concentrations of other aqueous species such as $\mathrm{CO}_{3}^{2-}, \mathrm{H}^{+}$and $\mathrm{OH}^{-}$by assuming that the water-bicarbonate reactions obey chemical equilibrium. Figure B3 demonstrates that generalized solute concentrations (Section 2.4) are strongly sensitive to lithology. For example, the transition between thermodynamic and kinetic weathering regimes of peridotite occurs at $P_{\mathrm{CO}_{2}}=1 \mu \mathrm{bar}$ for $q=0.3 \mathrm{~m} \mathrm{yr}^{-1}$, whereas this transition occurs at $P_{\mathrm{CO}_{2}}=1 \mathrm{mbar}$ for granite. Once these generalized concentrations are obtained, the generalized weathering flux is calculated using Equation (3).

\section{Appendix C \\ Equilibrium Constant of the $\mathrm{CO}_{2}$ Dissolution Reaction}

Henry's law states that the amount of gas dissolved in the liquid $\left(\left[\mathrm{CO}_{2}(a q)\right]=a_{\mathrm{CO}_{2}(a q)} \times 1 \mathrm{~mol} \mathrm{\textrm {dm } ^ { - 3 }}\right)$ is proportional to its partial pressure above the liquid, $P_{\mathrm{CO}_{2}}$. For the $\mathrm{CO}_{2}$ dissolution reaction ((o) in Table $\mathrm{B} 1)$, the proportionality constant is the equilibrium constant $K_{\mathrm{CO}_{2}}$ that itself depends on pressure and temperature,

$$
a_{\mathrm{CO}_{2}(a q) \text {, thermo }}=K_{\mathrm{CO}_{2}} P_{\mathrm{CO}_{2}} \text {. }
$$

We obtain the dimensionless $K_{\mathrm{CO}_{2}}$ as a function of $T$ and $P$ from the CHNOSZ thermodynamic database (Dick 2019).

Pierrehumbert (2010, Equation (8.14)) provides an approximate dimensional Arrhenius-type fitting function $K_{\mathrm{H}}$ at any temperature $T$ for Henry's law constant,

$$
K_{\mathrm{H}}(T)=K_{\mathrm{H}}^{0} \exp \left[-C_{\mathrm{H}}\left(\frac{1}{T}-\frac{1}{T_{0}}\right)\right],
$$

with empirical factors, $K_{\mathrm{H}}^{0}=1600 \frac{\mathrm{mol} \text { water }}{\mathrm{mol} \mathrm{CO}_{2}(\mathrm{aq})}$ at a reference temperature $T_{0}=298 \mathrm{~K}$, and $C_{\mathrm{H}}=2400 \mathrm{~K}$. The relation between $a_{\mathrm{CO}_{2}(a q)}$ and $P_{\mathrm{CO}_{2}}$ using $K_{\mathrm{H}}$ is given by

$$
a_{\mathrm{CO}_{2}(a q) \text {,arhen }}=\frac{u}{K_{\mathrm{H}}} P_{\mathrm{CO}_{2}},
$$

where $u=55.5 \frac{\mathrm{mol} \text { water }}{\mathrm{mol} \mathrm{CO}_{2}(\mathrm{aq})}\left(1 \mathrm{dm}^{3}\right.$ of water contains 55.5 moles of water) is a conversion factor between the standard states of $K_{\mathrm{H}}\left(1 \frac{\mathrm{mol} \mathrm{CO}_{2}(\mathrm{aq})}{\text { mol water }}\right)$ and $K_{\mathrm{CO}_{2}}\left(1 \frac{\mathrm{mol} \mathrm{CO}_{2}(\mathrm{aq})}{\mathrm{dm}^{3} \text { water }}\right)$.

In Figure C1, these two models (Equations (C4) and (C6)) are compared with the fit to experimental data on the solubility of $\mathrm{CO}_{2}$ in pure water compiled by Diamond \& Akinfiev (2003). The Arrhenius-type model is within $6 \%$ of that of the experimental data up to $330 \mathrm{~K}$ and deviates by up to $37 \%$ at higher temperatures. The thermodynamic model performs

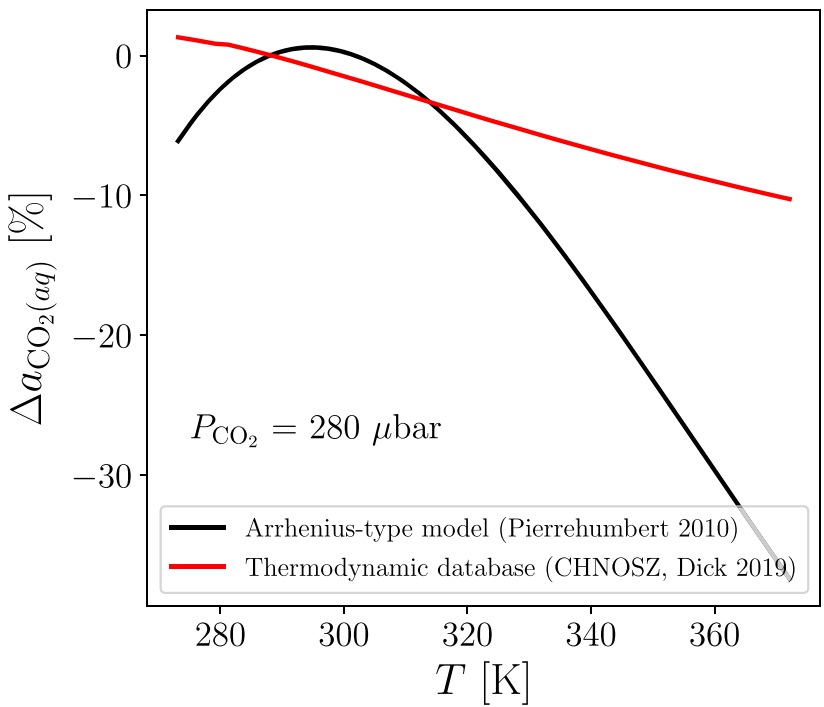

Figure C1. Difference between model and experimental data for $a_{\mathrm{CO}_{2}(a q)}$ as a function of $T$. The experimental data is obtained from the compilation of Diamond \& Akinfiev (2003). The models are given by the Arrhenius-type equation (Pierrehumbert 2010) and the thermodynamic database (Dick 2019).

better than the Arrhenius-type model at all temperatures except for $288-313 \mathrm{~K}$ and is within $10 \%$ of the experimental data at $373 \mathrm{~K}$. For this reason, we use the thermodynamic model to calculate the solubility of $\mathrm{CO}_{2}$ in water instead of the Arrhenius-type model (Equation (C5)).

\section{Appendix D \\ Sensitivity of the Damköhler Coefficient to Parameters}

The Damköhler coefficient $D_{w}$ depends on seven parameters and two computed quantities (Equation (9)). The two computed quantities, equilibrium solute concentration $C_{\mathrm{eq}}\left(=\left[\mathrm{HCO}_{3}^{-}\right]_{\mathrm{eq}}\right.$ in this study) and effective kinetic rate coefficient $k_{\text {eff }}$, are treated as free parameters in Figure D1. All nine parameters are varied for a maximum possible range of their known values (Figure D1). $D_{w}$ is largely sensitive to four quantities, $C_{\text {eq }}, k_{\text {eff }}$, $t_{\mathrm{s}}$ (age of soils), and $L$ (flow path length). The flow path length is absorbed into the dimensionless pore-space parameter $\psi$ which is a control parameter for the models in the main text (Equation (9)). Figures D1(b), (c) highlights the interdependence of $k_{\text {eff }}$ and $t_{\mathrm{s}}$. At low $k_{\mathrm{eff}}$ or low $t_{\mathrm{s}}, D_{w}$ is strongly sensitive to $k_{\text {eff }}$ and insensitive to $t_{\mathrm{s}}$, implying the presence of the "fast kinetic" regime. At high $k_{\text {eff }}$ or high $t_{\mathrm{s}}, D_{w}$ is independent of $k_{\text {eff }}$ and decreases strongly with $t_{\mathrm{s}}$, implying that weathering is in the "slow kinetic" or supply-limited regime due to insufficient supply of fresh rocks for weathering. Figure D1 also compares $D_{w}$ of our granite model to that of Maher \& Chamberlain (2014). These two models show similar trends between $D_{w}$ and the respective parameters. The difference between the two models arises mainly from our assumption of endmember silicate minerals, instead of solid solutions, for the granite model, which results in a higher $C_{\mathrm{eq}}$ in our model by a factor of 4 . 
(a)

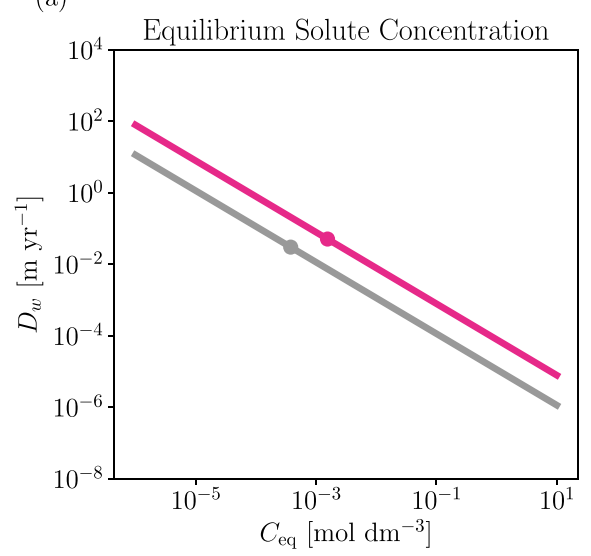

(d)

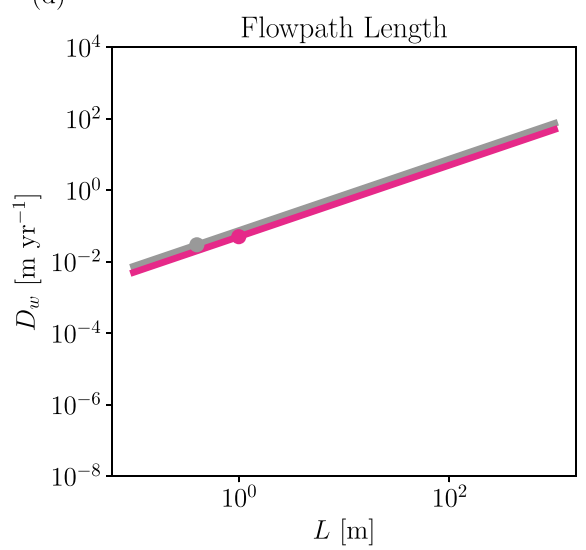

(g)

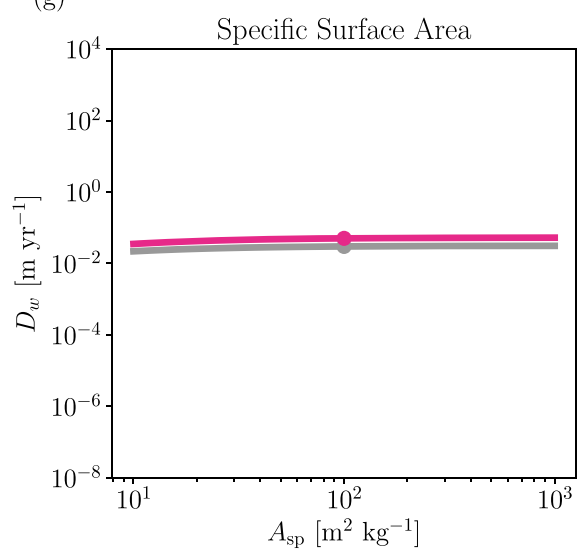

(b)

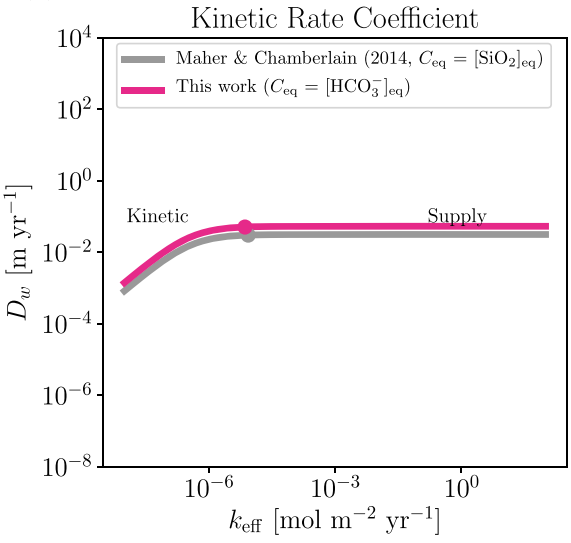

(e)

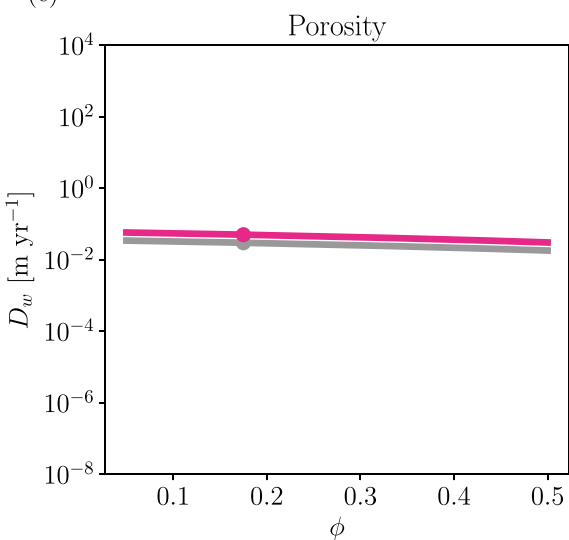

(h)

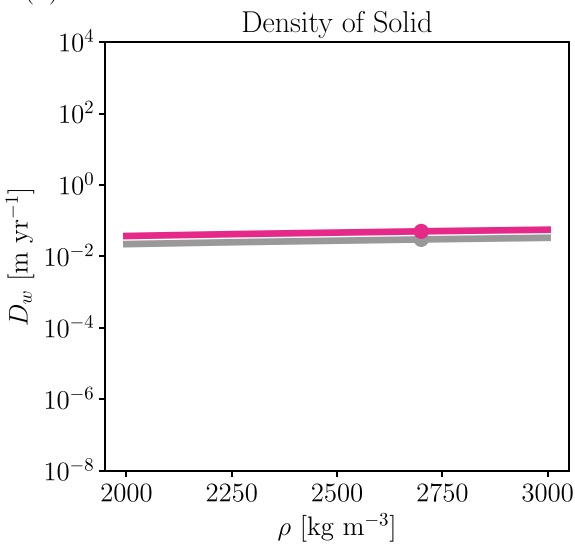

(c)

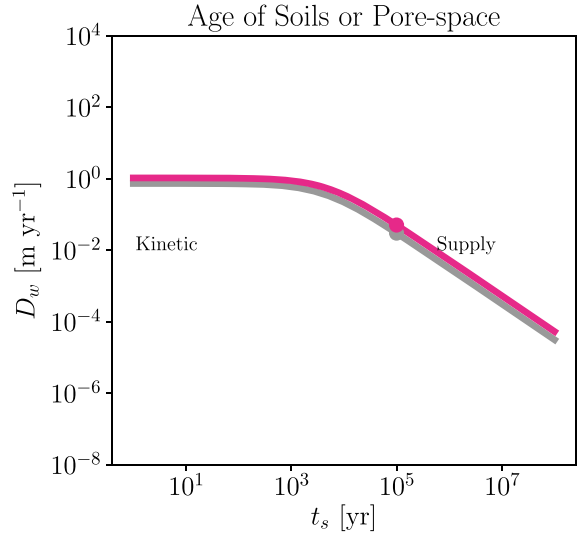

(f)

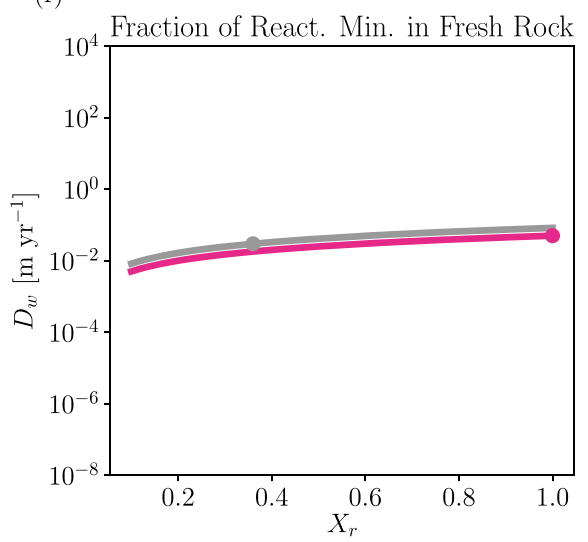

(i)

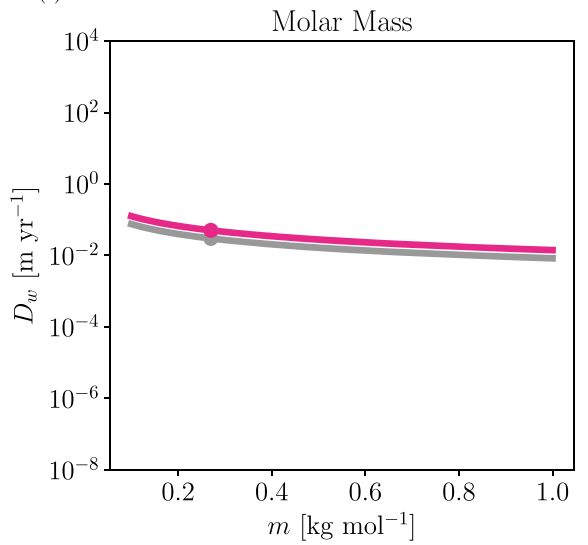

Figure D1. (a)-(i) Sensitivity of the Damköhler coefficient to all nine parameters (Equation (9)) and comparison between the Damköhler coefficients of the granitelike model from this work and the granite model from Maher \& Chamberlain (2014). Colored disks represent the default values of $D_{w}$ and the respective parameters. The lines represent the extent of the variation in parameters. The key difference between the two models is in the species of interest: $\mathrm{HCO}_{3}^{-}$with $\left[\mathrm{HCO}_{3}^{-}\right]_{\mathrm{eq}}=1555 \mu \mathrm{mol} \mathrm{dm}{ }^{-3}$ (this work) and $\mathrm{SiO}_{2}$ with $\left[\mathrm{SiO}_{2}\right]_{\mathrm{eq}}=380 \mu \mathrm{mol} \mathrm{dm}{ }^{-3}$ (Maher \& Chamberlain 2014). Other differences include the flow path length and fraction of reactive minerals: $L=1 \mathrm{~m}$ and $X_{r}=1$ (this work), and $L=0.4 \mathrm{~m}$ and $X_{r}=0.36$ (Maher \& Chamberlain 2014). These two differences result in $D_{w}=0.05 \mathrm{~m} \mathrm{yr}^{-1}$ (this work) and $D_{w}=0.03 \mathrm{~m} \mathrm{yr}^{-1}$ (Maher \& Chamberlain 2014). Kinetic and supply regimes of weathering are highlighted in (b) and (c).

\section{Appendix E Climate Models}

A climate model provides a relation between the surface temperature $T$, the $\mathrm{CO}_{2}$ partial pressure $P_{\mathrm{CO}_{2}}$, top-of-atmosphere stellar flux $S$, and planetary albedo $\alpha$. Kadoya \& Tajika (2019) provide a fitting function to the climate model of Kopparapu et al. $(2013,2014)$ which is valid for $T$ in the range $150-350 \mathrm{~K}$ with $P_{\mathrm{CO}_{2}}$ in the range $10^{-5}-10$ bar at saturated
$\mathrm{H}_{2} \mathrm{O}$ and 1 bar $\mathrm{N}_{2}$. The fitting function is given by

$$
\begin{gathered}
F_{\mathrm{OLR}}\left(T, P_{\mathrm{CO}_{2}}\right)=I_{0}+\boldsymbol{T} \boldsymbol{B} \boldsymbol{P}^{t}, \\
\boldsymbol{T}=\left[\begin{array}{lllllll}
1 & \xi & \xi^{2} & \xi^{3} & \xi^{4} & \xi^{5} & \xi^{6}
\end{array}\right], \\
\boldsymbol{P}=\left[\begin{array}{lllll}
1 & \chi & \chi^{2} & \chi^{3} & \chi^{4}
\end{array}\right],
\end{gathered}
$$

where $t$ denotes the transpose of the vector, the outgoing longwave radiation $F_{\mathrm{OLR}}$ is a function of $T$, and $P_{\mathrm{CO}_{2}}$, 
(a)

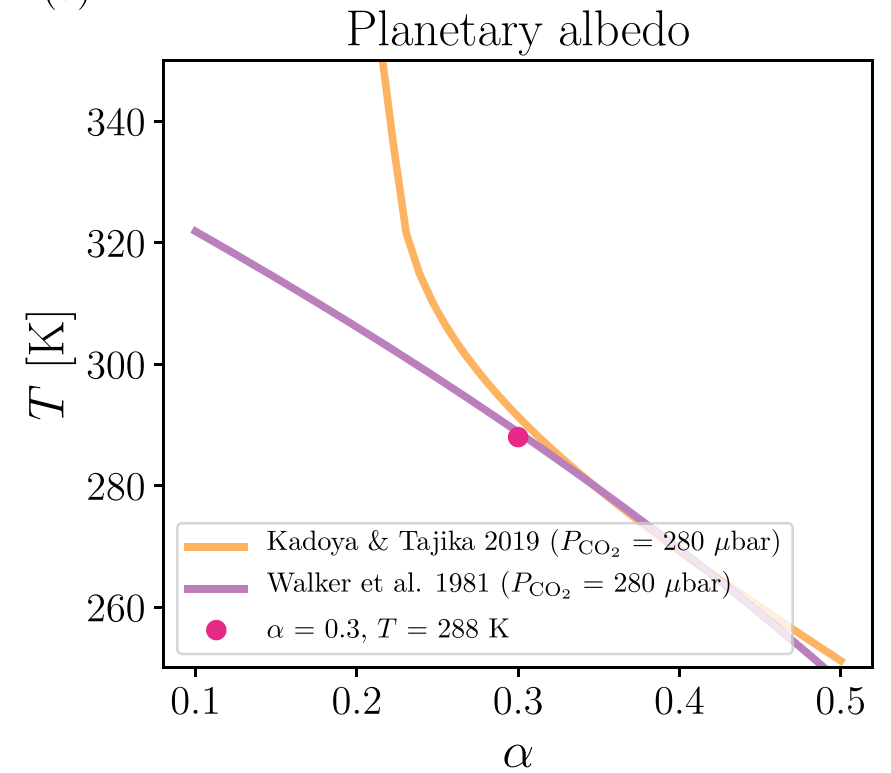

(b)

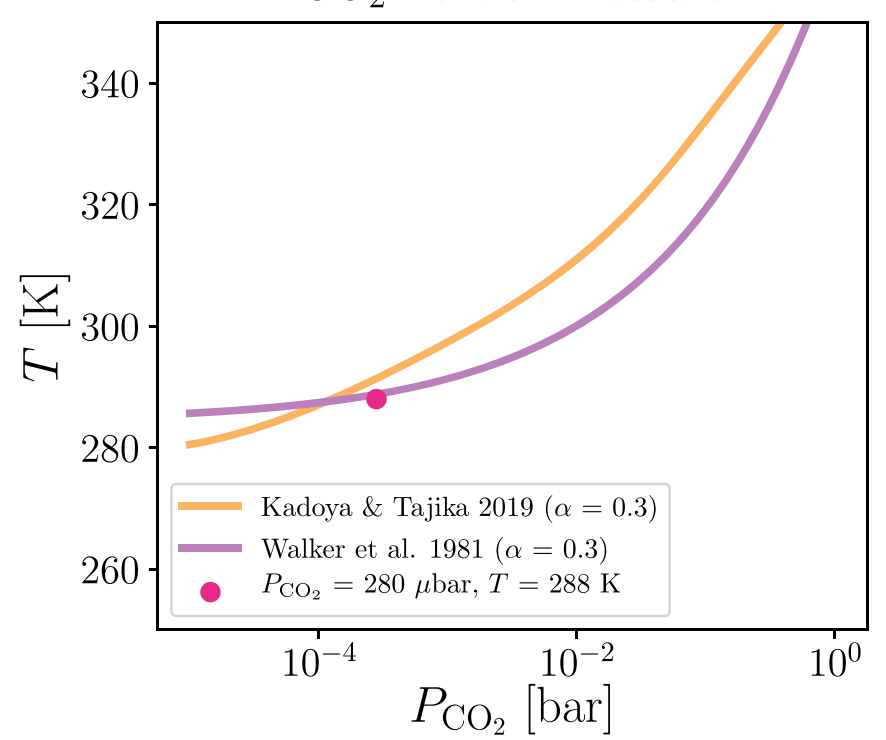

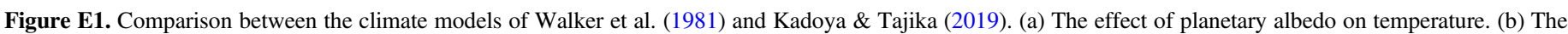
effect of the partial pressure of $\mathrm{CO}_{2}$ on temperature.

$I_{0}=-3.1 \mathrm{~W} \mathrm{~m}^{-2}$ and $\xi=0.01(T-250)$. For $P_{\mathrm{CO}_{2}}<1 \mathrm{bar}$,

$$
\boldsymbol{B}=\left[\begin{array}{ccccc}
87.8373 & -311.289 & -504.408 & -422.929 & -134.611 \\
54.9102 & -677.741 & -1440.63 & -1467.04 & -543.371 \\
24.7875 & 31.3614 & -364.617 & -747.352 & -395.401 \\
75.8917 & 816.426 & 1565.03 & 1453.73 & 476.475 \\
43.0076 & 339.957 & 996.723 & 1361.41 & 612.967 \\
-31.4994 & -261.362 & -395.106 & -261.600 & -36.6589 \\
-28.8846 & -174.942 & -378.436 & -445.878 & -178.948
\end{array}\right] .
$$

(E11)

For $P_{\mathrm{CO}_{2}}>1$ bar,

$$
\boldsymbol{B}=\left[\begin{array}{ccccc}
87.8373 & -52.1056 & 35.2800 & -1.64935 & -3.42858 \\
54.9102 & -49.6404 & -93.8576 & 130.671 & -41.1725 \\
24.7875 & 94.7348 & -252.996 & 171.685 & -34.7665 \\
75.8917 & -180.679 & 385.989 & -344.020 & 101.455 \\
43.0076 & -327.589 & 523.212 & -351.086 & 81.0478 \\
-31.4994 & 235.321 & -462.453 & 346.483 & -90.0657 \\
-28.8846 & 284.233 & -469.600 & 311.854 & -72.4874
\end{array}\right] .
$$

Equations (E7)-(E13) are solved by balancing the energy fluxes of the globally averaged absorbed instellation $S_{\text {avg }}$ and $F_{\text {OLR }}$, where

$$
F_{\mathrm{OLR}}=S_{\mathrm{avg}}
$$

and

$$
S_{\text {avg }}=\frac{(1-\alpha)}{4} S,
$$

where the geometric factor 4 comes from the ratio of the planet's surface area to the area of its cross-section. For present-day albedo $(\alpha=0.3)$ and present-day solar flux $\left(S=1360 \mathrm{~W} \mathrm{~m}^{-2}\right)$, this fit results in $T$ between 280 and $350 \mathrm{~K}$ and $P_{\mathrm{CO}_{2}}$ between $10^{-5}$ bar and 0.5 bar.
Another climate model used frequently in carbon cycle studies (e.g., Foley 2015) is the one from Walker et al. (1981). The relation between $T$ and $P_{\mathrm{CO}_{2}}$ is given by

$$
T=T^{*}+2\left(T_{e}-T_{e}^{*}\right)+4.6\left(\frac{P_{\mathrm{CO}_{2}}}{P^{*} \mathrm{CO}_{2}}\right)^{0.346},
$$

where $T_{e}$ is the effective temperature given by $T_{e}=$ $\left(S_{\text {avg }} / \sigma_{\mathrm{SB}}\right)^{1 / 4}$ with $\sigma_{\mathrm{SB}}=5.67 \times 10^{-8} \quad \mathrm{~W} \mathrm{~m}^{-2} \mathrm{~K}^{-4}$ as the Stefan-Boltzmann constant, and the present-day values of temperature, effective temperature, and $\mathrm{CO}_{2}$ partial pressure are assumed to be $T=285 \mathrm{~K}, T_{e}^{*}=254 \mathrm{~K}$ and $P^{*} \mathrm{CO}_{2}=330 \times$ $10^{-6}$ bar, respectively (Kasting et al. 1984).

Figure E1 shows the comparison between the models of Kadoya \& Tajika (2019) and Walker et al. (1981). Both models show almost the same temperatures for $\alpha$ between 0.3 and 0.5 at $P_{\mathrm{CO}_{2}}=280 \mu$ bar. However, for $\alpha<0.25$, the Kadoya \& Tajika (2019) model shows a steep temperature rise with decreasing $\alpha$. As a function of $P_{\mathrm{CO}_{2}}$ at $\alpha=0.3$, both models exhibit temperatures within $5 \%$ of each other.

\section{ORCID iDs}

Kaustubh Hakim (1) https://orcid.org/0000-0003-4815-2874 Dan J. Bower (i) https://orcid.org/0000-0002-0673-4860 Meng Tian (1) https://orcid.org/0000-0002-7384-8577 Russell Deitrick (i) https://orcid.org/0000-0001-9423-8121 Pierre Auclair-Desrotour ำ https://orcid.org/0000-00029577-2489

Daniel Kitzmann (10) https://orcid.org/0000-0003-4269-3311 Caroline Dorn (1) https://orcid.org/0000-0001-6110-4610 Klaus Mezger 나 https://orcid.org/0000-0002-2443-8539 Kevin Heng (i) https://orcid.org/0000-0003-1907-5910

\section{References}

Aagaard, P., \& Helgeson, H. C. 1982, AmJS, 282, 237 Abbot, D. S., Cowan, N. B., \& Ciesla, F. J. 2012, ApJ, 756, 178 Abe, Y. 1993, Litho, 30, 223 
Alt, J. C., Honnorez, J., Laverne, C., \& Emmermann, R. 1986, JGR, 91, 10309 Astropy Collaboration, Price-Whelan, A. M., Sipőcz, B. M., et al. 2018, AJ, 156,123

Astropy Collaboration, Robitaille, T. P., Tollerud, E. J., et al. 2013, A\&A, 558, A33

Bean, J. L., Abbot, D. S., \& Kempton, E. M. R. 2017, ApJL, 841, L24

Berner, R. A. 1991, AmJS, 291, 339

Berner, R. A. 2004, The Phanerozoic Carbon Cycle: $\mathrm{CO}_{2}$ and $\mathrm{O}_{2}$ (Oxford: Oxford Univ. Press)

Berner, R. A., \& Kothavala, Z. 2001, AmJS, 301, 182

Berner, R. A., Lasaga, A. C., \& Garrels, R. M. 1983, AmJS, 283, 641

Brady, P. V., \& Gíslason, S. R. 1997, GeCoA, 61, 965

Brantley, S. L., Kubicki, J. D., \& White, A. F. 2008, Kinetics of Water-Rock Interaction (Berlin: Springer)

Bristow, T. F., Rampe, E. B., Achilles, C. N., et al. 2018, SciA, 4, eaar3330

Caldeira, K. 1995, AmJS, 295, 1077

Charnay, B., Le Hir, G., Fluteau, F., Forget, F., \& Catling, D. C. 2017, E\&PSL, 474, 97

Charnay, B., Wolf, E. T., Marty, B., \& Forget, F. 2020, SSRv, 216, 90

Checlair, J., Abbot, D. S., Webber, R. J., et al. 2019, BAAS, 51, 404

Chen, K., Rudnick, R. L., Wang, Z., et al. 2020, GeCoA, 278, 16

Coogan, L. A., \& Dosso, S. E. 2015, E\&PSL, 415, 38

Coogan, L. A., \& Gillis, K. M. 2013, GGG, 14, 1771

Coogan, L. A., \& Gillis, K. M. 2018, AREPS, 46, 21

DeVoe, H. 2001, Thermodynamics and Chemistry, Thermodynamics and Chemistry No. pt. 48 (New York: Prentice Hall)

Dhuime, B., Hawkesworth, C. J., Delavault, H., \& Cawood, P. A. 2017, SedG, 357,16

Diamond, L. W., \& Akinfiev, N. N. 2003, Fluid Phase Equilibria, 208, 265

Dick, J. M. 2019, FrEaS, 7, 180

Driscoll, P., \& Bercovici, D. 2013, Icar, 226, 1447

Ebelmen, J.-J. 1845, Annales des Mines, 7, 66

Fekete, B. M., Vörösmarty, C. J., \& Grabs, W. 2002, GBioC, 16, 1042

Foley, B. J. 2015, ApJ, 812, 36

France-Lanord, C., \& Derry, L. A. 1997, Natur, 390, 65

Francois, L. M., \& Walker, J. C. G. 1992, AmJS, 292, 81

Gabet, E. J., \& Mudd, S. M. 2009, Geo, 37, 151

Gaillard, F., \& Scaillet, B. 2014, E\&PSL, 403, 307

Gaillardet, J., Dupré, B., Louvat, P., \& Allègre, C. J. 1999, ChGeo, 159, 3

Galvez, M. E., Manning, C. E., Connolly, J. A. D., \& Rumble, D. 2015, E\&PSL, 430, 486

Graham, R. J., \& Pierrehumbert, R. 2020, ApJ, 896, 115

Haqq-Misra, J., Kopparapu, R. K., Batalha, N. E., Harman, C. E., \& Kasting, J. F. 2016, ApJ, 827, 120

Hasterok, D. 2013, E\&PSL, 380, 12

Heimsath, A. M., Dietrich, W. E., Nishiizumi, K., \& Finkel, R. C. 1997, Natur, 388,358

Helgeson, H. C., Murphy, W. M., \& Aagaard, P. 1984, GeCoA, 48, 2405

Holland, T. J. B., \& Powell, R. 2011, Journal of Metamorphic Geology, 29,333

Höning, D., Tosi, N., \& Spohn, T. 2019, A\&A, 627, A48

Hunter, J. D. 2007, CSE, 9, 90

Ibarra, D. E., Caves, J. K., Moon, S., et al. 2016, GeCoA, 190, 265

Isson, T. T., \& Planavsky, N. J. 2018, Natur, 560, 471

Johnson, H. P., \& Pruis, M. J. 2003, E\&PSL, 216, 565

Kadoya, S., \& Tajika, E. 2019, ApJ, 875, 7

Kasting, J. F., Pollack, J. B., \& Ackerman, T. P. 1984, Icar, 57, 335

Kasting, J. F., Whitmire, D. P., \& Reynolds, R. T. 1993, Icar, 101, 108
Keller, C. B., \& Harrison, T. M. 2020, PNAS, 117, 21101

Kite, E. S., \& Ford, E. B. 2018, ApJ, 864, 75

Kite, E. S., Gaidos, E., \& Manga, M. 2011, ApJ, 743, 41

Kite, E. S., \& Melwani Daswani, M. 2019, E\&PSL, 524, 115718

Kopparapu, R. K., Ramirez, R., Kasting, J. F., et al. 2013, ApJ, 765, 131

Kopparapu, R. K., Ramirez, R. M., SchottelKotte, J., et al. 2014, ApJL, 787, L29

Krissansen-Totton, J., Arney, G. N., \& Catling, D. C. 2018, PNAS, 115, 4105

Krissansen-Totton, J., \& Catling, D. C. 2017, NatCo, 8, 15423

Krissansen-Totton, J., \& Catling, D. C. 2020, E\&PSL, 537, 116181

Kump, L. R., Brantley, S. L., \& Arthur, M. A. 2000, AREPS, 28, 611

Lagache, M. 1965, Bulletin de Minéralogie, 88, 223, doi:10.3406/bulmi. 1965.5840

Li, L., Maher, K., Navarre-Sitchler, A., et al. 2017, ESRv, 165, 280

Mackenzie, F. T., \& Garrels, R. M. 1966, AmJS, 264, 507

Maher, K. 2010, E\&PSL, 294, 101

Maher, K. 2011, E\&PSL, 312, 48

Maher, K., \& Chamberlain, C. P. 2014, Sci, 343, 1502

Milliken, R. E., Fischer, W. W., \& Hurowitz, J. A. 2009, GeoRL, 36, L11202

Nakajima, S., Hayashi, Y.-Y., \& Abe, Y. 1992, JAtS, 49, 2256

Palandri, J. L., \& Kharaka, Y. K. 2004, A Compilation of Rate Parameters of Water-Mineral Interaction Kinetics for Application to Geochemical Modeling, Tech. Rep. OF 2004-1068 (Menlo Park, CA: USGS), https:// pubs.usgs.gov/of/2004/1068/

Perez, F., \& Granger, B. E. 2007, CSE, 9, 21

Pierrehumbert, R. T. 2010, Principles of Planetary Climate (Cambridge: Cambridge Univ. Press)

Plummer, L. N., Wigley, T. M. L., \& Parkhurst, D. L. 1978, AmJS, 278, 179

Prinn, R. G., \& Barshay, S. S. 1977, Sci, 198, 1031

Pytkowicz, R. M. 1970, GeCoA, 34, 836

Ridgwell, A., \& Zeebe, R. E. 2005, E\&PSL, 234, 299

Riebe, C. S., Kirchner, J. W., \& Finkel, R. C. 2003, GeCoA, 67, 4411

Riebe, C. S., Kirchner, J. W., \& Finkel, R. C. 2004, E\&PSL, 224, 547

Sagan, C., \& Mullen, G. 1972, Sci, 177, 52

Schulz, K. G., Riebesell, U., Rost, B., Thoms, S., \& Zeebe, R. 2006, Marine Chemistry, 100, 53

Sleep, N. H., \& Zahnle, K. 2001, JGR, 106, 1373

Spaargaren, R. J., Ballmer, M. D., Bower, D. J., Dorn, C., \& Tackley, P. J. 2020, A\&A, 643, A44

Spycher, N. F., \& Reed, M. H. 1988, GeCoA, 52, 739

Stallard, R. F., \& Edmond, J. M. 1983, JGR, 88, 9671

Steefel, C. I., DePaolo, D. J., \& Lichtner, P. C. 2005, E\&PSL, 240, 539

Steefel, C. I., \& Maher, K. 2009, RvMG, 70, 485

Stein, C. A., \& Stein, S. 1994, JGR, 99, 3081

Thompson, J. B. 1959, Researches in Geochemistry (New York: Wiley), 427

Tsai, S.-M., Lyons, J. R., Grosheintz, L., et al. 2017, ApJS, 228, 20

Urey, H. C. 1952, Mrs. Hepsa Ely Silliman Memorial Lectures (London: Cumberlege)

van der Walt, S., Colbert, S. C., \& Varoquaux, G. 2011, CSE, 13, 22

Virtanen, P., Gommers, R., Oliphant, T. E., et al. 2020, Nature Methods, 17,261

Volk, T. 1987, AmJS, 287, 763

Walker, J. C. G., Hays, P. B., \& Kasting, J. F. 1981, JGR, 86, 9776

Wang, H. S., Liu, F., Ireland, T. R., et al. 2019, MNRAS, 482, 2222

West, A. J. 2012, Geo, 40, 811

West, A. J., Galy, A., \& Bickle, M. 2005, E\&PSL, 235, 211

Winnick, M. J., \& Maher, K. 2018, E\&PSL, 485, 111 